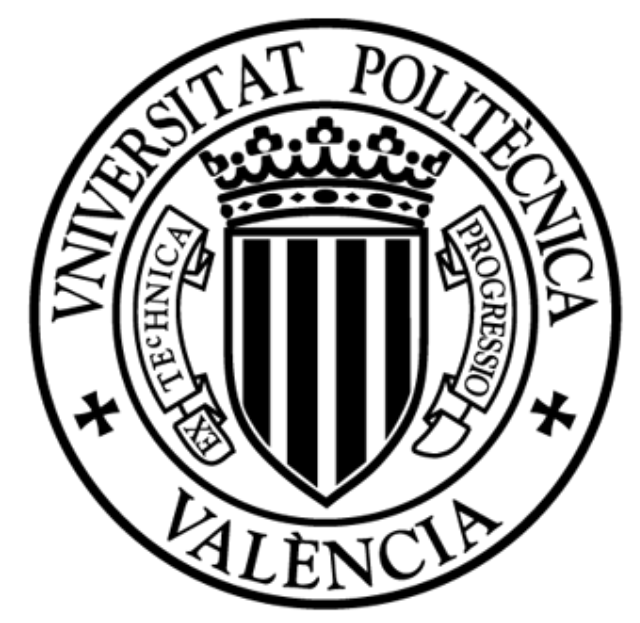

Universitat Politècnica de València

Programa de Doctorado en Tecnologías para la Salud y el Bienestar

\author{
Ph.D. Thesis
}

Virtual reality environments for the study of decision-making processes in risky contexts through the use of physiological measures and behavioural responses

Author:

Carla de Juan Ripoll

Supervisors:

Dr. Mariano Alcañiz Raya

Dra. Irene Alice Chicchi Giglioli 



\section{Abstract}

Understanding human behaviour in risk situations, how individual and external factors influence our decisions and to what extent it is possible to influence and modify our behaviours, constitutes a challenge both for scientists and for society in general. From the perspective of Occupational Safety and Health (OSH), as well as in numerous fields such as sociology of finance, this topic has important implications since risk situations are a common aspect in various domains of our lives.

Risk taking (RT) is part of the decision-making process in uncertain situations, in which the probability of each positive or negative consequence is known in advance. Although the concept of RT is well defined in the literature, it has been approached from different perspectives, so that the factors that have been proposed to explain or moderate RT are also very diverse. Focusing on the individual factors - cognitive and emotional processes - that influence RT, these may affect how hazardous situations are addressed in two different ways. First, they can skew the perception of a situation, so that an adequate evaluation is not carried out and therefore this leads to biased behaviors. Second, these factors shape a certain general propensity towards risk in humans, so that they may or may not be attracted to potentially dangerous situations.

In the same way that the definition of RT has been approached from different perspectives, the evaluation of RT has also been treated from different points of view and nowadays constitutes a challenge for researchers and practitioners, so that a clear consensus has not been found regarding the existence of a validated measure for RT. RT evaluation has traditionally been carried out using questionnaires; however, it has been demonstrated that these measures present various limitations that can lead to altered results. Behavioural tasks emerge as an alternative solution capable of overcoming some of these boundaries. Instead, their ability to transference to real life situations appears to be limited.

Virtual reality (VR) enables recreating real-simulated situations to carry out performance-based assessments. VR presents numerous advantages that can provide benefits for the evaluation of human behaviours, since it provides greater immersion, fidelity and a higher level of involvement than traditional evaluation methods, and numerous works in the field of applied psychology and organizational neuroscience have endorsed its use for human assessment.

In this investigation, we propose VR as technology capable of facilitating the study of RT processes, taking advantage of its numerous possibilities, which can be resumed as: simulation of realistic risk situations, natural interactions with the virtual environment, inclusion of implicit measures for stealth assessment and physiological real-time measurement. 
Starting from these premises, we present the results of a study in which participants permormed a series of tasks in a gamified VR environment: the Spheres \& Shield Maze Task (SSMT). By recording implicit behavioural measures, we found relationships between participants' behaviours in the SSMT and their answers to self-reported riskrelated constructs. After conducting this study, we conclude that gamified virtual environments are an appropriate tool for evaluating RT, and in particular, the approach used to design the SSMT is a good starting point that evokes behaviors and reactions capable of representing the risk propensity of the participants.

As a continuation of this first study, an investigation was carried out in order to identify in more detail which risk-related constructs constitute RT, in order to develop a VR Serious Game that evaluates RT in an accurate way. In this investigation, we took the approach that risk perception and risk proneness affect RT behaviours. The study hypothesised that locus of control, emotion regulation, and executive control act as perceptual biases in RT, and that personality, sensation seeking, and impulsivity traits act as proneness biases in RT. The results suggest that the dimensions identified as perceptual biases influence specific domains of RT, while the dimensions identified as proneness biases are involved in all domains of RT, representing a given degree of general risk proneness.

Finally, once the bases for the design of a virtual environment capable of measuring RT have been defined and the factors that make up this concept have been identified, we present the Assessment on dEcision Making in rIsk eNvironments (AEMIN) tool, as an extension of the SSMT. The main aim of this study was to analyze whether it is possible is to classify participants with high versus low risk proneness, through their behaviours and physiological responses during playing AEMIN. Applying machine learning methods to the dataset we studied: (a) if through these measures it is possible to discriminate between the two populations in each risk proneness variable (personality, sensation seeking and impulsivity); and (b) which parameters better discriminate between the two populations in each variable. The results suggest that AEMIN constitutes a valid tool for the evaluation of RT, especially because of its ability to evoke responses capable of classifying users in terms of their propensity towards risk in a transversal manner, regardless of the type of risk.

This thesis provides novel contributions to the definition of RT, particularly in the identification of which factors constitute this complex process. Moreover, it investigates the use of immersive VR in human behaviour research, specifically for RT assessment, providing design premises of virtual environments for the evaluation of the psychological constructs identified as determinants to define RT. Finally, it analyses the validity of VR in combination with physiological measures for the evaluation of RT in an implicit way. We believe that VR provides innumerable advantages applicable to the field of human behaviour research. Its ability to evoke behaviours and reactions similar to those in real life, the possibilities of integration with implicit measures as well as its 
Abstract

potential when applying machine learning techniques make this technology a tool that can completely transform the perspectives in the field of RT evaluation. 
Abstract 


\section{Resumen}

Comprender el comportamiento humano en situaciones de riesgo, cómo los factores individuales y externos influyen en nuestras decisiones y en qué medida es posible influir y modificar nuestros comportamientos, constituye un desafío tanto para los científicos como para la sociedad en general. Desde la perspectiva de la Seguridad y Salud en el Trabajo (SST), así como en numerosos campos como la sociología y las finanzas, este tema tiene importantes implicaciones ya que las situaciones de riesgo son un aspecto común en diversos ámbitos de nuestra vida.

La toma de riesgos (TR) es parte del proceso de toma de decisiones en situaciones de incertidumbre, en las que se conoce de antemano la probabilidad de cada consecuencia positiva o negativa. Si bien el concepto de la TR está bien definido en la literatura, se ha abordado desde diferentes perspectivas, por lo que los factores que se han propuesto para explicar o moderar la TR también son muy diversos. Centrándonos en los factores individuales (procesos cognitivos y emocionales) que influyen en la TR, estos pueden afectar la forma en que se abordan las situaciones peligrosas de dos maneras diferentes. En primer lugar, pueden sesgar la percepción de una situación, de modo que no se lleve a cabo una evaluación adecuada y por tanto esto lleve a conductas sesgadas. En segundo lugar, estos factores configuran una cierta propensión general al riesgo en los seres humanos, de modo que pueden o no sentirse atraídos por situaciones potencialmente peligrosas.

De la misma manera que la definición de la TR se ha abordado desde diferentes perspectivas, su evaluación también se ha tratado desde diferentes puntos de vista y constituye hoy en día un desafío para investigadores y profesionales, por lo que no se ha encontrado un consenso claro en cuanto a la existencia de una medida validada para la TR. La evaluación de la TR se ha realizado tradicionalmente mediante cuestionarios; sin embargo, se ha demostrado que estas medidas presentan diversas limitaciones que pueden conducir a resultados alterados. Las tareas comportamentales surgen como una solución alternativa capaz de superar algunas de estas barreras. En cambio, su capacidad de transferencia a situaciones de la vida real parece ser limitada.

La realidad virtual $(\mathrm{RV})$ permite recrear situaciones reales simuladas para realizar evaluaciones basadas en el desempeño. La RV presenta numerosas ventajas que pueden aportar beneficios para la evaluación de los comportamientos humanos, ya que aporta una mayor inmersión, fidelidad y un mayor nivel de implicación que los métodos de evaluación tradicionales, y numerosos trabajos en el campo de la psicología aplicada y la neurociencia organizacional han avalado su uso para evaluación humana.

En esta investigación, proponemos la RV como tecnología capaz de facilitar el estudio de los procesos de la TR, aprovechando sus numerosas posibilidades, que se pueden resumir como: simulación de situaciones de riesgo realistas, interacciones naturales con 
el entorno virtual, inclusión de medidas implícitas para evaluación oculta y medición fisiológica en tiempo real.

Partiendo de estas premisas, presentamos los resultados de un estudio en el que los participantes realizaron una serie de tareas en un entorno de realidad virtual gamificado: el Spheres \& Shield Maze Task (SSMT). Al registrar medidas de comportamiento implícitas, encontramos relaciones entre los comportamientos de los participantes en el SSMT y sus respuestas a los constructos autoinformados relacionados con el riesgo. Tras realizar este estudio, concluimos que los entornos virtuales gamificados son una herramienta adecuada para evaluar la TR, y en particular, el enfoque utilizado para diseñar el SSMT es un buen punto de partida que evoca comportamientos y reacciones capaces de representar la propensión al riesgo de los participantes.

Como continuación de este primer estudio, se llevó a cabo una investigación con el fin de identificar con más detalle qué constructos relacionados con el riesgo constituyen la TR, con el fin de desarrollar un juego serio en RV que evalúe la TR de forma precisa. En esta investigación, adoptamos el enfoque de que la percepción de riesgo y la propensión al riesgo afectan los comportamientos de la TR. El estudio planteó la hipótesis de que el locus de control, la regulación emocional y el control ejecutivo actúan como sesgos de percepción en la TR, y que los rasgos de personalidad, búsqueda de sensaciones e impulsividad actúan como sesgos de propensión en la TR. Los resultados sugieren que las dimensiones identificadas como sesgos de percepción influyen en dominios específicos de la TR, mientras que las dimensiones identificadas como sesgos de propensión están involucradas en todos los dominios de la TR, lo que representa un grado dado de propensión general al riesgo.

Finalmente, una vez definidas las bases para el diseño de un entorno virtual capaz de medir la TR y se han identificado los factores que componen este concepto, presentamos la herramienta Assessment on dEcision Making in rIsk eNvironments (AEMIN), como extensión de el SSMT. El objetivo principal de este estudio fue analizar si es posible clasificar a los participantes con una propensión hacia el riesgo alta frente a los de baja, a través de sus comportamientos y respuestas fisiológicas durante la reproducción de AEMIN. Aplicando métodos de aprendizaje automático al conjunto de datos estudiamos: (a) si a través de estas medidas es posible discriminar entre las dos poblaciones en cada variable de propensión al riesgo (personalidad, búsqueda de sensaciones e impulsividad); y (b) qué parámetros discriminan mejor entre las dos poblaciones en cada variable. Los resultados sugieren que AEMIN constituye una herramienta válida para la evaluación de la RT, especialmente por su capacidad de evocar respuestas capaces de clasificar a los usuarios en función de su propensión al riesgo de forma transversal, independientemente del tipo de riesgo.

Esta tesis proporciona aportaciones a la definición de la TR, particularmente en la identificación de qué factores constituyen este complejo proceso. Además, investiga el uso de la RV inmersiva en la investigación del comportamiento humano, 
específicamente para la evaluación de la TR, proporcionando premisas de diseño de entornos virtuales para la evaluación de los constructos psicológicos identificados como determinantes para definir la TR. Finalmente, analiza la validez de la RV en combinación con medidas fisiológicas para la evaluación de la TR de forma implícita. Creemos que la RV ofrece innumerables ventajas aplicables al campo de la investigación del comportamiento humano. Su capacidad para evocar comportamientos y reacciones similares a las de la vida real, las posibilidades de integración con medidas implícitas, así como su potencial a la hora de aplicar técnicas de aprendizaje máquina hacen de esta tecnología una herramienta que puede transformar completamente las perspectivas en el campo de la evaluación de la TR. 
Resumen 


\section{Resum}

Comprendre el comportament humà en situacions de risc, com els factors individuals i externs influeixen en les nostres decisions i en quina mesura és possible influir i modificar els nostres comportaments, constitueix un desafiament tant per als científics com per a la societat en general. Des de la perspectiva de la Seguretat i Salut en el Treball (SST), així com en nombrosos camps com la sociologia i les finances, aquest tema té importants implicacions ja que les situacions de risc són un aspecte comú en diversos àmbits de la nostra vida.

La presa de riscos (PR) és part del procés de presa de decisions en situacions d'incertesa, en les quals es coneix per endavant la probabilitat de cada conseqüència positiva 0 negativa. Si bé el concepte de la PR està ben definit en la literatura, s'ha abordat des de diferents perspectives, per la qual cosa els factors que s'han proposat per a explicar o moderar la PR també són molt diversos. Centrant-nos en els factors individuals (processos cognitius i emocionals) que influeixen en la PR, aquests poden afectar la forma en què s'aborden les situacions perilloses de dues maneres diferents. En primer lloc, poden esbiaixar la percepció d'una situació, de manera que no es duga a terme una avaluació adequada i per tant això porte a conductes esbiaixades. En segon lloc, aquests factors configuren una certa propensió general al risc en els éssers humans, de manera que poden o no sentir-se atrets per situacions potencialment perilloses.

De la mateixa manera que la definició de la PR s'ha abordat des de diferents perspectives, la seua avaluació també s'ha tractat des de diferents punts de vista i constitueix hui dia un desafiament per a investigadors i professionals, per la qual cosa no s'ha trobat un consens clar quant a l'existència d'una mesura validada per a la PR. L'avaluació de la PR s'ha realitzat tradicionalment mitjançant qüestionaris; no obstant això, s'ha demostrat que aquestes mesures presenten diverses limitacions que poden conduir a resultats alterats. Les tasques comportamentals sorgeixen com una solució alternativa capaç de superar algunes d'aquestes barreres. En canvi, la seua capacitat de transferència a situacions de la vida real sembla ser limitada.

La realitat virtual (RV) permet recrear situacions reals simulades per a realitzar avaluacions basades en l'acompliment. La RV presenta nombrosos avantatges que poden aportar beneficis per a l'avaluació dels comportaments humans, ja que aporta una major immersió, fidelitat i un major nivell d'implicació que els mètodes d'avaluació tradicionals, i nombrosos treballs en el camp de la psicologia aplicada i la neurociència organitzacional han avalat el seu ús per a avaluació humana.

En aquesta investigació, proposem la RV com a tecnologia capaç de facilitar l'estudi dels processos de la PR, aprofitant les seues nombroses possibilitats, que es poden resumir com: simulació de situacions de risc realistes, interaccions naturals amb l'entorn virtual, inclusió de mesures implícites per a avaluació oculta i mesurament fisiològic en temps real. 
Partint d'aquestes premisses, presentem els resultats d'un estudi en el qual els participants van realitzar una sèrie de tasques en un entorn de realitat virtual ludificat: l'Spheres \& Shield Maze Task (SSMT). En registrar mesures de comportament implícites, trobem relacions entre els comportaments dels participants en el SSMT i les seues respostes als constructes autoinformats relacionats amb el risc. Després de realitzar aquest estudi, concloem que els entorns virtuals ludificats són una eina adequada per a avaluar la PR, i en particular, l'enfocament utilitzat per a dissenyar el SSMT és un bon punt de partida que evoca comportaments i reaccions capaces de representar la propensió al risc dels participants.

Com a continuació d'aquest primer estudi, es va dur a terme una investigació amb la finalitat d'identificar $a m b$ més detall quins constructes relacionats $a m b$ el risc constitueixen la PR, amb la finalitat de desenvolupar un joc seriós en RV que avalue la PR de manera precisa. En aquesta investigació, adoptem l'enfocament que la percepció de risc i la propensió al risc afecten els comportaments de la PR. L'estudi va plantejar la hipòtesi que el locus de control, la regulació emocional i el control executiu actuen com a biaixos de percepció en la PR, i que els trets de personalitat, cerca de sensacions i impulsivitat actuen com a biaixos de propensió en la PR. Els resultats suggereixen que les dimensions identificades com a biaixos de percepció influeixen en dominis específics de la PR, mentre que les dimensions identificades com a biaixos de propensió estan involucrades en tots els dominis de la PR, la qual cosa representa un grau donat de propensió general al risc.

Finalment, una vegada definides les bases per al disseny d'un entorn virtual capaç de mesurar la PR i s'han identificat els factors que componen aquest concepte, presentem l'eina Assessment on dEcision Making in rIsk eNvironments (AEMIN), com a extensió del SSMT. L'objectiu principal d'aquest estudi va ser analitzar si és possible classificar als participants amb una propensió cap al risc alta enfront dels de baixa, a través dels seus comportaments i respostes fisiològiques durant la reproducció d'AEMIN. Aplicant mètodes d'aprenentatge automàtic al conjunt de dades estudiem: (a) si a través d'aquestes mesures és possible discriminar entre les dues poblacions en cada variable de propensió al risc (personalitat, cerca de sensacions i impulsivitat); i (b) quins paràmetres discriminen millor entre les dues poblacions en cada variable. Els resultats suggereixen que AEMIN constitueix una eina vàlida per a l'avaluació de la PR, especialment per la seua capacitat d'evocar respostes capaces de classificar als usuaris en funció de la seua propensió al risc de manera transversal, independentment de la mena de risc.

Aquesta tesi proporciona aportacions a la definició de la PR, particularment en la identificació de quins factors constitueixen aquest complex procés. A més, investiga l'ús de la RV immersiva en la investigació del comportament humà, específicament per a l'avaluació de la PR, proporcionant premisses de disseny d'entorns virtuals per a l'avaluació dels constructes psicològics identificats com a determinants per a definir la PR. Finalment, analitza la validesa de la RV en combinació amb mesures fisiològiques per a l'avaluació de la PR de manera implícita. Creiem que la RV ofereix innombrables 
avantatges aplicables al camp de la investigació del comportament humà. La seua capacitat per a evocar comportaments i reaccions similars a les de la vida real, les possibilitats d'integració amb mesures implícites, així com el seu potencial a l'hora d'aplicar tècniques d'aprenentatge màquina fan d'aquesta tecnologia una eina que pot transformar completament les perspectives en el camp de l'avaluació de la PR. 
Resum 


\section{Acknowledgements}

A mis directores, Mariano y Alice, por confiar en mí desde el principio, darme alas y hacerme sentir que puedo. Gracias por enseñarme tantas cosas y por permanecer siempre dispuestos a ayudarme durante todo el proceso de esta tesis y a lo largo de todos estos años trabajando juntos.

A Carlos, por apoyarme en cada paso y remar siempre hacia mí, sin importar si la fuerza es tuya o mía. Gracias por construir conmigo nuestro hogar y cuidarlo cada día.

A mi familia, por estar siempre y vivir estos años casi tan intensamente como los he vivido yo, celebrando conmigo cada pequeño logro y apoyándome cuando encontraba alguna piedra en el camino.

A mis amigas, por escuchar mis alegrías y lamentos y por darme siempre una opinión sincera. Gracias por crecer a mi lado, llenando mi vida de color en cada etapa.

A mis compañeros del I3B, por hacer que cada día vaya al trabajo con ganas y vuelva a casa con una sonrisa. Gracias por enseñarme con vuestro ejemplo qué persona quiero ser en el futuro.

A ti, por ser vida en estos últimos meses del proceso de mi tesis. Por llenarnos de ilusión y hacernos sentir vivos contigo. Estamos deseando conocerte.

Gracias. 
Acknowledgements 


\section{Content}

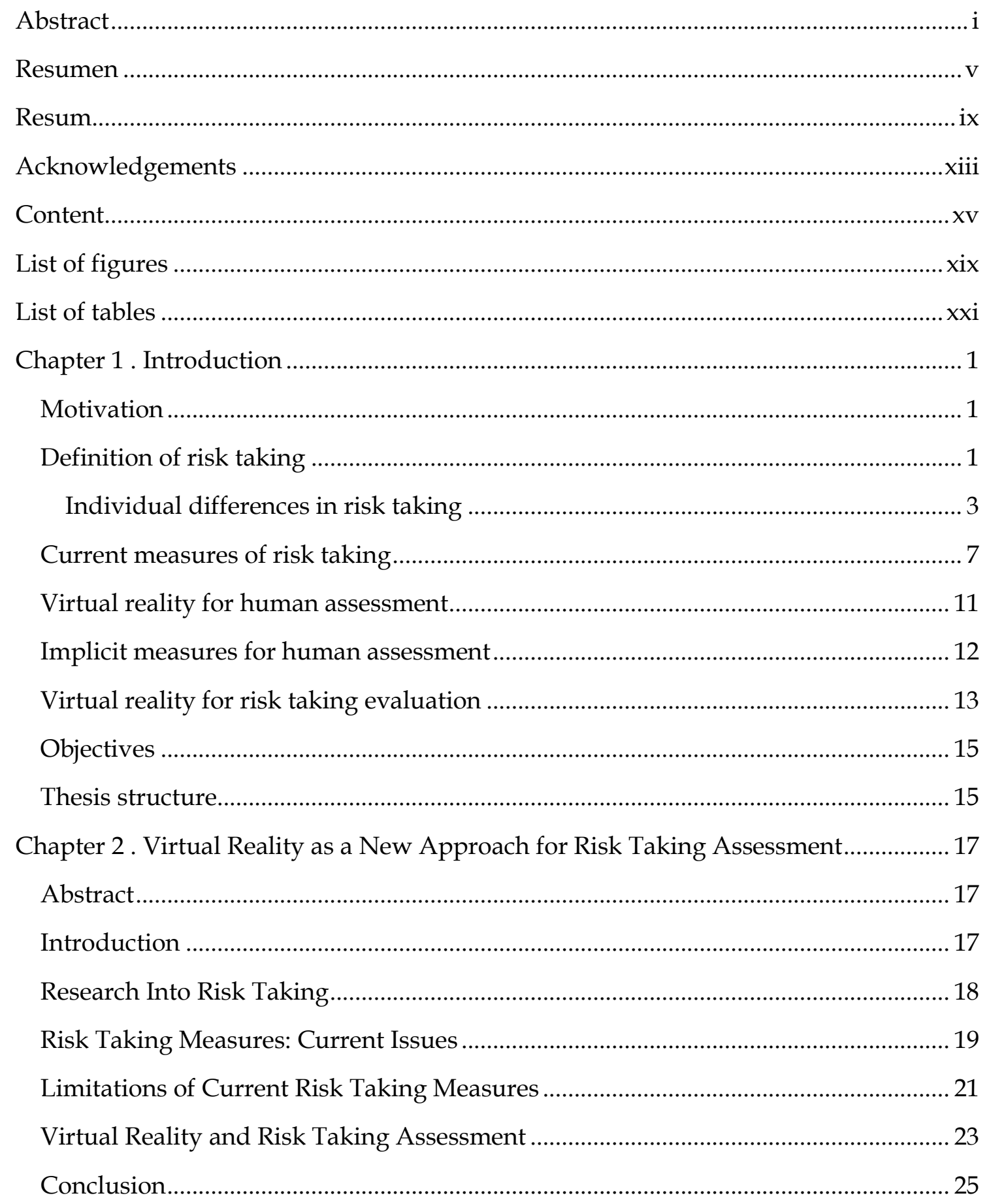

Chapter 3 . The Spheres \& Shield Maze Task: A Virtual Reality Serious Game for the Assessment of Risk Taking in Decision Making.............................................................. 27

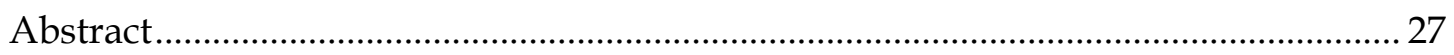

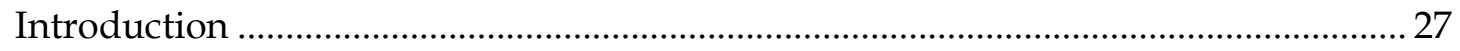

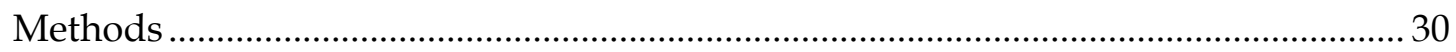


Content

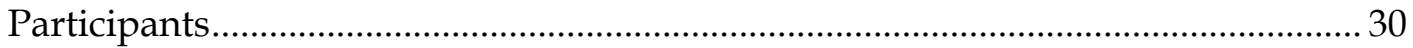

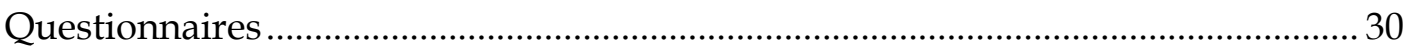

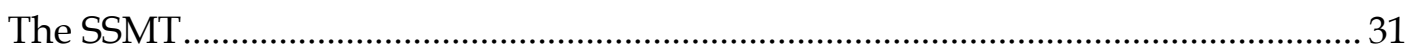

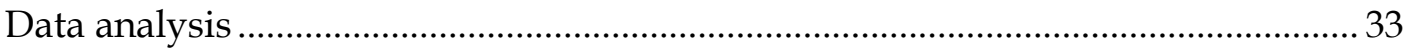

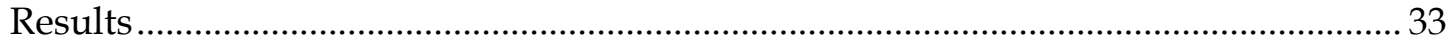

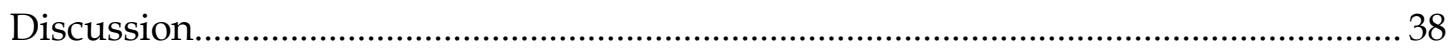

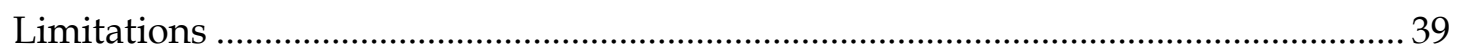

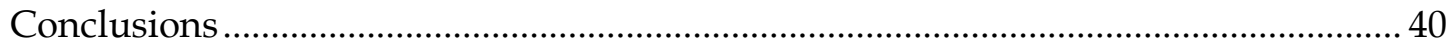

Chapter 4 . Why do we take risks? Perception of the situation and risk proneness predict

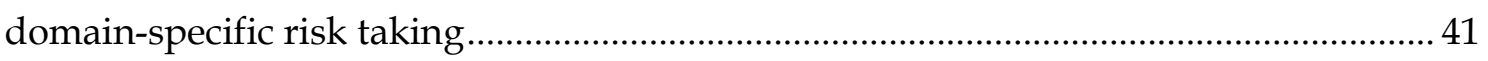

Introduction .

Chapter 5 . An Immersive Virtual Reality Game for Predicting Risk Taking through the

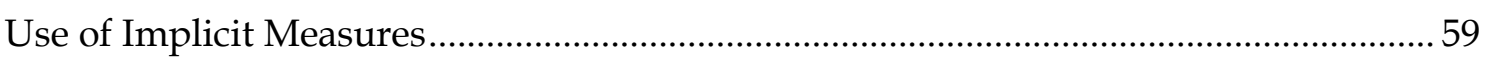

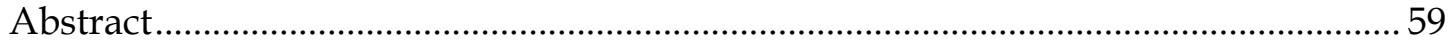

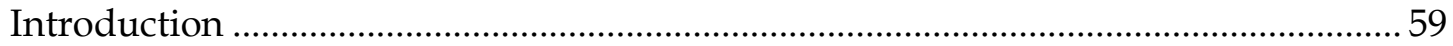

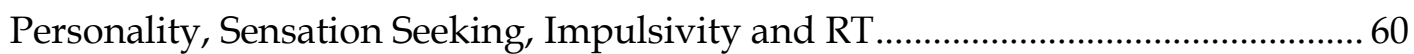

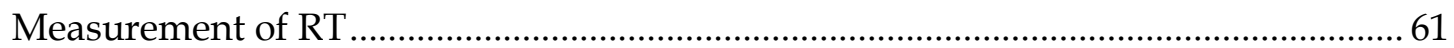




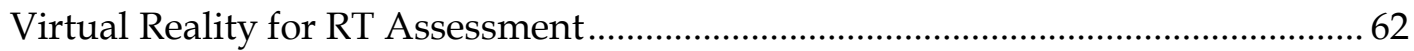

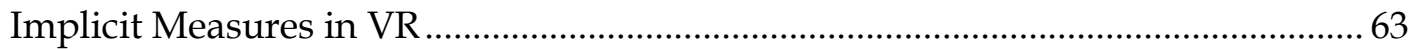

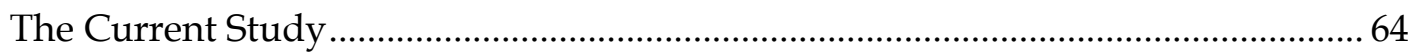

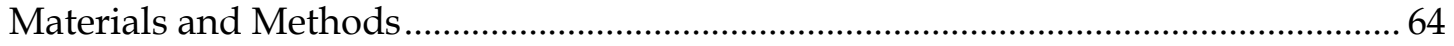

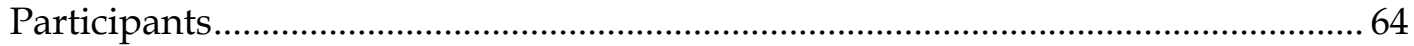

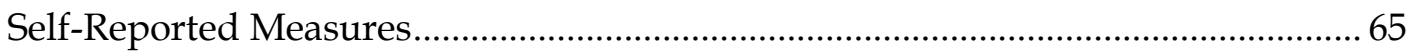

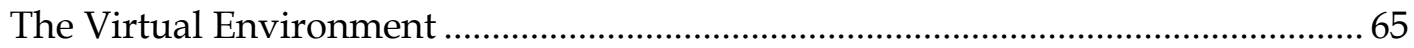

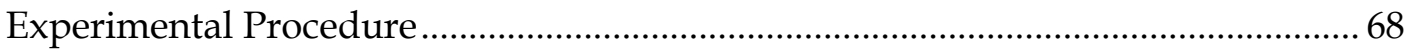

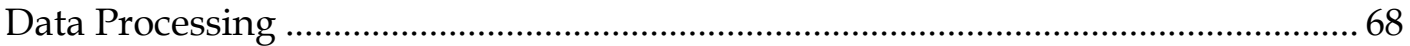

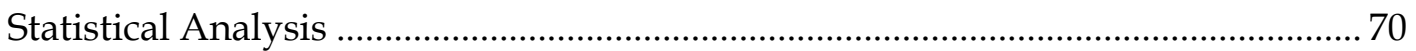

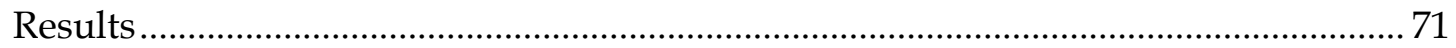

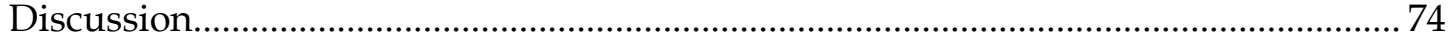

Accuracy of the Models to Discriminate RT Domains................................................... 75

Influence of the Features Used in Each Model Selected ............................................... 76

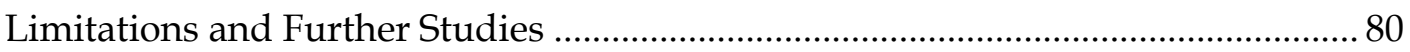

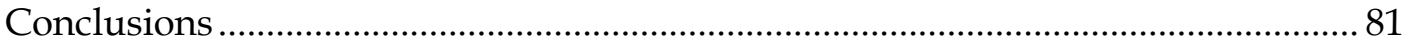

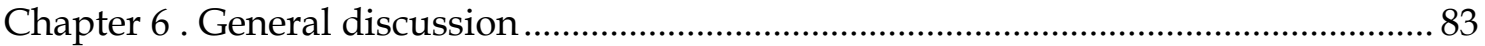

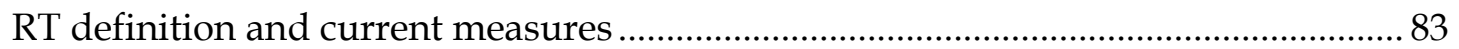

Identification of the psychological components of RT ............................................... 83

Current measures of RT and VR as an alternative tool............................................. 84

Design premises of virtual environments for RT assessment........................................ 86

VR stimulation and behavioural and physiological measures for RT assessment ..... 88

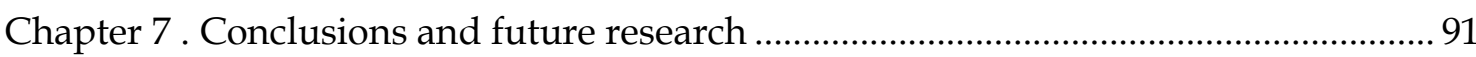

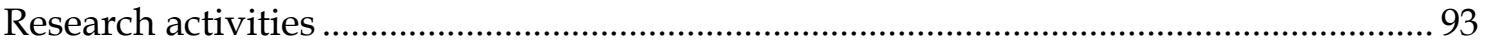

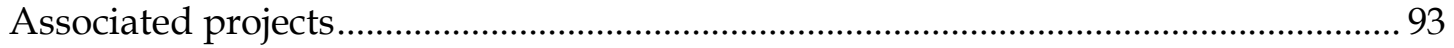

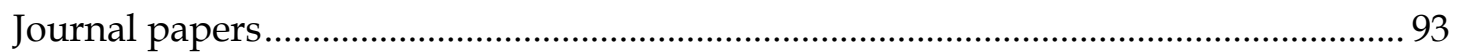

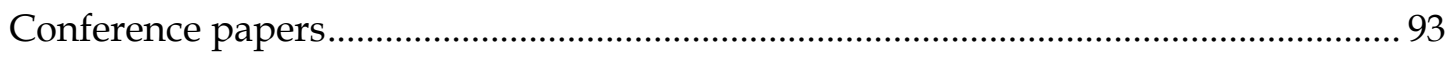

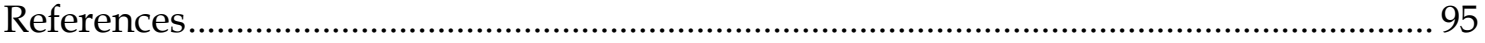


Content

xviii 


\section{List of figures}

Figure 1. Individual differences that influence risk taking ............................................ 19

Figure 2. Screenshots of the SSMT with fire and precipice (left) and slippery puddle (right). SSMT, Spheres \& Shield Maze Task ........................................................................ 31

Figure 3. Top view of the maze and risk distribution ........................................................ 32

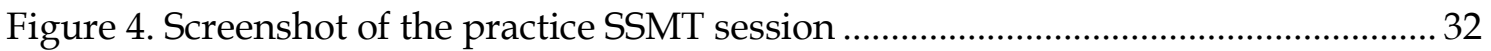

Figure 5. T-test results of self-report and SSMT variables between marijuana consumers and nonconsumers. Bars represent the average and lines represent the standard

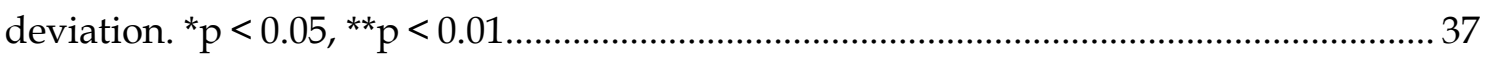

Figure 6. Study hypotheses. Green lines represent positive relation and orange lines represent negative relation. 46

Figure 7. Correlation matrix obtained by Pearson coefficients between every pair of variables and the range of statistical significance by correlation. $* \mathrm{p}<0.05, * * \mathrm{p}<0.01$, and

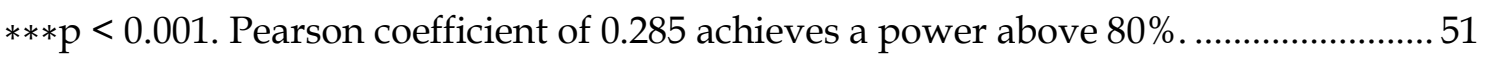

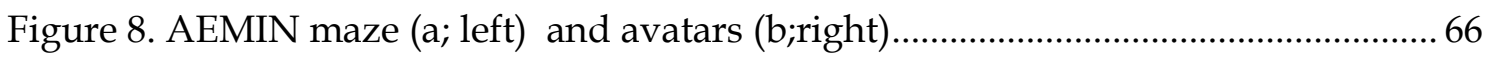

Figure 9. Scheme of ML pipeline and its overfitting check using a set of generated random targets. $\mathrm{M}$ indicates the number of the $\mathrm{CV}$ repetitions set to 4 , and $\mathrm{N}$ the number of random targets generated, equal to 6 71 
List of figures

$x x$ 


\section{List of tables}

Table 1. Individual factors influencing RT ……….................................................................... 3

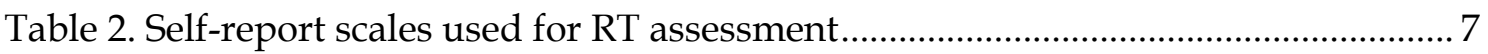

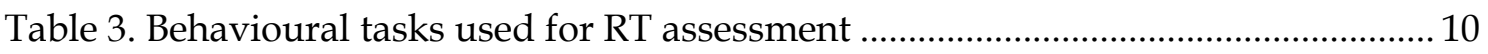

Table 4. VR features and benefits of risk taking measurement ........................................ 23

Table 5. Descriptive Statistics of Self-Report and Spheres \& Shield Maze Task Variables

Table 6. Pearson's correlations between Self-Report and Spheres \& Shield Maze Task Variables

Table 7. Spearman's Correlations Between Risk Behaviours, Risk-Related Constructs, and Spheres \& Shield Maze Task Variables 36

Table 8. Summary of the Logistic Regression Analysis Predicting Marijuana Consumption . 37

Table 9. Descriptive analysis of all variables, organized by subscales. 50

Table 10. Statistical table showing the multilinear regressions for all output variables. 51

Table 11. Description of the risks .66

Table 12. Description of the set of features obtained by data source. 68

Table 13. Statistical description of each target variable .71

Table 14. Results of the models obtained with highest accuracy for every target variable 72

Table 15. Selected features for each classification model. .73 
List of tables

xxii 


\section{Chapter 1. Introduction}

\section{Motivation}

Throughout our lives, people find ourselves in countless situations in which there is a certain level of uncertainty. Our decision-making process in these types of situations can result in positive or negative consequences both for ourselves and for others, which makes these situations of special importance. That is why the study of decision-making processes in risk situations is of great interest. First, examining which are the main psychological factors that are involved in these processes; second, studying how these factors work and are processed on an explicit and implicit level; third, developing an ecological tool to evaluate individuals regarding these factors, in order to predict their behaviours in the face of risk in different contexts.

The definition of risk taking (RT) is currently a challenge for researchers, since there is still no clear consensus in the literature as to which are the psychological factors that compose it. In this sense, it is considered essential to analyse which psychological factors have been previously studied in terms of their relation with RT, carry out a study that shed light on this issue and provide conclusions to this still unanswered question for researchers.

Another key point to highlight is how these factors are measured so far, how they are evaluated. In the literature, we can find various explicit assessment tools, in questionnaire format - which have been identified as presenting biased results - as well as some implicit measures designed to assess RT - which show weak correlations with those behaviours in real life - .

Regarding the evaluation of RT processes, it has been identified that, in the same way that there is a lack of consensus when defining the psychological factors that are involved in RT, a tool capable of measuring this process of RT in a reliable way is also needed. Recently, Virtual Reality (VR) has emerged as a useful tool when creating situations and generating realistic sensations in users that bring to light natural behaviours and responses similar to those in real life. Thanks to this tool, it is possible to study in an objective and quantifiable way natural behaviours and physiological reactions to various risk situations.

\section{Definition of risk taking}

A great variety of definitions for RT can be found in literature, as well as different nomenclatures for concepts that may seem similar. Therefore, it is essential to define the concept of RT as it is interpreted in this research, since this concept acts as a common thread in the following chapters. 
In this document, $\mathrm{RT}$ is understood as that risky behaviour in a situation in which there is uncertainty, but in which there is no ambiguity, so that the individual knows the probability of each possible consequence (Bechara et al., 2005; Krain et al., 2006). The concept of "risk" usually has a negative connotation, although this is not always the case. There are situations or domains in which a risk can be interpreted as something positive (Pellegrino, 2019; Duell and Steinberg, 2019). This differentiation between positive/negative RT among domains is of great interest for this research, since it aims to study whether the relationship between psychological constructs and RT depends in part on the positive or negative connotation of each situation.

It should be noted that there are other concepts in the literature that seem similar to RT, and that, although they do not refer exactly to RT, they are strongly related to this concept. Among these concepts, it is worth highlighting the following:

- Risk attitude: It is defined as the predisposition of an individual to assess a risk in a positive (risk proneness) or negative way (risk aversion), consistently over time (Rohrmann, 2008).

- Risk perception: refers to the evaluations that an individual makes in the face of dangers. Such perceptions guide the decision making and are a fundamental influence on behaviours (Weber, 2010).

Given that the definition of RT has been approached in the literature from different perspectives, the factors that have been proposed to explain or moderate RT are also very diverse. Considering RT as a decision-making component, we can understand that the subject goes through various states in the pre-decision phase (Byrnes, 2002; Hastie and Dawes, 2001): setting a goal (e.g., getting home as soon as possible), identifying alternatives (e.g., going over the speed limits or not, taking a road in a forbidden direction or not, ...), analysing the potential results and their consequences and rankordering them (e.g., crossing speed limits is better than taking a road in a forbidden direction), and finally selecting the alternative that has been highest in this ranking. After the implementation of the action, feelings arise from the consequences of this action, and can be positive, such as satisfaction (Houston et al., 1991), or negative, such as disappointment or regret (Zeelenberg et al., 1998).

RT is influenced by three types of factors based on the approach of Einhorn (1970) and Hunt et al. (1989) in the field of decision making: decision features, situational factors and individual differences. Decision features are the characteristics of the decision, such as the ordering of the choice options, the framing of choice options, or the requirement of choice justification (Appelt et al., 2011). Situational factors refer to the background of the decision, for example, time pressure (Dror et al., 1999) or social context (Nadler et al., 2001). Finally, individual differences refer to the characteristics of the decision-maker, and have been identified as the perception of risks, the expected benefits and risk attitude in the field of RT (Figner and Weber, 2011). According to the authors, the tradeoff between the perceived risk and the expected benefits may lead to assessing an 
alternative as more attractive when the expected benefit is greater than the lost risk, while this will be interpreted as less attractive if the perceived risk is greater than the expected benefit. Regarding the risk attitude, it has been defined above as the tendency to assess a risky situation in a favourable or unfavourable way.

\section{Individual differences in risk taking}

Although the role of individual differences in RT has been clearly accepted in the literature, it is observed that there is no clear consensus about which are the dimensions that influence the perception of risks/benefits and the attitude towards risk, and therefore, RT. To shed light on this topic, Table 1 lists those variables identified as the most influential in RT based on the scientific evidence.

Table 1. Individual factors influencing RT

Personality: Big Five factorial model of personality, composed of neuroticism, extraversion, openness, agreeableness and conscientiousness factors (McCrae and Costa, 1997)

Relation with RT

Neuroticism is connected to sensitivity to punishment and negative affect. Although it has been related to risk aversion, as a way of evading anxiety or guilt about negative outcomes, the relation between neuroticism and RT seems to be inverse in the health domain, in which some studies identified a trend to risk seeking to allevite negative emotions in subjects with high neuroticism.

Extraversion is defined as a need for stimulating experiences, is manifested in positive affect and sensitivity to reward and has been related to risk seeking. Individuals with high extraversion show interest for shinny colours and noisy environments.

Openness to experience, which relates to cognitive risk seeking, is relevant to an understanding of social behaviours, and participants with high scores in openness to experience present greater protection against social anxiety.

Agreeableness is characterized by trust and obedience, and has been related to risk aversion.

\section{Articles}

Elliot and Trash, 2010

Nicholson et al., 2005

Vollrath and Torgersen, 2002

Costa and McCrae, 1992

Eysenck, 1973

Lauriola and Levin, 2001
Costa and McCrae, 1992

Josef et al., 2016

Kaplan et al., 2015

Gullone and Moore, 2000

Hoyle et al., 2000

McCrae and Costa, 1997

Nicholson et al., 2005

Soane et al., 2010 
Conscientiousness is understood as a need for McCrae and Costa, 1997 compliance under conditions of conformity and control, Nicholson et al., 2005 and has been related to risk aversion.

Schwebel et al., 2006

Sensation seeking: It is the concern to live new experiences and is accompanied by the desire to take risks of various natures. Is composed of the thrill and adventure seeking, experience seeking, disinhibition and boredom susceptibility subtraits. Individuals with different degrees of sensation seeking tend to present differences in their levels of activation and attention, which generates differences in their information processing. The relation between sensation seeking and RT is well supported by the literature, which has related this construct to the approach to risk in various fields (Zuckerman 1994; Zuckerman, 1979; Zuckerman and Como, 1983, Wagner, 2001; Donohew et al., 2000).

Relation with RT

Thrill and adventure seeking reflects the intention to live new physical experiences and interest for shinny colours and noisy environments. It is positively related to RT in driving and sports.

Experience seeking has been related to lower sensitivity to aversive stimulation and appears as significant predictor of RT and risky habits. The experience seeking and disinhibition dimensions represent the less socially acceptable sensation seeking subtraits.

Disinhibition refers to the tendency toward pleasureseeking preferences and has been related to imprudent behaviours in several domains, as in rule-breaking behaviours and violations of societal norms. It also appears as significant predictor of RT in academically dishonest behaviours, gambling and health RT.

\section{Articles}

Costa and McCrae, 1992

Wishart et al., 2017

Zuckerman, 1994

Netter et al., 1996

Pedersen et al., 1989

Popham et al., 2011

Roberti, 2004

Zuckerman, 1978

Zuckerman, 1984

Bancroft, et al., 2003

Bonnaire and Barrault, 2018

De Vries et al., 2009

Donohew et al., 2000

Etter et al., 2006

Hittner and Swickert, 2006

Kopstein et al., 2001

Lozano et al., 2017

Orlebeke 1990

Popham et al., 2011

Roberti, 2004

Weber et al., 2002

Wolfgang, 1988

Zuckerman, 2008 
Boredom susceptibility is related to low tolerance Guszkowska et al., 2010 towards repetitive and routine tasks, which has been Zuckerman, 2006 related to an approach towards risk in sports contexts.

Impulsivity: Is the tendency to make quick and unplanned responses to internal or external stimuli, regardless of the negative effects of these responses. Impulsivity is comprised of a set of five impulse-related traits: negative urgency, lack of premeditation, lack of perseverance, sensation seeking, and positive urgency. Impulsivity has become one of the strongest predictors of RT in various fields (Moeller et al., 2001; Whiteside and Lynam, 2001; Moreno et al., 2012; Donohew et al., 2000; Blanco et al., 2009; Coskunpinar et al., 2013).

\section{Relation with RT}

Negative urgency is related to the tendency to behave impulsively in negative situations.

Lack of premeditation is related to thoughtless behaviors and a tendency to choose alternatives with short-term rewards rather than options that can lead to more valuable but delayed rewards.

Lack of perseverance reflects an absence of focus on a boring or difficult activity.

Sensation seeking is an attraction for exciting, new and potentially dangerous experiences. It has been related to recreational RT in activities such as high-risk sports.

\section{Articles}

Whiteside and Lynam, 2001

Whiteside et al., 2005

Whiteside and Lynam, 2001

Whiteside et al., 2005

Whiteside and Lynam, 2001

Whiteside et al., 2005

Gomà-i-Freixanet et al., 2012

Whiteside and Lynam, 2001

Whiteside et al., 2005

Woodman et al., 2013

Whiteside and Lynam, 2001

Whiteside et al., 2005 Positive urgency is related to the tendency
impulsively when facing positive situations. Locus of control: Indicates the extent to which a person perceives that events are
under their control (internal control) or under the control of external forces, such as fate or other people (external control) (Rotter, 1966).

\section{Relation with RT}

When the "hot" emotional process is prominent, internal locus of control plays an important role in the "cooling process". It has been shown that subjects with internal locus of control present riskyer behaviours in certain areas than externals in which "hot" emotional processes are highly involved, while the relation seems to be opposite other kind of situations.

\section{Articles}

Ahmed, 1985

Crisp and Barber, 1995

Gore and Rotter, 1963

Higbee, 1972

Salminen and Klen, 1994

Terry et al., 1993

You et al., 2013 
Executive control: Is the ability to control thoughts to inhibit or adjust behaviours according to the situation (Diamond, 2013).

Relation with RT

Research has shown that people with poor executive control are less likely to assess the situation and gather information before making a decision, which can lead to risky behaviours. People with high levels of executive control show a high degree of consistency in their responses. Failures in inhibition capabilities and maladaptive behaviour patterns can encourage the development of RT in certain areas, such as drug addiction, leading to dangerous behaviors in daily life.

Emotion regulation: Is the control of emotions, and can be applied through two strategies: cognitive reappraisal, an antecedent-focused strategy that involves changing the meaning of a situation by reformulating the way it is understood to minimize or modify its emotional impact; and expressive suppression, the inhibition of the emotional response associated with a specific emotion (Gross, 2002; Gross and John, 2003).

\section{Relation with RT}

It can affect three components of RT, which involve

different deliberative-versus-automatic strategies: interrupting a risk behaviour, thinking before acting, and choosing between two alternatives. The relation between the habitual use of either emotion-regulation strategy - cognitive reappraisal or emotional suppression - and RT does not seem to be entirely established in the literature. Some studies suggest that individuals under the cognitive reappraisal strategy tend to take greater risks, as this strategy mitigates the influence of negative emotions, which leads them to be less sensitive to both the probability and the magnitude of potential losses. Conversely, some authors have suggest that reappraisal strategy is related to positive affect and lower RT, in domains such as smoking, risky drinking and emotional eating. On the other hand, individuals under emotional suppression put things into perspective less frequently and are more susceptible to negative emotions.

\section{Articles}

Blair et al., 2018

Kalivas and Volkow 2005

Magar et al., 2008

Moore, Clark and Kane, 2008

Pharo et al., 2011

\section{Articles}

Evers et al., 2010

Fucito et al., 2010

Gross and John, 2003

Heilman et al., 2010

Magar et al., 2008

Panno et al., 2013

Pellegrino, 2019

Steinberg, 2004

As seen in Table 1, some of these dimensions tend to influence RT in a generalized way, regardless of the domain or type of decision, while others show a different influence on $\mathrm{RT}$, depending on the scope and context of the decision. In the literature, there is talk of 
a general disposition towards RT, known as risk proneness, and understood as the trend towards favorable assessment of risk situations, regardless of the domain (Raffaelli and Crockett, 2003). This cross-situational trait has been connected to temperamental aspects (Zuckerman and Kuhlman, 2000), so that it generates an initial predisposition towards risk in the decision making process. This approach is consistent with the aforementioned scheme, in which there is an attitude towards risk (risk proneness/aversion) and a perception of risks/benefits, which influence RT.

Thus, although an individual shows a certain attitude (be it proneness or avoidance) towards risk, there are other perceptual biases that will influence the final decision. These perceptual biases are context-dependent, since each of them can influence the perception of a situation to a greater or lesser extent, depending on the characteristics of the decision. For example, in a situation of financial risk, it is probable that an individual with high executive control makes a more accurate evaluation of the situation and the potential outcomes than an individual with poorer executive control. It should be also probable that, in a highly emotionally charged situation, an individual with high capacities to self-regulate emotionally, can analyse the situation in a more rational way than an individual with less self-regulation capacities.

\section{Current measures of risk taking}

The measurement of RT is currently a challenge for researchers, and has been approached from different perspectives over the years. Questionnaires or self-report scales are the most traditionally used technique for RT measurement, in some cases used as a single measure, and in others used in combination with other questionnaires. Table 2 lists the main questionnaires employed for RT measurement found in the literature.

Table 2. Self-report scales used for RT assessment

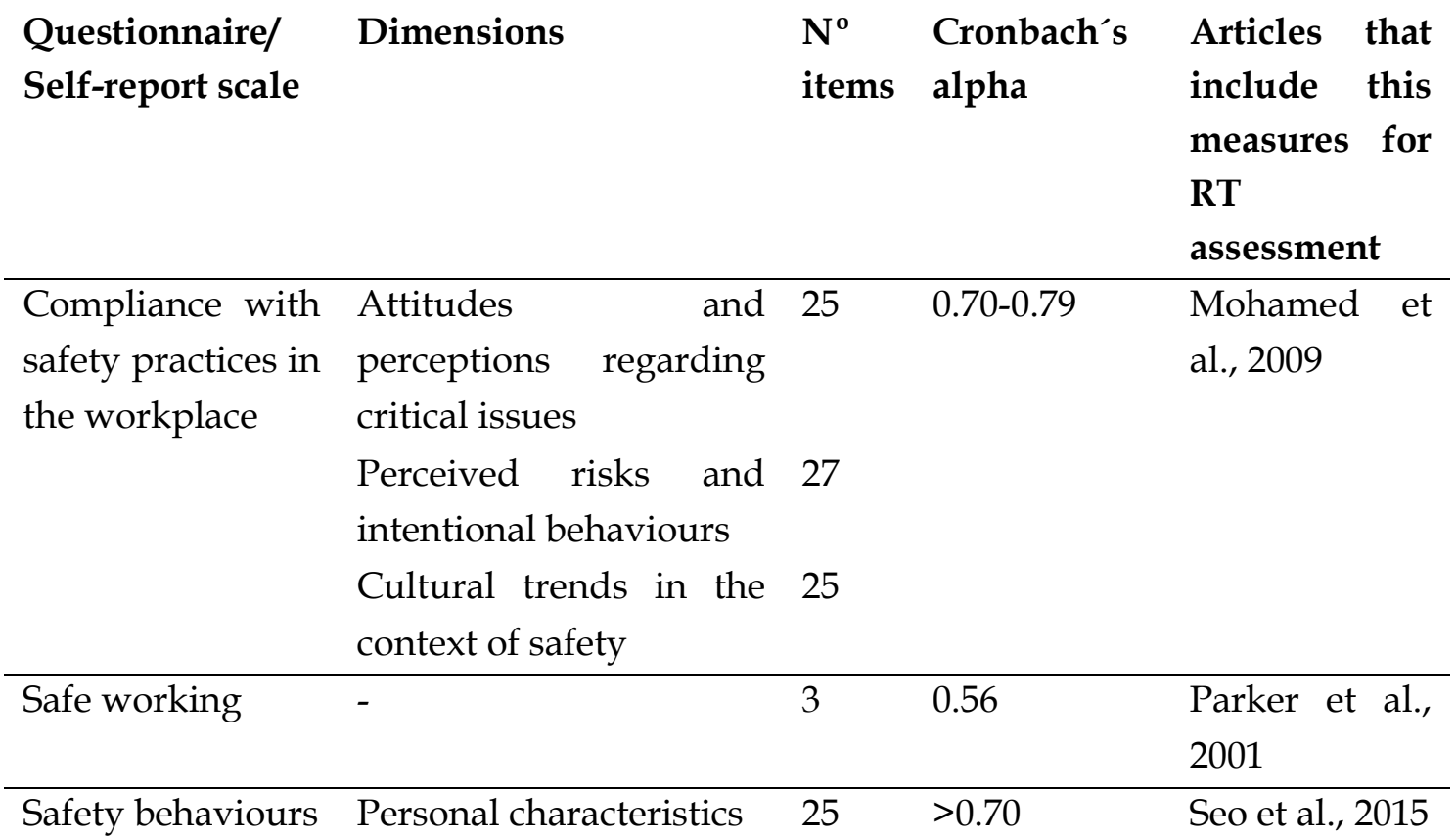




\begin{tabular}{|c|c|c|c|c|}
\hline & Job stress & 16 & & \\
\hline & Self-perceived fatigue & 19 & & \\
\hline & Safety culture & 9 & & \\
\hline & Safety climate & 25 & & \\
\hline & Safety behaviours & 10 & & \\
\hline \multirow{5}{*}{$\begin{array}{l}\text { Risk perception } \\
\text { towards nuclear } \\
\text { power }\end{array}$} & $\begin{array}{l}\text { Attitudes towards } \\
\text { nuclear power }\end{array}$ & 4 & \multirow[t]{5}{*}{$0.72-0.85$} & $\begin{array}{l}\text { Kivimäki and } \\
\text { Kalimo, } 1993\end{array}$ \\
\hline & Risks at work & 4 & & \\
\hline & $\begin{array}{l}\text { Features of work and } \\
\text { organization }\end{array}$ & 14 & & \\
\hline & Well-being at work & 14 & & \\
\hline & $\begin{array}{l}\text { Organizational } \\
\text { commitment }\end{array}$ & 8 & & \\
\hline $\begin{array}{l}\text { Risky decision- } \\
\text { making }\end{array}$ & - & 1 & - & $\begin{array}{l}\text { Sitkin and } \\
\text { Weingart, } \\
1995\end{array}$ \\
\hline $\begin{array}{l}\text { Multidimensional } \\
\text { Personality } \\
\text { Questionnaire } \\
\text { (Tellegen, 1982) }\end{array}$ & Behavioural Constraint & $19-34$ & $0.79-0.85$ & $\begin{array}{l}\text { Lejuez et al., } \\
2002\end{array}$ \\
\hline \multirow{5}{*}{$\begin{array}{l}\text { NEO-Five } \text { Factor } \\
\text { Inventory } \text { (Costa } \\
\text { \& McCrae, 1992) }\end{array}$} & Neuroticism & 12 & \multirow{5}{*}{$\begin{array}{l}\text { 0.75-0.83 } \\
\text { (Spanish } \\
\text { sample; } \\
\text { Cordero } \\
\text { al., 1999) }\end{array}$} & Parker et al., \\
\hline & Extraversion & 12 & & 2001 \\
\hline & Openness & 12 & & Skeel et al., \\
\hline & Conscientiousness & 12 & & 2007 \\
\hline & Agreeableness & 12 & & \\
\hline \multirow{2}{*}{$\begin{array}{l}\text { Barratt } \\
\text { impulsiveness }\end{array}$} & Motor impulsivity & 10 & \multirow[t]{3}{*}{$0.89-0.92$} & Lejuez et al., \\
\hline & Cognitive impulsivity & 8 & & 2002 \\
\hline $\begin{array}{l}\text { Scale (Barratt, } \\
\text { 1985) }\end{array}$ & $\begin{array}{l}\text { Future-planning } \\
\text { impulsivity }\end{array}$ & 12 & & \\
\hline \multirow{3}{*}{$\begin{array}{l}\text { Eysenck } \\
\text { Impulsiveness } \\
\text { Scale (Eysenck et } \\
\text { al., 1985) }\end{array}$} & Impulsivity & 19 & \multirow[t]{3}{*}{$0.69-0.84$} & Lejuez et al., \\
\hline & Venturesomeness & 16 & & 2002 \\
\hline & Empathy & 19 & & $\begin{array}{l}\text { Lejuez et al., } \\
2003\end{array}$ \\
\hline \multirow{5}{*}{$\begin{array}{l}\text { UPPS-P } \\
\text { Impulsivity scale } \\
\text { (Cándido et al., } \\
\text { 2012) }\end{array}$} & Negative urgency & 5 & \multirow{5}{*}{$\begin{array}{l}\text { 0.66-0.81 } \\
\text { (Spanish } \\
\text { sample; } \\
\text { Cándido } \\
\text { al., 2012) }\end{array}$} & Lozano et al., \\
\hline & Lack of premeditation & 5 & & 2017 \\
\hline & Lack of perseverance & 5 & & \\
\hline & Sensation seeking & 5 & & \\
\hline & Positive urgency & 5 & & \\
\hline $\begin{array}{l}\text { Sensation seeking } \\
\text { Scale (Zuckerman } \\
\text { et al., 1978) }\end{array}$ & $\begin{array}{l}\text { Thrill and adventure } \\
\text { seeking } \\
\text { Experience seeking }\end{array}$ & 10 & $\begin{array}{l}0.67-0.81 \\
\text { (Spanish } \\
\text { sample; }\end{array}$ & $\begin{array}{l}\text { Horvath and } \\
\text { Zuckerman, } \\
1993\end{array}$ \\
\hline
\end{tabular}




\begin{tabular}{|c|c|c|c|c|}
\hline & $\begin{array}{l}\text { Disinhibition } \\
\text { Boredom susceptibility }\end{array}$ & $\begin{array}{l}10 \\
10\end{array}$ & $\begin{array}{l}\text { Pérez and } \\
\text { Torrubia, } \\
\text { 1986) }\end{array}$ & $\begin{array}{l}\text { Lejuez et al., } \\
2002 \\
\text { Lejuez et al., } \\
2003 \\
\text { Lozano et al., } \\
2017\end{array}$ \\
\hline $\begin{array}{l}\text { Engagement in } \\
\text { RT behaviours in } \\
\text { daily life }\end{array}$ & - & 10 & - & $\begin{array}{l}\text { Lejuez et al., } \\
2003\end{array}$ \\
\hline $\begin{array}{l}\text { Life experiences } \\
\text { questionnaire } \\
\text { (Zuckerman and } \\
\text { Kuhlman, 2000) }\end{array}$ & $\begin{array}{l}\text { Drinking } \\
\text { Smoking } \\
\text { Drugs } \\
\text { Sexual behaviour } \\
\text { Driving habits } \\
\text { Gambling }\end{array}$ & $\begin{array}{l}2 \\
3 \\
3 \\
4 \\
5 \\
13\end{array}$ & 0.65 & $\begin{array}{l}\text { Zuckerman } \\
\text { and Kuhlman, } \\
2000\end{array}$ \\
\hline $\begin{array}{l}\text { Domain-Specific } \\
\text { Risk Taking Scale } \\
\text { (Blais and Weber, } \\
\text { 2006) }\end{array}$ & $\begin{array}{l}\text { Ethic } \\
\text { Financial } \\
\text { Health } \\
\text { Recreational } \\
\text { Social }\end{array}$ & $\begin{array}{l}6 \\
6 \\
6 \\
6 \\
6\end{array}$ & $\begin{array}{l}\text { 0.64-0.85 } \\
\text { (Spanish } \\
\text { sample; } \\
\text { Lozano et al., } \\
2017)\end{array}$ & $\begin{array}{l}\text { Lee and Jeong, } \\
2013 \\
\text { Foster et al., } \\
2009 \\
\text { Rolison et al., } \\
2013 \\
\text { Weller an } \\
\text { Tikir, } 2011 \\
\text { Zimerman et } \\
\text { al., } 2014\end{array}$ \\
\hline
\end{tabular}

In contrast, questionnaires present some limitations at a methodological level, as well as in terms of their ability to evaluate implicit processes:

i. They require comprehension skills and their interpretation may be different between subjects. In addition, they ask closed questions, which in many cases could constitute a loss of information.

ii. They are answered in a laboratory setting. Contextual elements, such as characteristics of the physical space, time pressure or the feeling of being observed can result in response biases.

iii. Questionnaires, and especially those that include questions related to taboos, illegal behaviours, extreme opinions and other sensitive content, present social desirability biases. In these cases, participants tend to underreport socially unacceptable behaviours, and to overreport socially acceptable behaviours (Krumpal, 2013).

iv. Since questionnaires are usually answered before or after the experiences or behaviours that are intended to be evaluated, the emotional and cognitive states 
of the subject are different during the evaluation and during the experience itself (Kivikangas et al., 2011).

v. Questionnaires pose decontextualized situations, so the user must "imagine" what their feeling or behaviour would be in the proposed situation. It has been shown that most of the processes that regulate our emotions, attitudes and behaviours are implicit, and therefore cannot be verbalized (Barsade et al., 2009; George, 2009; Becker et al., 2011).

vi. In questionnaires, responses to a set of questions provide the measure of a single dimension. Therefore, sometimes long and tedious tests are required to make a complete evaluation composed of various psychological dimensions.

To overcome these limitations, an emerging line of research focuses on how to assess emotions, attitudes and behaviours in an unbiased way. The "stealth assessment" paradigm (Shute, 2011) emerged as a methodology focused on measuring a series of parameters while the subject performs a task or a game. Subsequently, conclusions are raised based on the results obtained. It is interesting that the subject does not know that (s)he is being evaluated, and therefore the results obtained are free from biases. Under this paradigm, we can find those measurement tools that use behavioural tasks for the evaluation of RT. In these tasks, the user is in a controlled laboratory environment and solves a task, generally in 2D format on a computer, although there are also original versions on paper-and-pencil format of some of them. Table 3 lists the main behavioural tasks employed for RT measurement found in the literature.

Table 3. Behavioural tasks used for RT assessment

Name of the measure and brief description

Bechara Gambling Task: participants are given four decks of cards, and they must select a card from one of them. By placing the card face up, the participant wins or loses an amount of money. This process is repeated a hundred times, so that the participant learns, based on these repetitions, what probability of gains or losses exists in each deck.

Balloon Analogue Risk Task: a balloon is presented accompanied by a button that allows it to be inflated. The more participants inflate the balloon without it exploding, the greater the financial reward they get. The moment in which the balloon explodes is different in each case and unknown for participants.

Angling Risk Task: participant must catch red fishes from a pond Pleskac, 2008 that contains 127 red fishes and 1 blue fish. Each time the subject catches a red fish, (s)he increases his/her potential profit (5 cent) but if (s)he catches the blue fish, (s)he will lose all the money he has earned. The participant can decide when (s)he wants to stop fishing and collect the money earned up to that point. This is repeated in 30 trials. Furthermore, the user can play under two weather
Articles

Bechara et al., 1994

Lejuez et al., 2002 
conditions (clear or cloudy) and under two release conditions (the

fishes are not returned to the pond after being caught or the fishes are returned to the pond after being caught).

Bomb Risk Elicitation Task: the subject is in front of a grid of 10x10 parcels, among which is a hidden bomb. At the beginning of the Crosetto and task, the participant must indicate how many plots (s)he wants to uncover, taking into account that (s)he will earn more money the more plots (s)he uncovers, as long as the pump is not found among them. If the bomb is found between the uncovered plots, the subject will lose all the money collected in this round.

Cake Gambling Task: a cake with 6 pieces is presented, of which a Van Leijenhorst
random number are brown and the rest are pink. The task consists et al., 2008
of betting which of the two colours the computer will choose,
taking into account that the colour that has the most portions will
have a greater probability of being chosen. If the subject is correct,
(s)he takes the stake, while (s)he will not win anything if the
opposite occurs.

At a general level, all these tasks have two important points in common: (1) in all of them a series of bets is raised, so that the consequences are related to a greater or lesser gain in money; and (2) are based on a series of trials, so that the subject learns and makes decisions influenced by the results of his/her previous decisions. On the one hand (1), the fact that these behavioural tasks focus the measurement of RT on decisions of a financial nature, calls into question its validity in terms of the possibility of extrapolating these results to other areas of RT. On the other hand (2), although the study of RT is interesting taking into account the results of previous decisions, this sequential task approach (Pleskac, 2008) supposes the existence of learning in decision making throughout the task. This decontextualized approach, in combination with a format that is easy to administer but is probably not capable of activating the implicit processes that are intended to measure, causes a low correspondence between the results in neuropsychological tasks and real-life behaviors (Manchester et al., 2004; Sbordone, 2008; Bottari et al., 2009). In this sense, VR-based instruments have been raised as alternative tools to traditional instruments, such as questionnaires and neuropsychological tasks, which allows taking a further step in the evaluation of human behaviour, allowing to evaluate implicit processes in an ecological and unbiased way, thanks to the immersive capabilities of VR technology.

\section{Virtual reality for human assessment}

VR consists of a synthetic 3D environment capable of simulating situations in which situations are simulated with which users can interact in a natural and realistic way (Alcañiz et al., 2003). This technology has been applied in numerous fields of human 
behaviour research (e.g. Alcañiz et al., 2003), providing better results than 2D solutions (Giglioli et al., 2019) thanks to its capacity to generate responses of great ecological validity (Parsey and Schmitter-Edgecombe, 2013). VR presents numerous advantages that can provide benefits for the evaluation of human behaviours, since it provides greater immersion and realism than traditional assessment methods, ensuring a higher level of user involvement (Hedberg and Alexander, 1994).

VR allows to propose an approach focused on the study of behaviours in realistic situations or perceived as realistic by the user. The combination of the elements that make up a VR set-up - type of device used, graphic quality of the virtual environment, refresh rate, etc. - provide the system with a specific level of immersion. This level of immersion, in combination with the design of the virtual environment, its dynamics and navigation metaphors, generate the sense of presence, defined as the psychological state of "being there", and for which the user forgets for a while that (s)he is in a virtual context (Slater 2009). This "plausibility illusion", by which the user perceives as real what (s)he is experiencing, implies that the neural mechanisms that the subject experiences while (s)he is in the virtual environment are similar to those when (s)he experiences this same situation in real life (Tarr and Warren, 2002; Alcañiz et al., 2009).

Additionally, VR facilitates physical interactions with the virtual elements, generating an embodied experience (Kilteni et al., 2012). This coherence, by which the elements of

a virtual environment behave in a realistic and natural way before the movements of the user, allows us to design virtual situations in which the user carries out the actions in the first person, without using metaphors, but rather their own movements. This nuance, which differentiates these actions from others posed in the third person, has been studied within the scope of the dual-process theory of moral judgment. It has been shown that when actions are posed in the first person and involve physical actions the subjects tend to make more emotional decisions (Greene et al., 2001; Amit et al., 2014).

\section{Implicit measures for human assessment}

Implicit measures are defined as those that aim to capture psychological attributes without requiring participants to make a subjective assessment of these attributes (Gawronski and De Houwer, 2014) and have been shown to be reliable predictors of behaviours (Perugini et al., 2010). They provide unbiased responses, since they reduce the ability of users to voluntarily modify their answers, and they do not require psychological introspection to provide answers (Gawronski and De Houwer, 2014). There are implicit measures of various natures, behavioural (such as eye tracking) and physiological (such as galvanic skin response (GSR)), and both have been widely used in the field of experimental psychology, in order to find implicit markers of specific psychological dimensions.

Eye tracking is an experimental method that collects the eye movements of an individual for a certain time while carrying out a task (Carter and Luke, 2020). The main eye 
movements that can be measured through eye tracking tools are fixations and saccades. A fixation is the period of time during which the eye remains viewing a target in a stable manner. Fixations usually last between 180-330 milliseconds (Rayner, 2009), so it is possible that several fixations on the same object are necessary to acquire information. Saccades are the eye movements that occur between one fixation and the next, so that during these movements the eye stops acquiring information (Rayner, 2009; Burr et al., 1994). Saccades can last an average of 30 milliseconds and typically cover about 2-5 degrees of rotation (Abrams et al., 1989; Rayner, 1978). Eye movements are a reliable indicator to assess visual attention (Just and Carpenter, 1980) and therefore those cognitive processes related to attention (Carter and Luke, 2020). Gaze movements have shown to be related to information processing in risky decisions (Glöckner and Herbold, 2010) and problem solving (Knoblich et al., 2001).

The GSR is a reflection of a psychological reaction that generates excitement, and that reveals changes in the sympathetic nervous system (Ayata et al., 2017). It is measured through the electrical conductance of the skin caused by a particularly prevalent sweat reaction on the surface of the hands and fingers, as well as on the soles of the feet (Ayata et al., 2017). The GSR has been used successfully as an indicator of emotional activation (Nourbakhsh et al., 2013).

\section{Virtual reality for risk taking evaluation}

In the field of RT, VR can provide great advantages in terms of immersion and sense of presence, thanks to which the user is able to perceive what is happening in the virtual environment in a very realistic way, as if this was happening in real life. This is very interesting when we find ourselves with the need to generate or simulate situations that are difficult or impossible to recreate in real life, such as risk situations. From this point of view, VR can be a very useful tool to "bring" the subject to risky situations, and evaluate his/her behaviours without danger. Additionally, VR allows us to carry out actions in the first person, physically interacting with the elements of the virtual environment, and not only using a computer mouse, but using the whole body, just as we do in real life (Kilteni et al., 2012). This is a great distinction compared to other types of measurement tools, since it allows a much more natural and intuitive interaction.

Few VR-based tools for RT assessment have been found in the literature. The few that have been found focus on specific contexts such as roof fall hazard simulation (Isleyen and Duzgun, 2019) or gas engineering (Asghar et al., 2019). Conversely, there is a greater number of tools in the field of safety training that use VR as a means to teach and train users how to act in certain risk situations. As in the case of evaluation, these tools are also usually based on specific contexts, and their designs are based on the simulation of these situations, such as driving (Ojados González et al., 2017), construction (Hasanzaeh et al., 2020; Sacks et al., 2013; Shi et al., 2019) or gas engineering (Asghar et al., 2019). Seen that the simulation is the majority approach when finding VR tools for RT 
evaluation and training, RT evaluation tools designed under a decontextualized approach have not been found that allow RT to be evaluated from a psychological point of view, which could be extrapolated to some extent to different contexts.

Regarding the possibilities offered by VR from the point of view of behavioural and physiological measurement, VR allows the evaluation of behaviours under the stealth assessment paradigm (Shute, 2011), incorporating implicit measures to evaluate implicit processes. It allows the collection of behavioural responses from the subjects while they are interacting with the virtual environment (Parsons, 2015), and the inclusion of additional measures such as eye tracking and GSR.

Currently there are commercial solutions that integrate eye tracking systems in headmounted display devices (HTC VIVE ProEye, https://www.vive.com/uk/product/vive-pro-eye/overview/; Pico Neo 2 Eye, https://www.pico-interactive.com/us/neo2.html), which guarantees an adequate data collection. Thus, fixations and saccades can be collected during a VR experience. Both technologies - eye tracking and VR - have been used together to study the influence of contextual elements in human behaviours, such as in street robbery (Yand et al., 2020), identifying if the presence of particular components of a physical space can influence in decision-making. Furthermore, ET has been employed to study whether if exists a relationship among gaze patterns and human behaviour (Pettersson et al., 2018; PorrasGarcía et al., 2019), or even if these gaze patterns could contribute to predict humans' decisions (Rojas et al., 2020).

In addition to these behavioural measures, VR can also be combined with physiological measures, which have been proposed as implicit measures (Kivikangas et al., 2011), in order to record in real time the physiological response of the subject while (s)he is in a virtual environment. Specifically, GSR has been used in combination with VR to evaluate the stress generated by changes in contextual aspects, such as architectural stimuli (Ergan et al., 2019), as predictor of anxiety level (Šalkevicius et al., 2019) and as a measure to discriminate between Autism Spectrum Disorder and typical development populations (Alcañiz et al., 2020), among others.

In the field of RT, there is previous evidence in the application of ET and GSR measurement tools. ET has been used as a reliable indicator of information processing patterns in risky decisions (Kwak et al., 2015; Su et al., 2013; Payne and Braunstein, 1978; Velichkovsky et al., 2002; Habibnezhad et al., 2016); and GSR has emerged as an indicator of physiological activation, which acts as a "warning signal" in risky situations and tends to lead to safe decisions (Bechara et al., 2005). Despite these measures having been widely adopted in VR-based experiments, to our knowledge, ET and GSR have not been employed in combination with VR to evaluate RT.

In conclusion, the lack of consensus in the literature when defining the concept of RT and the need for a tool to its measurement, in combination with the advantages provided 
by VR in the field of human behaviours study, constitute the main motivation to perform the present research.

\section{Objectives}

The general objective of this thesis is to study the use of immersive VR environments as a tool of high ecological validity for the evaluation of decision-making processes in the face of risk. For this, the concept of RT has been studied in depth and two virtual reality environments have been developed to study its capacity to predict risk behaviours. The specific objectives are:

SO1. To study the context regarding the definition of RT based on the literature, to study the existing measures of RT as well as their limitations, and to propose VR as an interesting alternative for the evaluation of RT.

SO2. To establish a clear definition of RT, to analyse the psychological dimensions that compose it, and to study the existence of generalized features that influence RT regardless of the type of risk.

SO3. To develop a first virtual environment that allows to evaluate the subjects in terms of RT, and to establish the first bases for the design of virtual environments for the evaluation of RT.

SO4. To develop a virtual environment for evaluating RT, following the design premises established above, and to study its predictive capacity in combination with physiological measures using machine learning techniques.

\section{Thesis structure}

The thesis document is structured as follows:

Chapter 1 introduces and describes the motivation behind the thesis. In addition, it includes the objectives and thesis structure.

Chapter 2 presents the paper "Virtual Reality as a New Approach for Risk Taking Assessment", published in Frontiers in Psychology (Q2, 2.607 JCR 2019) as a Perspective article. The article suggests that a new RT measure is needed to contribute to the existing instruments, based on VR technology and under the stealth assessment paradigm.

Chapter 3 presents the paper "The Spheres \& Shield Maze Task: A Virtual Reality Serious Game for the Assessment of Risk Taking in Decision Making", published in Cyberpsychology, Behaviour, and Social Networking (Q2, 2.347 JCR 2019) as a Research article. The article presents a new VR tool for RT assessment called Spheres \& Shield Maze Task. 
Introduction

Chapter 4 presents the paper "Why do we take risks? Perception of the situation and risk proneness predict domain-specific risk taking", published in Frontiers in Psychology (Q2, 2.607 JCR 2019) as a Research article. The article investigates whether if RT behaviours can be explained largely by both perceptual and proneness biases.

Chapter 5 presents the paper "An Immersive Virtual Reality Game for Predicting Risk Taking through the Use of Implicit Measures", published in Applied Sciences (Q2, 2.474 JCR 2019) as a Research article. The article presents a new VR tool for RT assessment called AEMIN, as an enhanced version of the Spheres \& Shield Maze Task presented in Chapter 3.

Chapter 6 discusses the results and the major contributions of the thesis.

Chapter 7 provides an overall conclusion and future research directions.

Finally, the manuscript enumerates the publications and research stages derived from this thesis and provides a list of references. 


\title{
Chapter 2. Virtual Reality as a New Approach for Risk Taking Assessment
}

de-Juan-Ripoll, C., Soler-Domínguez, J. L., Guixeres, J., Contero, M., Álvarez Gutiérrez, N., \& Alcañiz, M. (2018). Virtual reality as a new approach for risk taking assessment. Frontiers in psychology, 9, 2532.

\begin{abstract}
Understanding how people behave when facing hazardous situations, how intrinsic and extrinsic factors influence the risk taking (RT) decision making process and to what extent it is possible to modify their reactions externally, are questions that have long interested academics and society in general. In the spheres, among others, of Occupational Safety and Health (OSH), the military, finance and sociology, this topic has multidisciplinary implications because we all constantly face RT situations. Researchers have hitherto assessed RT profiles by conducting questionnaires prior to and after the presentation of stimuli; however, this can lead to the production of biased, non-realistic, $\mathrm{RT}$ profiles. This is due to the reflexive nature of choosing an answer in a questionnaire, which is remote from the reactive, emotional and impulsive decision making processes inherent to real, risky situations. One way to address this question is to exploit VR capabilities to generate immersive environments that recreate realistic seeming but simulated hazardous situations. We propose VR as the next-generation tool to study RT processes, taking advantage of the big four families of metrics which can provide objective assessment methods with high ecological validity: the real-world risks approach (high presence VR environments triggering real-world reactions), embodied interactions (more natural interactions eliciting more natural behaviours), stealth assessment (unnoticed real-time assessments offering efficient behavioural metrics) and physiological real-time measurement (physiological signals avoiding subjective bias). Additionally, VR can provide an invaluable tool, after the assessment phase, to train in skills related to RT due to its transferability to real-world situations.
\end{abstract}

\section{Introduction}

Each year, deficient Occupational Safety and Health (OSH) practices cause a global cost of approximately 2680 billion euros (Elsler et al., 2017). Although OSH training has shown positive impacts in the workplace, its effectiveness is below expectations (Robson et al., 2012). It has been demonstrated that the natural differences between individuals can appreciably influence this low effectiveness at several levels, cognitive, motivational and functional, among others (Motowildo et al., 1997). Risk propensity, defined as the "willingness to take risks" (MacCrimmon and Wehrung, 1990) and risk perception, 
defined as the individual's assessment of how risky a situation is (Baird and Thomas, 1985), have been shown to have strong influence on risky decision making behaviours (Sitkin and Weingart, 1995). The measurement of risk taking (RT) attitudes is a recognized challenge for researchers and practitioners. Researchers have mostly employed self-report instruments to assess individual constructs based on theoretical psychological models (Brockhaus Sr, 1980; Ford et al., 1990; Gullone et al., 2000; Portell and Solé, 2001; Steinberg, 2004; Gardner and Steinberg, 2005; Sneddon et al., 2013; Rodríguez-Garzón et al., 2015). We have not found any one model that defines RT, thus its measurement requires further investigation. Lejuez et al. (2002) developed and validated a laboratory-based behavioural measure of RT (Balloon Analog Risk Task BART). While this is a validated tool that has been used in several studies, we believe that it is desirable to develop a more ecological system to measure RT. VR provides the capability of creating interactive environments in which users can perform while their behavioural responses are recorded (Parsons, 2015). Accordingly, we propose that virtual environment based assessments are tools that can enhance the ecological validity of the evaluation of the responses evoked (Parsey and Schmitter-Edgecombe, 2013).

In this article we focus on the measurement of RT using physiological and behavioural metrics, with VR being employed as a tool to create immersive situations. We propose to use VR to assess RT attitudes under the paradigm of stealth assessment. VR can provide engaging virtual worlds which will allow real time measurement of RT behaviours.

This paper is comprised of four sections. In the first we review the theoretical framework of RT in the previous literature. In the second we summarize the extant instruments for the measurement of RT behaviours and discuss the current issues that make us believe that there is a need to establish a new approach. In the third we propose VR as a step forward in the assessment of RT. The fourth section briefly discusses the substantial implications raised by the article and our proposals for future research in this field.

\section{Research Into Risk Taking}

RT research can be said to have started with the nuclear debate of the sixties. It was focused on risk acceptance and dealt with factors such as benefits and voluntariness. Since then, several more factors have been proposed for the explanation of RT: trust, trustworthiness and trust propensity (Colquitt et al., 2007); supportive supervision, job autonomy and communication quality (Parker et al., 2001); problem framing and outcome history (Sitkin and Weingart, 1995); expected utility (Kahneman and Tversky, 1986); genre (Byrnes et al., 1999) and boredom (Schroeter et al., 2014).

While these factors have been demonstrated to influence RT, individual differences constitute a key element in decision making processes (see Figure 1). According to Rundmo, 1996, a biased perception of risk - understood as the subjective evaluation of a risk - can lead to misjudgements of potentially hazardous risk sources. Therefore, if the 
subjective evaluation of a risk differs from the objective risk, this should be corrected (Risk Research Committee, 1980). Personality traits influence attitude toward risk, prompting risk seeking or risk aversion behaviours. This set of personal, innate, basic characteristics associated with risk were named Intrinsic Risk Attitude (IRA) by Schoemaker (1993) and have been shown to be consistent in various situations and contexts (Dohmen et al., 2011). Additionally, cognitive and affective states are also considered to be key influencers in the decision making process. We highlight mood and cognitive load as two main representative factors in this category. Mood has a strong influence on RT. People in a positive mood tend to focus on the benefits of a risky situation, much more so than those in neutral mood, making them more susceptible to undertake risky behaviours (Forgas, 1982, 1995; Forgas and Bower, 1987; Yuen and Lee, 2003). On the other hand, people in a negative mood overestimate risks and try to avoid potential loss and, therefore, think and act more carefully (Jorgensen, 1996). Cognitive load, the amount of mental activity involved in working memory, might also play a role in risk perception, since some kind of decisions, based on utilitarian judgments, require additional cognitive resources (Greene et al., 2008).

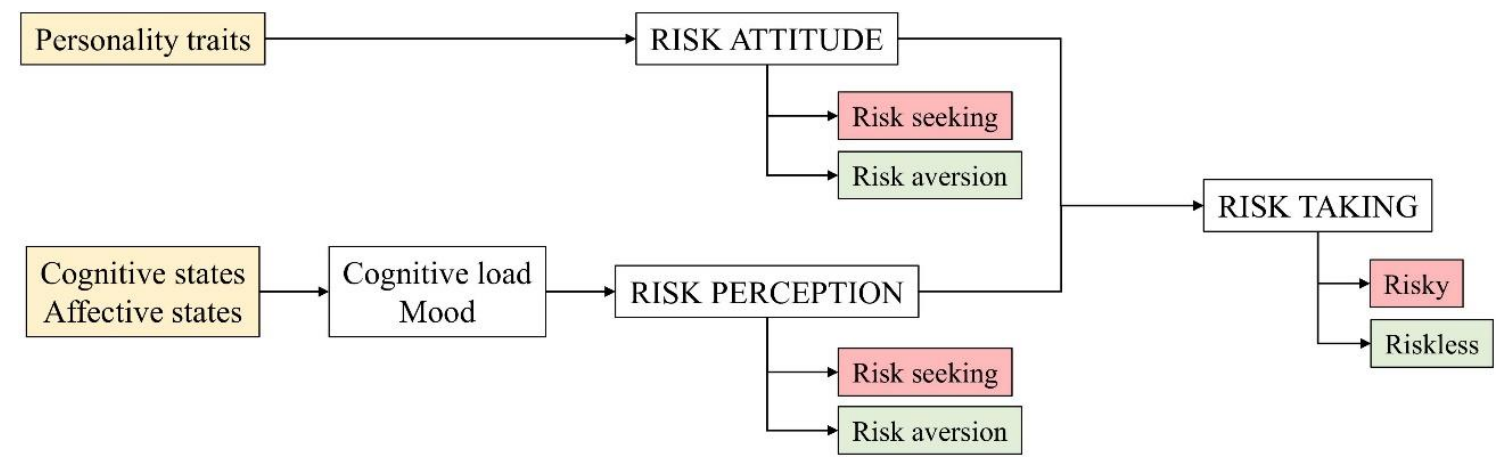

Figure 1. Individual differences that influence risk taking

\section{Risk Taking Measures: Current Issues}

RT measurement is a non-deterministic and non-standardized process based on different perspectives. Traditionally, most theories of human behaviour are based on a model of the human mind that assumes that humans can think and verbalize accurately about their attitudes, emotions and behaviours (Simon, 1976; Brief, 1998). To date, most of the theoretical constructs used in RT assessment are based on explicit measures such as self-reports. However, recent advances in neuroscience have demonstrated that most of the brain processes that regulate our emotions, attitudes and behaviours are not conscious. That is, they are implicit processes that, in contrast to explicit processes, humans cannot verbalize (Barsade et al., 2009; George, 2009; Becker et al., 2011).

Several explicit measures of RT, oriented to evaluate attitude to risk, deferred risk perception or expected risk behaviour, have been proposed in the last fifty years. Some authors have employed self-report measures based on questionnaires on compliance with safety practices in the workplace (Parker et al., 2001; Mohamed et al., 2009; Seo et 
al., 2015), attitude toward risk and organizational commitment (Kivimäki and Kalimo, 1993) and in studies into decision making (Sitkin and Weingart, 1995). On the other hand, some works have drawn on theoretical multidimensional models based on psychological constructs, such as personality (Lejuez et al., 2002; Skeel et al., 2007), impulsivity (Lejuez et al., 2002), sensation seeking (Horvath and Zuckerman, 1993; Lejuez et al., 2002) and situational awareness (Lejuez et al., 2002).

However, as in many other disciplines, pre- and post-experiment questionnaires have an important intrinsic bias since individuals' cognitive and psychological states will be different when they answer the questionnaires to when they actually underwent the experiences that the researchers wish to analyse (Kivikangas et al., 2011). As stated in (Wang et al., 2015), this tendency is primarily due to "social desirability effects," which can lead to untrue accounts of behaviour, attitudes and beliefs (Paulhus, 1991). In addition, there may be different interpretations of specific self-report items, resulting in unreliability and poorer validity (Lanyon and Goodstein, 1997). Lastly, some selfreporting questions need people to possess overt knowledge of their dispositions (Schmitt, 1994) and this does not always run true.

To our knowledge, the BART (Lejuez et al., 2002) constitutes, to date, the only tool for RT measurement using implicit measures. The authors developed and validated a laboratory-based behavioural measure of risky behaviours. In this task, a balloon was presented in the middle of the screen. Subjects were asked to pump it as much as possible, knowing that it could exploit at any time. Participants were told that they would obtain a financial reward the more they could inflate the balloon without breaking it. Although the reliability of this tool has been retested (White et al., 2008), extensive investigations have demonstrated that the correspondence between performance in neuropsychological tests and real-life behaviours is very weak (Manchester et al., 2004; Sbordone, 2008; Bottari et al., 2009).

In the BART validation study, researchers employed measures of impulsivity, sensation seeking and behavioural constraint. We consider this a good basis to build on, since each of these constructs has been investigated independently and associated with RT. Firstly, impulsivity has been associated with RT in terms of drug use, drink driving and seatbelt use (de Wit, 2009; Stanford et al., 1996). Some authors have also demonstrated its connection with emotional self-control, inhibition and, especially, the management of frustrating situations (Cooper et al., 2000; Boyer, 2006). In addition, researchers have studied the relationship between the sensation seeking trait and RT in several domains, such as recreation, health, career, finance, safety and social life (Nicholson et al., 2005). Donohew et al. (1999) concluded that sensation seeking is an important factor in sexual RT. According to Tellegen's (1985), model behavioural constraint is one of the dimensions that composes personality. The behavioural constraint factor encompasses control, harm avoidance and traditionalism facets. In the same way, there is empirical evidence of the influence of personality traits on RT attitudes, in particular punishment 
avoidance (Paulus et al., 2003). We can find an interesting study from Wills et al. (2006) supporting this idea in the substance abuse field.

\section{Limitations of Current Risk Taking Measures}

As mentioned previously, to date the majority of RT assessment tools has been based on explicit measures and the use of questionnaires.

BART, with its multi-dimensional set of psycho-cognitive influences, represents the only alternative to explicit measures of RT behaviour, but its design has some intrinsic limitations that current technologies could help to overcome.

In this regard, we believe that the existing measurement instruments do not reflect real situations, in which the subjects can perform as in real life, which leads to skewed results. In the laboratory the controlled stimuli given to subjects often do not include variables that are present in real life situations. Thus, the ecological validity of these methodologies, such as BART, is quite limited. Furthermore, these measurement tools do not involve any strong physical interaction, but require only simple actions, such as clicking a mouse, ignoring the influence of the reactions of the rest of the body. In addition, when an individual is submitted to the currently available tests, (s)he is aware that (s)he is being assessed and can alter the outcomes; so we propose stealth assessment as a means of obtaining reliable results about real behaviours unnoticed by the subject. Lastly, we suggest that physiological processes must be considered as important measures of RT, as these measurements are uncontaminated by the participant's answering style, social desirability, interpretations of questionnaire item wording, the limits of his or her memory or by observer bias (Kivikangas et al., 2011). Thus, we propose an alternative measurement method which aims to advance in four specific aspects:

(1) Real-world risks: As stated in Bornovalova et al. (2009), p.261. “[BART] ...... did not collect information on "real-world" risk-taking. It would be of both theoretical interest and clinical relevance to examine whether the current results "hold" when considering actual risk-taking behaviour". We want to expose individuals to (almost) real risks in order to obtain (almost) real reactions. Amit et al. (2014) found that humans demonstrate two kinds of thought processes in any given situation, verbal and visual. A person who tends to verbal thinking builds meanings using words. This generates an abstract interpretation of a concept. It is usual, in this circumstance, to exhibit controlled cognitive processes, experience high psychological distance and to make utilitarian judgements. In contrast, visual thinking is associated with the use of images to represent concepts, generating a sense of proximity and the making of deontological judgements. People who tend toward visual thinking are willing to be guided by emotional automatic processes and are strongly influenced by secondary emotions. Using the real-world risks approach, we suggest that we can evoke the 
sensation of physical risk and initiate visual thinking that would arise in a real life, risky situation.

(2) Embodied cognition: How the actions of our bodies influence our perception, communication and learning processes is a field of study known as Embodied Cognition (EC). EC can be defined by stating that cognition is solidly based on corporal interactions with the physical environment (Wilson, 2002; Gallagher, 2005). Going into more detail, systems for sensing, acting and thinking are intrinsically interdependent and human cognition is made up of complex, specific representations combining all three systems (Soler et al., 2017). During recent years, instructional methods based on bodily interactions have been developed to create meaningful connections between physical activity and different knowledge domains, mainly in the STEM (Science, Technology, Engineering and Maths) area, strongly linked to the new Mixed Reality media (Lindgren and Johnson-Glenberg, 2013). To a certain extent, embodied learning could represent an important foundation on which to build a whole set of interactive, immersive learning environments. This concept is supported by previous research (Kontra et al., 2012) that argues that taking a meaningful action enhances learning in comparison to passively perceiving that action. This idea has been strongly supported for decades by classical learning theorists such as Piaget and Cook (1952) and Vygotsky (1978). We propose to take advantage of the ideas underlying embodied learning theory and use high level cognitive experiences, involving sensing, acting and thinking, to measure and change attitudes in a deeper, more effective way.

(3) Stealth assessment: "When embedded assessments are seamlessly woven into the fabric of the learning environment so that they are virtually invisible or unnoticed by the learner, this is stealth assessment" (Shute and Spector, 2008, unpublished, p.2). More specifically, this method offers the possibility of assessing different behaviours related to concrete capabilities, providing indirect evaluations in real time (Mislevy et al., 2003) and reducing test anxiety, while maintaining validity and reliability (Shute et al., 2008). Stealth assessment fits into the framework of evidence-centered design (ECD), which considers three conceptual models that must be present in stimuli design: the competency model, which aims to define the skills that the researcher wishes to assess; the evidence model, that aims to define specific behaviours and their relationships with particular skills and capabilities; and the task model, which is designed to develop specific scenarios and tasks to prompt skills-related behaviours (Shute, 2011). Thus, stealth assessment allows the setting of tasks and creation of situations that can elicit particular behaviours connected with the skills and capabilities to be evaluated.

(4) Physiological real-time measurement: Several physiological measures have recently been proposed as implicit measures of human behaviour (Kivikangas et 
al., 2011). Skin conductance level has been successfully used as a measure of implicit processes such as stress, affective arousal and cognitive processing (Sequeira et al., 2009). Heart variability (HV) has been used for the implicit measurement of complex phenomena, for example cognitive load (Durantin et al., 2014). Eye tracking (ET) is a very interesting measure of subconscious brain processes, showing correlations with information processing in risky decisions (Glöckner and Herbold, 2011) and problem solving (Knoblich et al., 2001). Recent studies, using Functional Near-Infrared Spectroscopy (fNIRS), into decision making under pressure (Tsujii and Watanabe, 2010) and decision making processes in approach-avoidance theories (Ernst et al., 2013), are highly relevant for RT measures.

\section{Virtual Reality and Risk Taking Assessment}

Virtual Reality is a 3D synthetic environment able to simulate real experiences in which subjects can interact as if they were in the real world (Alcañiz et al., 2003). VR provides greater immersion, fidelity and higher level of active user involvement than traditional methods of assessment and training (Hedberg and Alexander, 1994). In our view, VR constitutes a suitable tool for behavioural measurement, since it complies with the requirements (see Table 4) of the four specific aspects discussed in the previous section: (1) the real-world risks approach, (2) embodied learning, (3) stealth assessment and (4) physiological real-time measurement.

Table 4. VR features and benefits of risk taking measurement

\begin{tabular}{|c|c|c|}
\hline Domain & VR features & Benefits of measurement \\
\hline Real-world risks & $\begin{array}{l}\text { Evokes the sensation of } \\
\text { physical risk }\end{array}$ & $\begin{array}{l}\text { Neural mechanisms similar to } \\
\text { real life }\end{array}$ \\
\hline $\begin{array}{l}\text { Embodied } \\
\text { interactions }\end{array}$ & $\begin{array}{l}\text { Actions raised in the first } \\
\text { person }\end{array}$ & More emotional decisions \\
\hline Stealth assessment & $\begin{array}{l}\text { Indirect evaluation in real } \\
\text { time }\end{array}$ & $\begin{array}{l}\text { Reduction of test anxiety } \\
\text { More validity and reliability }\end{array}$ \\
\hline $\begin{array}{l}\text { Physiological real- } \\
\text { time measurement }\end{array}$ & $\begin{array}{l}\text { Physiological measurement } \\
\text { during performance }\end{array}$ & $\begin{array}{l}\text { Involuntary, uncontaminated } \\
\text { by participant answering bias }\end{array}$ \\
\hline
\end{tabular}

(1) According to Slater (2009), the result of immersion through technology is the psychological state of "being there," where the subject essentially forgets that (s)he is in a virtual reality setting. This produces a sense of presence and a "plausibility illusion" which evoke the perception that what is happening in the VR is actual and allows subjects to interact and behave as they might in real life. VR is being used increasingly for natural phenomena and social interactions simulation, since it has been demonstrated that neural mechanisms in humans when they are immersed in a virtual environment are similar to those in real life (Alcañiz et al., 2009). When we talk about 
training and learning, failure is a necessary ingredient. There is evidence that people who have faced real hazards have a more cautious attitude toward OSH (Cavalcanti and Soares, 2012). Hazards in real life can involve serious danger. This is why VR emerges as a potential medium for RT assessment and training, allowing users to operate, without risks, in a quasi-real environment (Amokrane et al., 2008). VR allows the exposure of a person to a risky situation and the activation of high fidelity cognitive processes and behaviours due to the plausibility of the immersion. (2) VR environments allow users to take part in an embodied learning experience, mainly through physical interactions (Kilteni et al., 2012). Going further with this concept (Dourish, 1999, unpublished), we consider a virtual interaction to be fully embodied when it is believable, in the sense of using our body coherently as we do in the real world. The dual-process theory of moral judgment, when it refers to moral dilemmas, makes a distinction between personal and impersonal dilemmas (Greene et al., 2001; Greene, 2009): personal dilemmas are conflicts in which the subject experiences the situation in the first person and actions are carried out physically - e.g., pushing. Conversely, impersonal dilemmas are seen from the outside, and the subjects do not take overt physical actions, but make only minor responses, such as pressing switches or levers. Based on this distinction, it has been demonstrated that when actions are based on the first person perspective and involve physical acts, the subjects tend to make more emotional decisions (Greene et al., 2001; Amit et al., 2014). (3) Stealth assessment can be also defined as a performance-based method, in which what is evaluated is latent (Rupp et al., 2010). Under this paradigm, embedding assessments in immersive virtual worlds is an innovative approach (Shute and Spector, 2008) that, in our view, is an improvement from the standpoint of ecological validity. (4) Regarding physiological real-time measurement, VR provides interactive and multimodal sensorial stimuli that provide unique advantages over other methodologies in neuroscientific investigation (Bohil et al., 2011). Thus, due to technological advances, researchers can now use accurate, affordable devices to obtain physiological measures which have been found to be more effective than self-reported measures as they (a) are not intrusive, (b) do no rely on participants' self-assessment of their emotional or cognitive experience, and (c) can detect changes in participants in real time. We have previous experience in combining VR technology with brain activity measures, and these results have shown that interactive virtual environments allow the measurement of emotional responses (MarínMorales et al., 2018).

For these reasons, customizable, domain independent VR environments, in which individuals can, to a certain extent, act freely and react naturally to different risks or hazards, open to researchers an uncharted field of information about RT attitudes and behaviours. The set of these requirements may result in an application that includes a virtual environment, with a specific narrative that face the users with risky situations. This should be designed following stealth assessment methodology, and would allow physiological and behavioural measurement to provide information about individual decision making in the field of RT. We will show an example of how this tool might 
perform: the user could be in a virtual environment that consists in a path which (s)he must cover from start to finish, within the shortest possible time. Suddenly, (s)he meets a bifurcation, where (s)he has to choose whether a safe but log way - less risk, less potential benefit -, or a dangerous but short path - higher risk, higher potential benefit . During this decision making process, we could take measures of galvanic skin response to assess emotional activation, and behavioural measures such as reaction time and the decision made by the user. As a result, we could obtain information about specific weight of emotional processes in RT, and its influence on behaviour.

Our future research aims to study to what extent a VR tool is able to measure the cognitive and affective processes that influence RT. Furthermore, we would focus on how virtual interactions and narratives weight on the decision making process.

\section{Conclusion}

RT measurement is a major challenge for companies and researchers. Investigations into behavioural measurement are at a turning point as, due to the potential of technological advances, we can generate virtual worlds to evaluate and, going further, train people in certain skills and competences. We suggest that virtual reality is the most appropriate medium for assessing attitudes to risk and risk perception, conditioning factors in the RT process, due to their immersive capabilities. We propose to undertake future investigations into real-world risks, embodied interactions, stealth assessment and physiological real-time measurement as differentiating elements in RT assessment. If we can study and measure the real, unbiased reactions of people facing risky or hazardous situations, it will be possible to create customized training programs to fit their individual characteristics. This can be expected to contribute to the improvement of OSH training programs, reducing work-related incidents and, consequently, costs for companies. 
Virtual Reality as a New Approach for Risk Taking Assessment 


\title{
Chapter 3. The Spheres \& Shield Maze Task: A Virtual Reality Serious Game for the Assessment of Risk Taking in Decision Making
}

de-Juan-Ripoll, C., Soler-Domínguez, J. L., Chicchi Giglioli, I. A., Contero, M., \& Alcañiz, M. (2020). The spheres $\&$ shield maze task: a virtual reality serious game for the assessment of risk taking in decision making. Cyberpsychology, Behaviour, and Social Networking, 23(11), 773-781.

\begin{abstract}
Risk taking (RT) is an essential component in decision-making process that depicts the propensity to make risky decisions. RT assessment has traditionally focused on selfreport questionnaires. These classical tools have shown clear distance from real-life responses. Behavioural tasks assess human behaviour with more fidelity, but still show some limitations related to transferability. A way to overcome these constraints is to take advantage from virtual reality (VR), to recreate real-simulated situations that might arise from performance-based assessments, supporting RT research. This article presents results of a pilot study in which 41 individuals explored a gamified VR environment: the Spheres \& Shield Maze Task (SSMT). By eliciting implicit behavioural measures, we found relationships between scores obtained in the SSMT and self-reported risk-related constructs, as engagement in risky behaviours and marijuana consumption. We conclude that decontextualized Virtual Reality Serious Games are appropriate to assess RT, since they could be used as a cross-disciplinary tool to assess individuals' capabilities under the stealth assessment paradigm.
\end{abstract}

\section{Introduction}

Risk taking (RT) is a component of the decision-making process in a particular situation that involves uncertainty, in which the subject rationally knows the probability of each outcome for each option (Bechara et al., 2005; Krain et al., 2006). Decision making is influenced by three main factors: decision features, situational factors, and individual differences (Einhorn, 1970; Hunt et al., 1989). Within this framework, the role of RT as a component of decision-making process makes this tendency to take risks dependent on decision features, situation factors, and individual differences as well. Several decisional and situational factors have been proposed as RT determinants. Risk and return tradeoff, "hot" versus "cold" involvement, and uncertainty seem to be the most well-accepted contextual determinants of RT (Figner and Weber, 2011). 
The Spheres \& Shield Maze Task: A Virtual Reality Serious Game for the Assessment of Risk Taking in Decision Making

Meanwhile, these three contextual elements depend largely on the individual perception and interpretation of the situation. In this context, situation awareness is a stage in the decision-making process, which can influence the final decision (Endsley, 2000). It is described as the perception of the elements that compose the environment, the interpretation of this information, and the projection of possible changes in the near future (Endsley, 1988), and has been seen as a contributory factor in accidents and incidents in different areas (Tremblay, 2017).

To the extent of our knowledge, individual differences in the RT field, specifically the role of personality traits, have received less scientific attention than the decisional and situational factors. Personality may lead to cognitive and emotional biases in risky decision making (Lauriola and Levin, 2001), affecting expected benefits, the perception of the risks, and the risk attitude when facing a situation. A biased perception of riskunderstood as the subjective evaluation of a risk-can lead to misjudgments of potentially hazardous risk sources (Rundmo, 1996), and should be corrected (Risk Research Committee, 1980).

RT process starts with a deliberation and weighing-up phase. During this stage, the subject thinks about the possible positive/negative outcomes of his/her actions before acting (Zuckerman and Kuhlman, 2000). During this process, personality traits influence the individual's approach to RT, prompting risk-seeking or risk-aversion behaviours. In particular, sensation seeking and impulsivity have been shown to be related to RT as they predetermine the individual's perspective of the reward/risk conflict (Zuckerman and Kuhlman, 2000). This pursuit of intense sensations and experiences, combined with nonreflexive behaviours, may result in daring decisions. Both impulsivity and sensation seeking have been related to RT behaviours in several domains, such as driving (Dahlen et al., 2005), risky sex (Donohew et al., 2000), substance use (Leeman et al., 2014), and marijuana consumption (Moreno et al.,2012). For example, in marijuana consumption, individuals with high impulsivity and sensation seeking have shown to be more likely to consume marijuana, since they present poor inhibitory control and susceptibility to the expected reward (Dvorak and Day, 2014; Trocki et al., 2009; Ames et al., 2002). Although these studies analyze RT behaviours in relation to conducts and habits in specific domains, they provide overall interesting results because they demonstrate that there is a general personal disposition toward RT, which can be generalized to several situations (Highhouse et al., 2017; Jackson et al., 1972). In fact, this cross-situation risk factor and its relation to sensation seeking and impulsivity are consistent with personality theories, which argue that personality traits remain fairly stable during different situations (Jackson et al., 1972). We underline the contribution of this important issue to the final goal of our work, which is to foster the creation of domain-independent RT evaluation tools.

RT assessment is a nonstandardized practice that has been addressed from varying perspectives. Self-report measurement is the method most used for evaluating RT behaviours, although, to our knowledge, no single scale can measure RT from just one 
point of view. On the one hand, some authors employ self-reported measures based on risk-related psychological constructs, such as personality (Lejuez et al., 2002; Skeel et al., 2007), impulsivity (Lejuez et al., 2002), sensation seeking (Lejuez et al., 2002; Horvath and Zuckerman, 1993), and situational awareness (Lejuez et al., 2002). On the other hand, some authors used self-reported daily habits as a measure of RT (Zuckerman and Kuhlman, 2000; Lejuez et al., 2003). In addition, diverse issues in the use of survey measures have been identified (Verhulst et al., 2019), as well as matching self-report measures with real-world actions may lead to low-validity conclusions (de-Juan-Ripoll et al., 2018).

To overcome these issues, an emerging research field is focusing on how psychocognitive states can be assessed in an ecological, nonintrusive, nonbiased way. The approach is termed "stealth assessment" (Shute, 2011); and is a process where subjects' performance data are continuously recorded during a game/ serious game and, at its end, conclusions are drawn about individual competencies based on the data. In this framework, behavioural tasks can be an alternative method to self-reports that might provide a more ecological and nonbiased response. In RT domain, the most used behavioural tasks are the Bechara Gambling Task (Bechara et al., 1994) and the Balloon Analogue Risk Task (Lejuez et al., 2002). Behavioural tasks, undertaken at the laboratory level, enable close monitoring of all the potentially influential variables affecting subjects' responses.

However, subjects are normally confronted with controlled stimuli that do not include variables present in real-life situations. This compromises the ecological validity of measurements. Previous results indicate that these tasks have weak correspondence with real-life behaviours (Manchester et al., 2004; Sbordone 2008; Bottari et al., 2009), mainly because of the absence of consequences (Verschoor et al., 2016).

In contrast, there is empirical evidence demonstrating similarities between neural mechanisms that subjects experience when immersed in a virtual reality (VR) environment and in real life (Tarr and Warren, 2002; Alcañiz et al., 2009). In support of this idea, and due to recent advances in hardware and software costs and performance, Virtual Reality Serious Games (VRSGs) have become an innovative, effective, active, engaging, and adaptive medium capable of overcoming the limitations of most traditional methodologies (Chittaro and Ranon, 2009; Lovreglio et al., 2017). There is a sound research basis supporting the proposition that VRs immersive capabilities make VRSG a better choice than 2D and nonstereoscopic 3D displays (Rizzo et al., 2006; Chicchi Giglioli et al., 2019; Alcañiz et al., 2003; Huang et al., 2010; Dalgarno and Lee, 2010; Mora, 2013; Fowler, 2015). Starting from these premises, we propose VR as a powerful, reliable, ecological tool to study, under laboratory conditions, the cognitive and affective aspects of human behaviour related to RT processes.

We present the Spheres \& Shield Maze Task (SSMT) as a VR behavioural task for RT measurement. The aim of this study is to understand the relationship between the SSMT 
The Spheres \& Shield Maze Task: A Virtual Reality Serious Game for the Assessment of Risk Taking in Decision Making

outcomes and sensation seeking and impulsivity (risk-related factors), work situational awareness (WSA), engagement in risky behaviours and marijuana consumption. The study hypotheses are as follows:

Sensation seekers and impulsive individuals will show differences with nonsensation seekers and nonimpulsive participants in the SSMT (H1).

Participants with a high level of work situation awareness (WSA) will present differences in the SSMT with those with low WSA (H2).

Participants that feel drawn to engage in risky behaviours will show higher levels of impulsivity and sensation seeking (H3) and different results in the SSMT (H4) than those who feel less drawn to engage in risky behaviours.

Participants that reported marijuana consumption during the previous 12 months will show higher levels of impulsivity and sensation seeking (H5) and different results in the SSMT (H6) than those who did not report marijuana consumption.

\section{Methods}

\section{Participants}

Forty-one individuals participated in the study (29 men and 12 women, mean age $=24.22$, SD $=7.80$ ). They are students at the degree in the Design and Development of Videogames and Interactive Experiences. Before their participation, they received written information on the study and gave their written consent for their involvement. The study obtained the ethical approval of the Ethical Committee of the authors' institution (Approval Number: P1_06_06_18).

\section{Questionnaires}

- Spanish version of the 40-item Sensation Seeking Scale-V (SSS-V; Pérez and Torrubia, 1986; Zuckerman et al., 1964).

- Spanish version of the 30-item Barratt Impulsiveness Scale (BIS-11; Barratt, 1985; Oquendo et al., 2001; Patton et al., 1995).

- WSA scale (Sneddon et al., 2013).

- As a measure of RT propensity, participants responded "yes" or "no" to engaging in the following during the previous year: (1) smoking, (2) drug use, (3) alcohol consumption, (4) risky sex, (5) stealing, and (6) not using a seat belt while driving. These measures have been used previously to assess RT and as an index of engagement in risky behaviours in daily life (Lejuez et al., 2003). We produced a total index by summing the reported risk behaviours ( $\min .0$; max. $6)$.

- As a measure of marijuana consumption, participants responded "yes" or "no" to the question of whether they had taken marijuana during the previous 12 months (even once). 


\section{The SSMT}

The SSMT is an interactive virtual environment that mimics an out-of-context maze, through which participants have to pass without (virtually) hurting themselves, from start to finish before the allocated time expires. The subjects have 3 minutes to negotiate the maze (primary mission), and they are instructed to accumulate as much "karma" as possible (secondary mission). There are spheres distributed throughout the maze, which earn participants "karma" if they collect them. Furthermore, participants can lose "karma" if they are attacked by a risk. These risks are also distributed throughout the maze and are of three types: fires, precipices, and slippery puddles. Some spheres are close to hazards, and others are located in no-risk zones.

Participants have the option of activating a shield, which protects them from the risks. When the shield is active, the user's speed is reduced and (s)he cannot collect any spheres. The shield is a finite resource that subjects need to optimize. While passing through the maze, the participants have information about the remaining battery life of the shield and how much of their allocated time remains. The navigation metaphor is natural walking combined with indirect walking, in which pushing down on the controller's integrated touchpad moves the user's avatar in the direction (s)he is facing at $2 \mathrm{~m} / \mathrm{s}$ (speeds $>3 \mathrm{~m} / \mathrm{s}$ can increase cybersickness symptoms) (Figs. 2 and 3) (So et al., 2001).
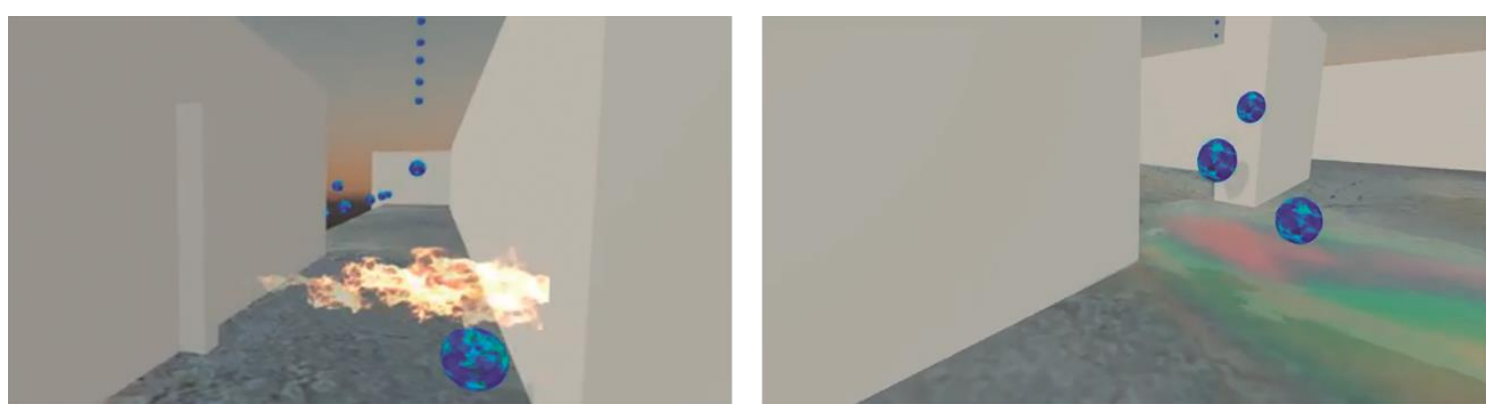

Figure 2. Screenshots of the SSMT with fire and precipice (left) and slippery puddle (right). SSMT, Spheres E Shield Maze Task 
The Spheres \& Shield Maze Task: A Virtual Reality Serious Game for the Assessment of Risk Taking in Decision Making
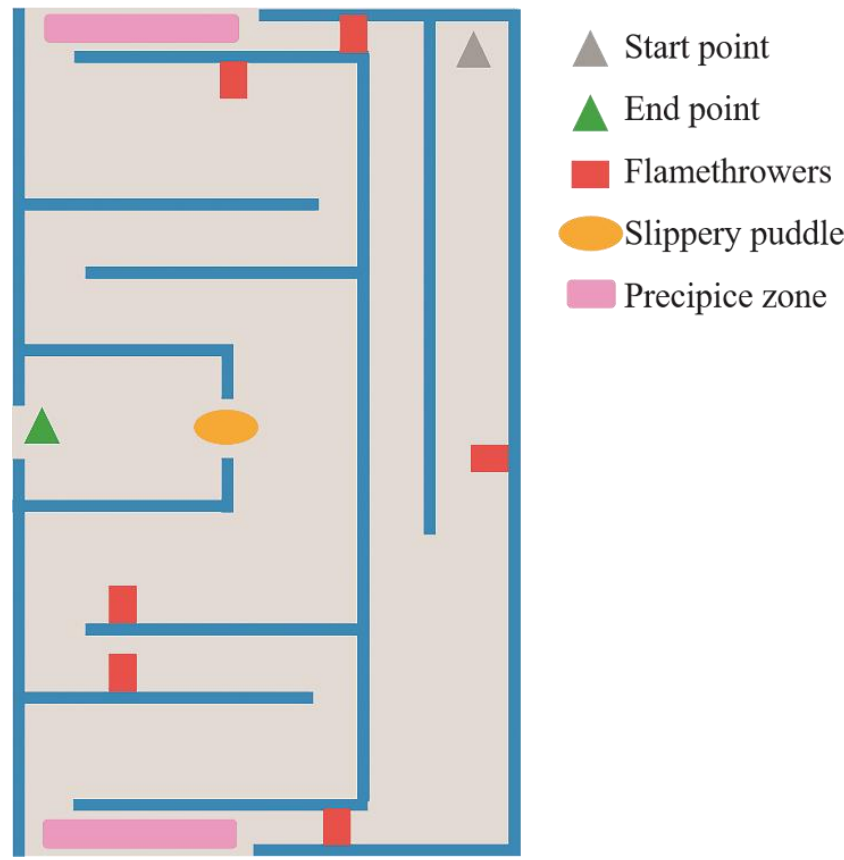

Figure 3. Top view of the maze and risk distribution

Before undertaking the SSMT, the participants underwent a practice session. As seen in Figure 4, the subjects had to travel to three spotlights on the floor to practice the locomotion technique. They were also asked to collect some spheres and to activate the shield while they traveled through the training area. To assess if the time dedicated to the practice session was appropriate, the participants passed through the maze twice after they received the SSMT instructions.

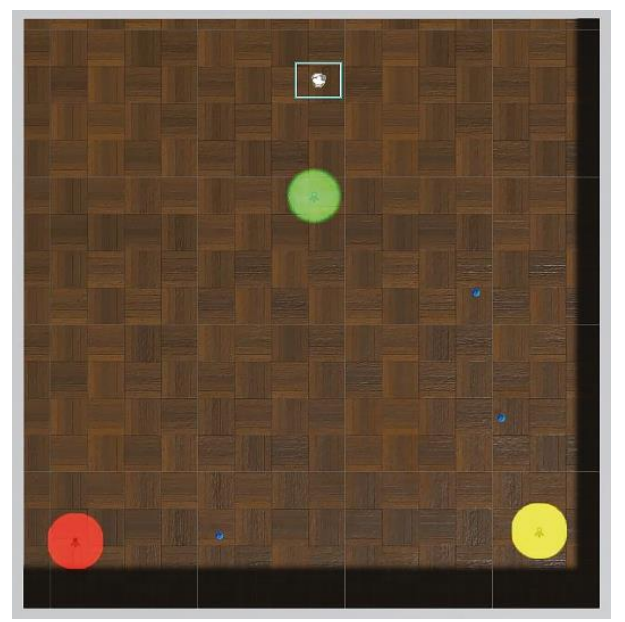

Figure 4. Screenshot of the practice SSMT session

Participants performed the SSMT using the HTC Vive head mounted display, with $2,160 \times 1,200$ pixels $\left(1,080 \times 1,200\right.$ per eye), a field of view of $110^{\circ}$, working at $90 \mathrm{~Hz}$ refresh rate. We analyzed the metrics of solving time, distance covered, "karma" collected, and shield use. The solving time refers to the time elapsed since the subject began the maze until (s)he reached the exit and was calculated in seconds. The distance covered is the total distance traveled by the subject from the beginning of the maze until 
(s)he reached the exit, measured in meters. The "karma" is a score derived from the difference between the number of spheres collected and the seconds elapsed while the subject was attacked by a risk. Finally, the shield use is a score calculated by multiplying the seconds with the shield active and the intensity with which the shield was used. The intensity is a value between 0 and 100 that reflects the intensity with which the trigger of the controller was pressed.

\section{Data analysis}

Statistical analyses were carried out using SPSS version 22.0 (Statistical Package for the Social Sciences for Windows, Chicago, IL) for PCs. First, a multivariate outlier detection test was performed. The Mahalanobis distances between the subjects were calculated, and thereafter a chi-square $(x 2)$ test was performed. The subjects who belonged to the most extreme one percent of the data distribution were defined as outliers. In total, three outliers were found. We assessed the normality of the variables and the internal consistency of the self-report scales. T-test analyses were carried out to identify if there were significant differences between the first and second trial of the SSMT. The Pearson correlations between each pair of numerical variables were computed to examine the linear dependency between the measures of the risk-related constructs, the WSA and the SSMT variables.

We carried out Spearman's correlations to verify if there were significant associations between risk behaviours, risk-related constructs, and the SSMT variables. A Poisson regression was performed to predict the number of risky behaviours that subjects would engage in based on the risk-related constructs and the SSMT scores. To explore the importance of each variable, a first Poisson regression was performed accounting for the risk-related and the SSMT variables. The subscale with the highest $P$ value was removed from the initial inputs, which resulted in a new set of inputs for the following regression. The computation of the $\mathrm{P}$ value of the inputs was based on the null hypothesis that all the linear coefficients of the regression were zero. This process continued iteratively until the model included a set of inputs with every P value $<0.05$.

Regarding marijuana consumption, we carried out t-test analyses to verify if there were significant differences between groups (consumers and nonconsumers) in risk-related constructs, WSA and SSMT outcomes, and finally we performed a logistic regression to analyze the effects of self-report variables and SSMT metrics on the subjects' marijuana use. In the same way as in the Poisson regression mentioned above, an iterative process of removing the variable with the highest $\mathrm{P}$ value was performed until the model included a set of inputs with every $\mathrm{P}$ value $<0.05$.

\section{Results}

The final dataset included 38 subjects ( 26 men and 12 women; mean age $=23.87$, $\mathrm{SD}=7.46$ ). The assumption of normality was confirmed in all variables (KolmogorovSmirnov $\mathrm{p}>0.05$ ), except in the SSMT Time variable and in the risky behaviours score 
The Spheres \& Shield Maze Task: A Virtual Reality Serious Game for the Assessment of Risk Taking in Decision Making

$(p<0.05)$, and the internal consistency of the self-report scales was confirmed (Cronbach's aBIS $=0.616$, aSSS-V $=0.877$, aWSA $=0.713$, bootstrap; 95\%). Table 5 presents the descriptive statistics for the self-report and SSMT variables.

Table 5. Descriptive Statistics of Self-Report and Spheres \& Shield Maze Task Variables

\begin{tabular}{lccc}
\multicolumn{1}{c}{ Variable } & Mean & SD & Range \\
\hline 1. BIS_CO & 14,89 & 3,94 & $6-22$ \\
2. BIS_MO & 16,53 & 6,09 & $5-29$ \\
3. BIS_NP & 16,11 & 5,43 & $7-27$ \\
4. BIS & 46,16 & 10,24 & $28-69$ \\
5. SSS_AS & 5,95 & 2,88 & $0-10$ \\
6. SSS_ES & 6,95 & 1,79 & $4-10$ \\
7. SSS_DI & 3,71 & 2,56 & $0-9$ \\
8. SSS_BS & 3,42 & 2,13 & $0-9$ \\
9. SSS-V & 20,03 & 7,38 & $8-35$ \\
10. WSA_CON & 21,71 & 5,41 & $9-32$ \\
11. WSA_ANT & 7,89 & 3,09 & $2-14$ \\
12. WSA_ATT & 7,97 & 1,81 & $3-11$ \\
13. WSA_DIS & 6,47 & 2,15 & $1-10$ \\
14. WSA & 44,05 & 7,75 & $26-58$ \\
15. SSMT_T_FT & 166,34 & 23,19 & $96.89-180$ \\
16. SSMT_D_FT & 258,86 & 42,46 & $181.74-346.36$ \\
17. SSMT_K_FT & 15,42 & 6,25 & $3-32$ \\
18. SSMT_S_FT & 1358,04 & 165,50 & $982.26-1621.42$ \\
19. SSMT_T_ST & 155,81 & 29,18 & $81.97-180$ \\
20. SSMT_D_ST & 249,00 & 42,15 & $148.66-344.07$ \\
21. SSMT_K_ST & 14,29 & 8,82 & $-8-35$ \\
22. SSMT_S_ST & 1356,55 & 120,59 & $987.40-1558.94$ \\
23. RB & 1,37 & 1,50 & $0-5$ \\
\hline
\end{tabular}

1. Barratt Impulsiveness Scale (BIS), cognitive impulsiveness; 2. BIS, motor impulsiveness; 3. BIS, nonplanning impulsiveness; 4. BIS; 5. Sensation Seeking Scale-V (SSS-V), adventure seeking; 6 . SSS-V, experience seeking; 7 . SSS-V, disinhibition; 8. SSSV, Boredom susceptibility; 9. SSS-V; 10. Work Situation Awareness (WSA), concentration; 11. WSA, anticipation; 12. WSA, attention; 13. WSA, distraction; 14. WSA; 15. Solving Time in SSMT-First Trial (SSMT_T_FT); 16. Distance in SSMT-First Trial (SSMT_D_FT); 17. Karma in SSMT-First Trial (SSMT_K_FT); 18. Shield in SSMT-First Trial (SSMT_S_FT); 19. Solving Time in SSMT-Second Trial (SSMT_T_ST); 20. Distance in SSMT-Second Trial (SSMT_D_ST); 21. Karma in SSMT-Second Trial (SSMT_K_ST); 22. Shield in SSMT-Second Trial (SSMT_S_ST); 23. Risk behaviours score. SD, standard deviation; SSMT, Spheres \& Shield Maze Task; WSA, work situational awareness.

T-test analyses were carried out to identify if there were significant differences between the first and second trial performance. Although we did not find significant differences $(p>0.05)$, we observed an adaptation period that distorted the data in first trial. Although participants seemed to be prepared to enter the maze after the practice session, they showed disorientation during the first trial. Furthermore, some subjects expressed doubts about the interaction and mechanics of the task, which remained unclear after the practice session. In addition, some of the subjects verbalized after the experiment 
that in the second trial they felt more secure and had not doubts about interactions and mechanics of the task. For this reason, we assumed that there was a lack of practice and expertise in the first trial, which will be discussed in later sections; and the following analyses were performed with the results of the second trial.

Table 6 shows the correlations between the self-report measures and the variables SSMT_Distance, SSMT_Karma, SSMT_Shield, and SSMT_Time.

Table 6. Pearson's correlations between Self-Report and Spheres \& Shield Maze Task Variables

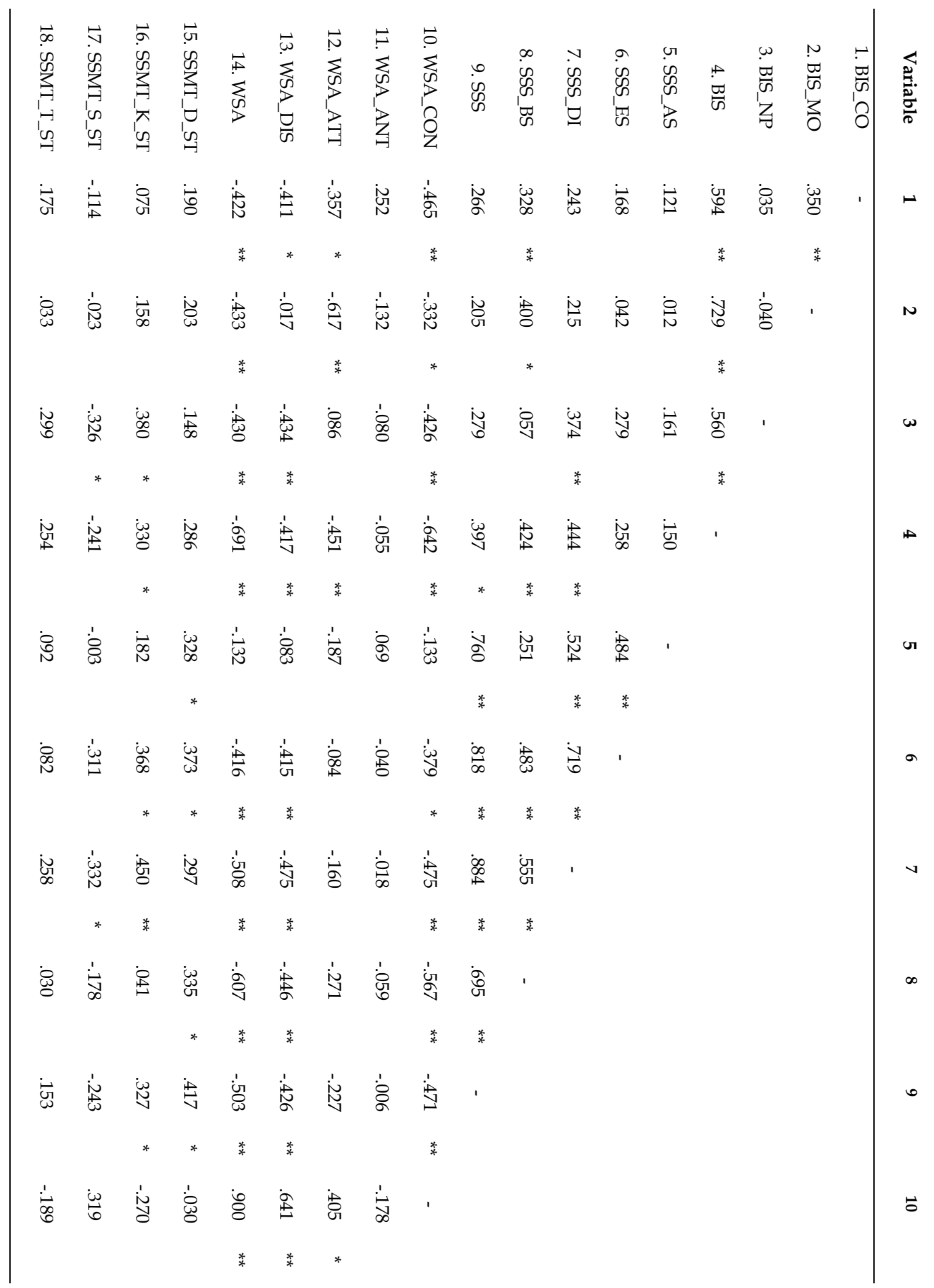


The Spheres \& Shield Maze Task: A Virtual Reality Serious Game for the Assessment of Risk Taking in Decision Making

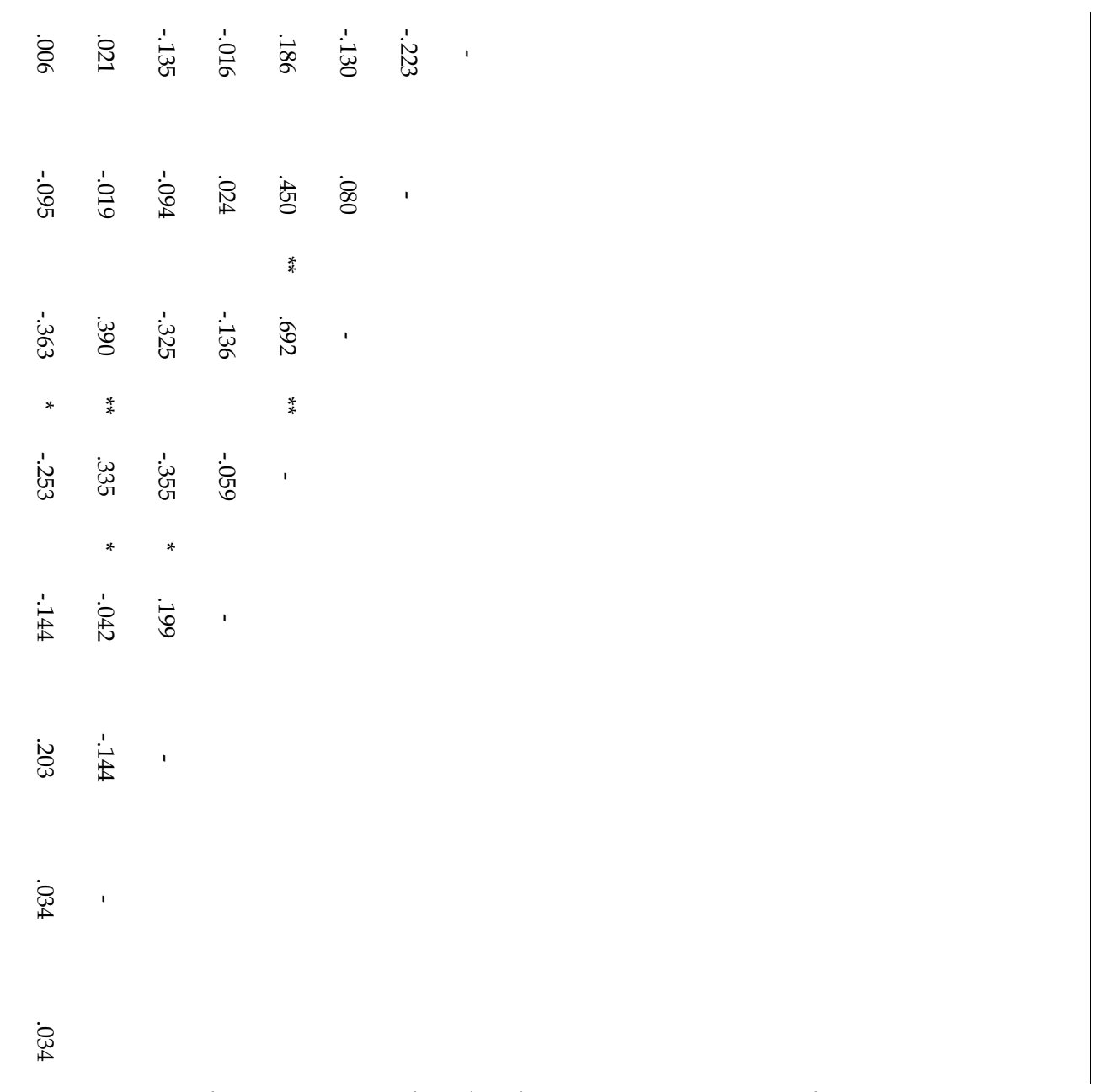

$\Xi$

$\vec{N}$

$\vec{\omega}$

$\not$

जั

Һ

$\checkmark$

$\vec{\infty}$

1. Barratt Impulsiveness Scale (BIS), Cognitive impulsiveness; 2. BIS, Motor impulsiveness; 3. BIS, Non-planning impulsivity; 4. BIS; 5. Sensation Seeking Scale-V (SSS-V), Adventure seeking; 6. SSS-V, Experience seeking; 7. SSS-V, Disinhibition; 8. SSSV, Boredom susceptibility; 9. SSS-V; 10. Work Situation Awareness (WSA), Concentration; 11. WSA, Anticipation; 12. WSA, Attention; 13. WSA, Distraction; 14. WSA; 15. Distance in SSMT-Second Trial (SSMT_D_ST); 16. Karma in SSMT-Second Trial (SSMT_K_ST); 17. Shield in SSMT-Second Trial (SSMT_S_ST); 18. Time in SSMT-Second Trial (SSMT_T_ST).* $p<.05 ;{ }^{* *} \mathrm{p}<.01$.

We carried out Spearman's correlations to verify if there were significant associations between risk behaviours, risk-related constructs, and SSMT outcomes (Table 7).

Table 7. Spearman's Correlations Between Risk Behaviours, Risk-Related Constructs, and Spheres E Shield Maze Task Variables

\begin{tabular}{lcc} 
& Risk \\
\hline BIS_CO & .103 & \\
BIS_MO & .146 & \\
BIS_NP & -.119 & \\
BIS & .054 & \\
SSS_AS & -.009 & \\
SSS_ES & .485 & $*$ \\
SSS_DI & .355 & $*$ \\
SSS_BS & .176 &
\end{tabular}




\begin{tabular}{lcr} 
SSS & .277 & \\
SSMT_D_ST & .143 & \\
SSMT_K_ST & .041 & \\
SSMT_S_ST & -.501 & $* *$ \\
SSMT_T_ST & .022 & \\
\hline
\end{tabular}

BIS_CO: Barratt Impulsiveness Scale (BIS), Cognitive impulsiveness; BIS_MO: BIS, Motor impulsiveness; BIS_NP: BIS, Non-planning impulsiveness; SSS_AS: Sensation Seeking Scale-V (SSS-V), Adventure seeking; SSS_ES: SSS-V, Experience seeking; SSS_DI SSS-V, Disinhibition; SSS_BS: SSS-V, Boredom susceptibility; SSMT_D_ST: Distance in SSMT-Second Trial; SSMT_K_ST: Karma in SSMT-Second Trial; SSMT_S_ST: Shield in SSMT-Second Trial; SSMT_T_ST: Time in SSMT-Second Trial. ${ }^{*} \mathrm{p}<.05 ;{ }^{* *} \mathrm{p}<.01$.

A Poisson regression was performed to predict the number of risky behaviours that subjects would engage in based on the risk-related constructs and the SSMT scores. According to the results, for each point scored in experience seeking, 1.340 (95\% CI 1.102-1.630) times riskier behaviours will be engaged in by the participants $(P=0.003)$. For each point of the shield use scored in the SSMT, 0.998 (95\% CI 0.996-1) times riskier behaviours will be engaged in by the participants $(p=0.038)$.

As an additional analysis, we compared the results of participants who reported marijuana consumption $(\mathrm{N}=15)$ and those who did not $(\mathrm{N}=23)$. We carried out $\mathrm{t}$-test analyses to verify if there were significant differences between groups in risk-related constructs, WSA and SSMT outcomes (Fig. 5).

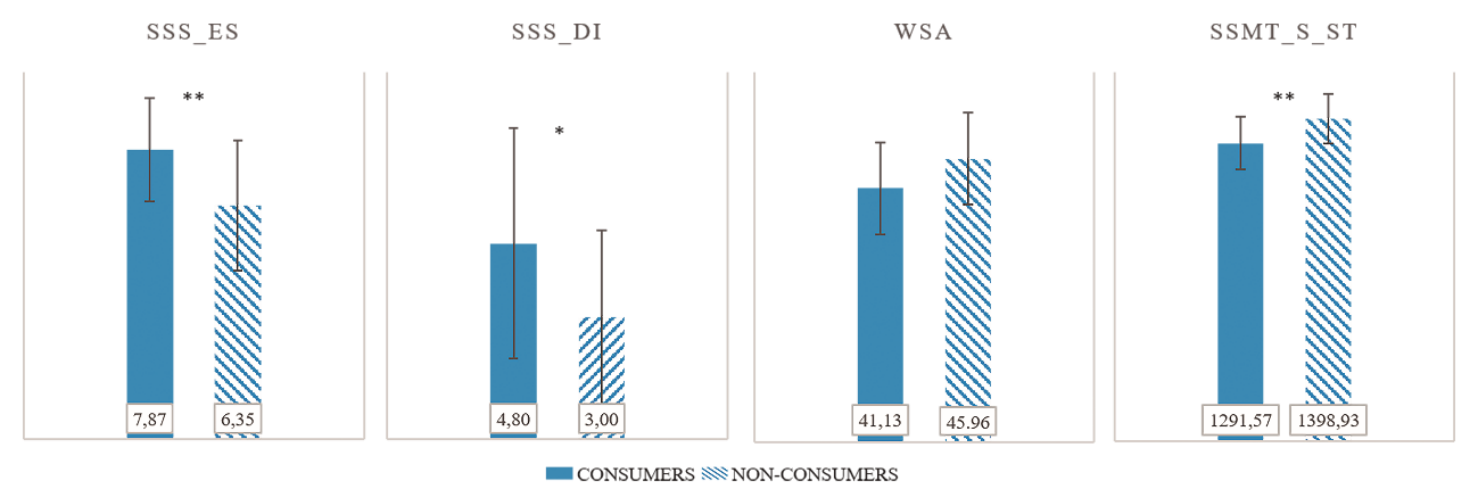

Figure 5. T-test results of self-report and SSMT variables between marijuana consumers and nonconsumers. Bars represent the average and lines represent the standard deviation. ${ }^{*} p<0.05,{ }^{* *} p<0.01$

We performed a logistic regression to analyze the effects of self-report variables and SSMT metrics on the subjects' marijuana use. The logistic regression model was statistically significant ( $\chi^{2} 12.424, \mathrm{P}<0.01$ ) and explained 37.8 percent (Nagelkerke R2) of the variance in marijuana use. The model correctly classified 76.3 percent of cases. The model shows that marijuana consumers have higher scores in experience seeking and reduced use of the shield in the SSMT (see Table 8 for further details on the regression analysis).

Table 8. Summary of the Logistic Regression Analysis Predicting Marijuana Consumption

Variable

Coefficient s.e. p- $\quad 95 \%$ C.I. 
The Spheres \& Shield Maze Task: A Virtual Reality Serious Game for the Assessment of Risk Taking in Decision Making

\begin{tabular}{lllll} 
Sensation seeking: & .490 & .252 & .052 & $.995-2.676$ \\
SSMT Shield & -.008 & .004 & .040 & $.984-1.000$ \\
\hline
\end{tabular}

Nagelkerke R $=37.8 \% ; p<0.01$

s.e.: standard error; C.I.: confidence interval

\section{Discussion}

The main goals of this article were to evaluate a VRSG designed to assess RT and to prove that virtual environments can provide effective metrics under the stealth assessment paradigm.

We found significant associations between the SSMT results and the risk-related constructs measured-impulsivity and sensation seeking. Sensation seekers covered more distance in the maze and were not satisfied only with finding the exit. Collecting spheres located next to hazards involves a risk of coming to harm. In this case, impulsive individuals would be less reflective about the potential risk and decided to collect spheres although they are next to hazards. Participants with high nonplanning impulsivity and disinhibition preferred not to use the shield in most cases, even though this carried danger. Nonplanning impulsivity involves lack of anticipation (Barratt, 1985), which is consistent with limited shield use. Nonimpulsive participants may take the shield into account and use it more than impulsive participants. Disinhibition refers to the tendency toward hedonistic preferences (Zuckerman, 2008) and has been related to imprudent behaviours (Orlebeke 1990). Disinhibited participants might see the shield as unnecessary overprotection, so they did not use it as much as nondisinhibited subjects. These results support hypothesis 1 , since sensation seeking and impulsivity were expected to be related to the SSMT results.

Regarding hypothesis 2, the WSA showed negative significant correlations with "karma" and positive significant correlations with shield use. WSA also showed negative significant correlations with impulsivity and sensation seeking. This could represent a thoughtless individual who gets bored easily, is looking always for new experiences, and has less risk awareness. These results suggest that participants with high WSA anticipated and planned for what was going to occur, inhibited impulses, and did not underestimate the risks in the SSMT, accepting hypothesis 2.

The associations among impulsivity, sensation seeking, and engaging in risky behaviours were calculated. The results showed that there is a positive relationship between the experience seeking and disinhibition dimensions and engaging in risky behaviours. These results are consistent with other investigations that found significant associations between engaging in risky behaviours and sensation seeking (Lejuez et al., 2003). Furthermore, the dimensions of experience seeking and disinhibition are shown to be significant predictors of RT (Popham et al., 2011), and have been related to risk habits (Roberti, 2004). The experience seeking and disinhibition dimensions represent less socially acceptable forms of sensation seeking (Zuckerman, 1978). In particular 
social circles, this nonacceptance is diluted, since individuals with similar levels of sensation seeking tend to join together (Roberti, 2004). These results partially support hypothesis 3 , which pointed out that both impulsivity and sensation seeking are related to engaging in risky behaviours.

Regarding hypothesis 4, participants with higher scores for engaging in risky behaviours used the shield less than those with low scores for engaging in risky behaviours. The results of the regression analysis showed that experience seeking and shield use are significant predictors of engaging in risky behaviours. Consequently, hypothesis 4 is accepted.

Regarding hypotheses 5 and 6, differences between marijuana consumers and nonconsumers in risk-related constructs and in the SSMT were calculated. The results showed that marijuana users have higher levels of experience seeking and disinhibition than nonusers, partially supporting hypothesis 5, which pointed out that both impulsivity and sensation seeking are related to marijuana consumption. The relation between marijuana consumption and sensation seeking has previously been established (Palmgreen et al., 2001). Other studies have found that sensation seekers show high levels of intention to use marijuana in the future (Hoyle et al., 2002). Nonconsumers also showed higher WSA. This outcome is consistent with the above results, since risk underestimation seems to be common among marijuana consumers and those who score low in the WSA. Regarding SSMT metrics, consumers protected themselves with the shield less than nonconsumers. The logistic regression analyses showed that experience seeking and shield use are both predictors of marijuana consumption. This is in line with hypothesis 6, which also posited that distance covered and "karma" would be related to marijuana consumption. As previously mentioned, shield use seems to be related to planned and prudent behaviours. These results are consistent with the results of BT that aim to measure RT. The degree of inflation of the balloons in the Balloon Analogue Risk Task was correlated with drug use, and this metric was a predictor of substance use and risky sexual behaviours (Lejuez et al., 2002). Poor performance in the Bechara Gambling Task was related to participants with substance use disorders (Barry and Petry, 2008). The Bechara Gambling Task is shown to be an appropriate measure for substance use disorders only for men, since the results for this task varied significantly between males and females (Businelle et al., 2008).

\section{Limitations}

We acknowledge that this study has some methodological limitations. First, the sample size is not large, and the participants were recruited in a university environment, so it is not a sample that faces occupational risks in daily life. For future investigations, we will recruit a larger sample of participants who face risks in the workplace. Second, the practice session and adaptation period needed for the SSMT were unknowns, so the participants performed the SSMT twice to guarantee they fully understood the task. We 
The Spheres \& Shield Maze Task: A Virtual Reality Serious Game for the Assessment of Risk Taking in Decision Making

will take this in account in future research, and will allow the participants a longer practice session. In addition, we will include mechanisms to make sure participants have fully understood mechanics and interactions of the game, to avoid potential external biases. Third, we assessed only the behavioural metrics of time, "karma," distance, and shield use, ignoring real-time behavioural and psychophysiological measures, such as trajectories, eye movements, and galvanic skin response. Last, the risks in the SSMT had no consequences in the virtual world, besides a reduced "karma" score. For future investigations, we intend to improve the SSMT by enriching its appearance and giving the risk consequences to make them more realistic. In addition, we will include eye tracking and galvanic skin response measures to supplement and better interpret the SSMT scores.

\section{Conclusions}

RT is essential in the decision-making process, and is a field of interest both for psychologists and for safety authorities. In this article, we present the SSMT as a first step in the development of a new VR behavioural tool to measure implicit processes involved in RT. The results of this study suggest that decontextualized VRSGs are appropriate to assess RT, since they could be used as a crossdisciplinary tool to assess individuals' capabilities. 


\title{
Chapter 4. Why do we take risks? Perception of the situation and risk proneness predict domain- specific risk taking
}

de-Juan-Ripoll, C., Chicchi Giglioli, I. A., Llanes Jurado, J., Marín-Morales, J., \& Alcañiz, M. (2021). Why do we take risks? Perception of the situation and risk proneness predict domain-specific risk taking. Frontiers in Psychology, 12, 655.

\begin{abstract}
Risk taking (RT) is a component of the decision-making process in situations that involve uncertainty and in which the probability of each outcome - rewards and/or negative consequences - is already known. The influence of cognitive and emotional processes in decision making may affect how risky situations are addressed. First, inaccurate assessments of situations may constitute a perceptual bias in decision making, which might influence RT. Second, there seems to be consensus that a proneness bias exists, known as risk proneness, which can be defined as the propensity to be attracted to potentially risky activities. In the present study, we take the approach that risk perception and risk proneness affect RT behaviours. The study hypothesises that locus of control, emotion regulation, and executive control act as perceptual biases in RT, and that personality, sensation seeking, and impulsivity traits act as proneness biases in RT. The results suggest that locus of control, emotion regulation and executive control influence certain domains of RT, while personality influences in all domains except the recreational, and sensation seeking and impulsivity are involved in all domains of RT. The results of the study constitute a foundation upon which to build in this research area and can contribute to the increased understanding of human behaviour in risky situations.
\end{abstract}

\section{Introduction}

Risk taking (RT) is a component of the decision-making process in situations that involve uncertainty and in which the probability of all outcomes - rewards and/or negative consequences (Brand et al., 2007) - is already known (Bechara et al., 2005; Krain et al., 2006). Risk takers tend to make decisions with both high potential benefits and high potential adverse outcomes, rather than choosing more cautious alternatives (Slovic, 1987; Mellers et al., 1997). The decision-making process is influenced by three main elements: decision features, situational factors, and individual differences (Einhorn, 1970; Hunt et al., 1989). Decision features are the characteristics of the decision itself, such as the ordering of the choice options (Appelt et al., 2011) and situation framing 
Why do we take risks? Perception of the situation and risk proneness predict domainspecific risk taking

(Levin et al., 2002). Situational factors refer to the context of the decision, for example, time pressure (Dror et al., 1999). Individual differences are the third main factor in the decision-making process. Appelt et al. (2011) argued that, although the influence of individual differences in decision making has been widely studied, there is no consensus as to how to interpret these relations.

Some authors have identified the perception of benefits, the perception of risks, and risk attitude - "how much risk they [the subjects] are willing to accept in exchange for a specific return" (Figner and Weber, 2011; p. 212) - as the individual factors that may drive RT. Within this framework, the influence of the cognitive and emotional processes in decision making may affect the way in which a risky situation is perceived; they have also been identified as key elements of individual differences that may affect RT. First, an inaccurate assessment of a situation may constitute a perceptual bias in decision making, which might influence RT. In situations in which "hot" affective processes are prominent (e.g., condom use; Figner and Weber, 2011), emotion regulation skills - the control of emotions (Gross, 2002) - and internal locus of control - the perception that events are under one's own control (Rotter, 1966) - have been highlighted as influential factors in the "cooling process" (Crisp and Barber, 1995; Miu and Crişan, 2011). In addition, executive control is the ability to control thoughts to inhibit or adapt behaviours according to the situation (Diamond, 2013). It involves top-down mental processes that require the individual to make an effort, meaning that the process is not automatic. Individuals with low executive control have been shown to more poorly evaluate situations and search for less information before making decisions, which can lead to risky behaviours (Magar et al., 2008). Finally, there seems to be consensus across different domains that risk proneness influences RT. This trait has been defined as the propensity to be attracted to potentially risky activities (Raffaelli and Crockett, 2003), and could be considered a cross-situational trait in RT as it has been related to temperamental aspects, such as sensation seeking and impulsivity (Zuckerman and Kuhlman, 2000). Indeed, while some individuals are characterised by strong directional risk proneness, others are situation-sensitive (Weber and Milliman, 1997; Nicholson et al., 2002; Weber et al., 2002). In the latter cases, the decision-making process may be highly dependent on decision features and situational factors. In light of these results, we consider it necessary to study these findings in an aggregated way, and provide clear conclusions regarding the influence of perceptual and cognitive biases in RT. In the following sections, the psychological dimensions that influence RT both in perceptual processes and risk proneness are discussed and the aim of our study is presented.

\section{Individual Differences in the Perception of Benefits and Risks}

Locus of Control

Rotter (1966) found that locus of control indicates the degree to which an individual perceives events to be under his/her control (internal control) or under the control of outside forces, such as fate or other people (external control). Marsh and Richards (1986) identified five factors for the Rotter's locus of control scale: general luck, which is related 
to attributing one's life course to luck or chance; political control, which refers to low expectations of influencing political institutions and world affairs; personal initiative, which attributes to the influence of external elements in their work and personal situation rather than to the effort of oneself; interpersonal control, which refers to the little control of one's influence over other people; and academic situation, which is related to the attribution to the influence of external elements in their academic results. The relation between locus of control and RT has been widely examined, although it seems that previous studies have reached opposite conclusions, based on the nature of the situations examined. Individuals with an internal locus of control have been shown to take more risks in some areas, such as the civil rights struggle (Gore and Rotter, 1963), the military (Higbee, 1972) and in entrepreneurship (Ahmed, 1985). Conversely, other studies have found that individuals with an internal locus of control take less risks in the domains of forestry and construction (Salminen and Klen, 1994), sexual practices (Terry et al., 1993) and piloting (You et al., 2013). Crisp and Barber (1995) suggested that individuals with an internal locus of control more accurately assess situations. Thus, locus of control may influence how situations are perceived, but not necessarily RT. Instead, it might be expected that internals, who perceive greater risk, would make safer decisions. In contrast, externals may perceive situations as if they are under other people's control.

\section{Emotion Regulation}

Emotion regulation is the control of emotions (Gross, 2002). It can influence three components of RT, which involve different deliberative-versus-automatic strategies: interrupting a risk behaviour, thinking before acting, and choosing between two alternatives (Steinberg, 2004). Emotion regulation can be applied through two strategies, cognitive reappraisal and expressive suppression. Cognitive reappraisal is an antecedent-focused strategy that involves changing the meaning of a situation by reformulating the way it is understood to minimize or modify its emotional impact (Gross and John, 2003). It allows individuals to psychologically distance themselves from situations (Mischel and Ayduk, 2004). In contrast, the response-focused strategy of expressive suppression is the inhibition of the emotional response associated with a particular emotion (Gross and John, 2003). Generally, suppression is understood to be a maladaptive strategy, which involves an active effort sustained over time, while reappraisal is considered to be an adaptive strategy that modifies the emotion at an early stage (Gross, 2002; Evers et al., 2010). The relation between the habitual use of either emotion-regulation strategy and RT does not appear to be entirely established. Some studies have suggested that individuals who use cognitive reappraisal tend to take greater risks, as this strategy mitigates the influence of negative emotions, which leads them to be less sensitive to both the probability and the magnitude of potential losses (Heilman et al., 2010; Panno et al., 2013). On the other hand, some authors have suggested that reappraisal is related to positive affect and lower RT, in domains such as smoking, risky drinking (Magar et al., 2008; Fucito et al., 2010) and emotional eating (Evers et al., 2010). These results suggest that the relation between emotion regulation 
Why do we take risks? Perception of the situation and risk proneness predict domainspecific risk taking

strategies and RT relies heavily upon the decision-making context. Hence, we may find positive relations between reappraisal strategy and RT in the contexts in which the positive outcomes are perceived as more salient than the negative consequences, or in which RT is not necessarily considered to be a maladaptive behaviour (Duell and Steinberg, 2019; Pellegrino, 2019), such as in entrepreneurship or social situations. In contrast, emotional suppression strategies may be positively related to RT in contexts in which the negative outcomes are perceived as more salient than the positive outcomes, or in which RT is clearly a maladaptive behaviour, such as health and ethical RT (Duell and Steinberg, 2019; Pellegrino, 2019).

\section{Executive Control}

Executive control has an important role in decision making (Eslinger and Damasio, 1985; Manes et al., 2002; Del Missier et al., 2010) as it operates in perception, conflict resolution, and retention processes (Pessoa, 2009). The relation between executive control and RT has been widely examined in adolescents and young adults, as these groups tend to show less cognitive control, particularly when facing situations with desirable or immediately accessible rewards (Falk and Rickardsson, unpublished). These studies suggested that executive control, as a fundamental mediator in the inhibition of pleasurable stimuli, and in the development of adaptive behaviour patterns, might contribute to RT in some domains when it is weak, such as drug addiction (Kalivas and Volkow, 2005), prompting riskier behaviours in daily life (Pharo et al., 2011). Executive control is comprised of inhibition, working memory and cognitive flexibility (Diamond, 2013). Cognitive flexibility is the ability to adjust perspectives to adapt to the changing demands of a situation. It is related to the other two executive functions, since it requires inhibition to deactivate the previous perspective and working memory to activate a new perspective (Diamond, 2013). Deficits in cognitive flexibility have been shown to influence RT, leading to violent and offending behaviours (Vilà-Balló et al., 2015) as well as eating disorders (Perpiñá et al., 2017).

\section{Individual Differences in Risk Proneness}

Personality: The Big Five-Factor Model

Personality has been found to have a strong influence on RT behaviours (e.g., Zuckerman and Kuhlman, 2000; De Vries et al., 2009). Individual personality trait differences influence risk proneness, as they involve motivational forces that promote risky decisions, insulation against concerns about negative consequences, and they act as cognitive barriers (Nicholson et al., 2002). Among the numerous personality models developed in psychology research, the Big Five-factor model of personality - composed of neuroticism, extraversion, openness, agreeableness and conscientiousness factors (McCrae and Costa, 1997) - seems to be the most generally recognized in the study of the relation between personality and risk behaviour. Neuroticism has been related to negative affect and sensitivity to punishment (Elliot and Thrash, 2010). High levels of neuroticism may lead to risk aversion in most domains, as a way of avoiding guilt or anxiety regarding negative outcomes. In contrast, there seems to be an inverse relation 
between neuroticism and RT in the health domain (Nicholson et al., 2005). In these cases, some studies identified a tendency to take risks to alleviate anxiety and other emotions (Vollrath and Torgersen, 2002). Nicholson et al. (2005) suggested that health-related RT is most strongly influenced by environmental factors, and least under the control of individual psychological disposition. Conversely, extraversion, as a generalized need for stimulation, is manifested in positive affect and sensitivity to reward (Eysenck, 1973), prompting RT behaviours (Lauriola and Levin, 2001). Openness to experience relates to cognitive risk seeking, acceptance of experimentation, and tolerance of uncertainty, change, and innovation (McCrae and Costa, 1997). Agreeableness, which is characterized by trust, straightforwardness, and compliance, has been related to risk aversion (Gullone and Moore, 2000; Hoyle et al., 2000). Conscientiousness, which is a need for compliance under conditions of conformity and control, has been related to risk avoidance (Nicholson et al., 2005; Schwebel et al., 2006).

Personality: Sensation Seeking

Sensation seeking has been defined as "the seeking of varied, novel, complex and intense sensations and experiences, and the willingness to take physical, social, legal, and financial risks for the sake of such experience" (Zuckerman, 1994; p. 27). Individuals with varying levels of sensation seeking may exhibit differences in arousal and attention, which leads to differential information processing (Zuckerman, 1979; Zuckerman and Como, 1983). Several studies have shown a positive relation between sensation seeking and RT in different domains, such as substance abuse, risky sexual behaviour, reckless driving, and vandalism (e.g., Donohew et al., 2000; Wagner, 2001). Zuckerman (1994) identified four dimensions of the sensation-seeking trait: thrill and adventure seeking, experience seeking, disinhibition, and boredom susceptibility. The thrill and adventure seeking dimension reflects a desire to engage in physical activities and is positively related to risky behaviours in driving and sports (Zuckerman, 1994; Wishart et al., 2017). The experience-seeking subtrait has been shown to be a predictor of the openness personality trait, due to its relation to arousal seeking through the mind and senses (Zuckerman, 1984; Roberti, 2004). High experience-seeking individuals present lower sensitivity to aversive stimulation (Netter et al., 1996), and tend to display risky substance use behaviours (Pedersen et al., 1989). Disinhibition is a significant predictor of RT in several domains, including rule-breaking behaviours and violations of societal norms (Donohew et al., 2000; Roberti, 2004; De Vries et al., 2009). Boredom susceptibility, which is intolerance for routine and repetitive activities (Zuckerman, 2006), tends to be reflected in RT behaviours in domains such as sports (Guszkowska and Bołdak, 2010).

Personality: Impulsivity

Impulsivity is defined as the "predisposition toward rapid, unplanned reactions to internal or external stimuli without regard to the negative consequences of these reactions to the impulsive individual or to others" (Moeller et al., 2001; p. 1784). Whiteside and Lynam (2001) argued that impulsivity is comprised of a set of five impulse-related traits: negative urgency, lack of premeditation, lack of perseverance, 
Why do we take risks? Perception of the situation and risk proneness predict domainspecific risk taking

sensation seeking, and positive urgency. According to Whiteside and Lynam (2001) and Whiteside et al. (2005), negative and positive urgency traits relate to the tendency to exhibit impulsive behaviours when facing negative/positive situations. Lack of premeditation relates to thoughtless behaviours and to the tendency to favour alternatives with short-term rewards over options that might lead to more valuable but delayed rewards. Lack of perseverance reflects an absence of focus on a tedious or difficult activity. Sensation seeking is an attraction toward exciting, new, and potentially dangerous experiences.

Impulsivity has emerged as one of the strongest predictors of RT in different domains. Moreno et al. (2012) found that recreational cannabis consumption was associated with high levels of impulsivity and sensation seeking, and with inhibitory control deficits. Donohew et al. (2000) showed that impulsivity and sensation seeking were strongly related to some sexual RT indicators: intention to have sex, number of lifetime sexual partners, being pregnant or having caused a pregnancy, having unwanted sex when drunk, having unwanted sex under pressure, and using alcohol or having a partner who used alcohol before sex. Furthermore, this relation has been demonstrated in other contexts, such as gambling (Blanco et al., 2009) and alcohol use (Coskunpinar et al., 2013).

\section{The Current Study}

The aim of the present study is to examine the relation between RT biases and risk behaviours, in order to identify the components of the cross-situational factors that influence RT and the variables that operate only in specific domains. This study aims to fill an existing gap in the literature, since there is no study, to our knowledge, that analyses the influence of psychological biases on RT from both, domain-dependent and cross-domain RT perspectives. The study hypotheses are the following (see Figure 6):

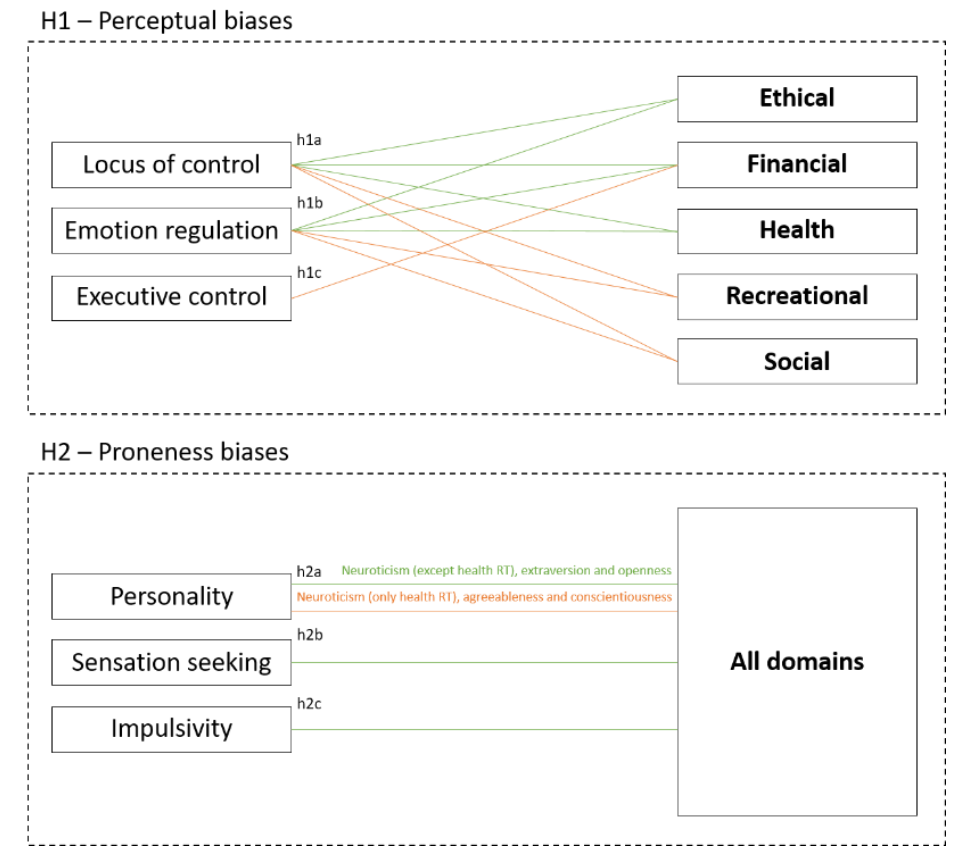

Figure 6. Study hypotheses. Green lines represent positive relation and orange lines represent negative relation. 
Hypothesis 1. Perceptual biases in RT: locus of control (h1a), emotion regulation (h1b), and executive control (h1c) are variables in the perception of benefits and risks in the decision-making process that each influence RT in those specific domains, requiring an accurate assessment of risks and benefits. On one hand, an internal locus of control and the use of the cognitive reappraisal strategy could lead to safe behaviours in the ethical and health domains. Additionally, financial decisions tend to involve complex situations, which require effortful processing - executive functions (Diamond, 2013) - to perceive and interpret each option. In this domain, high executive control would also be related to risk avoidance. On the other hand, recreational and social RT involve more salient potential positive outcomes, an internal locus of control, and the use of the cognitive reappraisal strategy which could lead to risky behaviours.

Hypothesis 2. Proneness biases in RT: personality (h2a), sensation seeking (h2b), and impulsivity (h2c) will influence RT consistently in all domains, constituting a trend toward risk proneness or risk avoidance, regardless of the type of risk. Regarding personality, neuroticism is expected to show a positive relation with RT in all domains, except in the case of health, in which it is expected to show a negative relation. Extraversion and openness are expected to appear as facilitators of RT, while agreeableness and conscientiousness may be related to safe behaviours. Sensation seeking and impulsivity are expected to show a positive relation with RT in all domains.

\section{Materials and Methods}

\section{Participants}

A total of 98 subjects balanced in terms of gender ( 50 men and 48 women) and age ( $35 \%$ under $30,35 \%$ among $30-45,30 \%$ above 45 ; mean age $=37.08$, SD $=10.91$ ) were recruited by a sampling company to participate in the experiment. The sample company contacted each participant and made an appointment for them to come to the laboratory. Before beginning the experiment, the participants gave their informed consent for their involvement. The responses were anonymised and randomised to ensure the privacy of the information. The study obtained prior ethical approval of the Ethical Committee of the Polytechnic University of Valencia.

\section{Measures}

The risk-related constructs were assessed by means of a battery of self-reported measures and neuropsychological tests, which included the following:

Locus of control: Spanish version of the 23-item Rotter's I-E scale (Rotter, 1966; Tous, 1984; Ferrando et al., 2011). This includes subscales for general luck, political control, personal initiative, interpersonal control, academic situation, and a total external locus of control score. The internal consistency of the scale in the present study was 0.613 .

Emotion regulation: Spanish version of the 10-item Emotion Regulation Questionnaire (ERQ), which measures suppression and reappraisal strategies (Gross and John, 2003; 
Why do we take risks? Perception of the situation and risk proneness predict domainspecific risk taking

Cabello et al., 2013). The Cronbach's alpha coefficients previously reported for a Spanish sample were 0.75 for suppression and 0.79 for reappraisal (Cabello et al., 2013). The internal consistency of the scales in the present study was 0.77 for suppression and 0.73 for reappraisal.

Executive control: Two neuropsychological tasks were performed: Wisconsin Card Sorting Test (WCST; Grant and Berg, 1993), a measure of cognitive flexibility; and the Trail Making Task (TMT), a paper-and-pencil-based measure of attention and set switching (Reitan, 1958). To measure cognitive flexibility, we calculated the perseverative errors in the WCST. To assess attention and set switching, we measured the resolution times of parts $\mathrm{A}$ and $\mathrm{B}$, respectively.

Personality: Spanish version of the NEO five-factor inventory (NEO-FFI). This comprises 60 items and includes the following factors: neuroticism, extraversion, openness, conscientiousness, and agreeableness (Costa and McCrae, 1989; Cordero et al., 1999). The reliability coefficients' Cronbach's alpha values ranged from 0.75 to 0.83 in a Spanish sample (Cordero et al., 1999). The internal consistency of the scales in the present study was: neuroticism $\alpha=0.77$, extraversion $\alpha=0.85$, openness $\alpha=0.79$, agreeableness $\alpha=$ 0.75 , and conscientiousness $\alpha=0.84$.

Sensation seeking: Spanish version of the 40-item Sensation Seeking Scale-V (SSS-V) (Zuckerman et al., 1964; Pérez and Torrubia, 1986). This includes subscales for thrill and adventure seeking, experience seeking, disinhibition and boredom susceptibility, and a total sensation seeking score. The reliability coefficients' Cronbach's alphas ranged between 0.67 and 0.81 in a Spanish sample (Pérez and Torrubia, 1986). The internal consistency of the scale in the present study was: thrill and adventure seeking $\alpha=0.81$, experience seeking $\alpha=0.54$, disinhibition $\alpha=0.63$; boredom susceptibility $\alpha=0.53$, total sensation seeking $\alpha=0.78$.

Impulsivity: Short Spanish version of the UPPS-P impulsive behaviour scale (Whiteside and Lynam, 2001; Cándido et al., 2012). Composed of 20 items, this measures five impulsivity traits: negative urgency, lack of premeditation, lack of perseverance, sensation seeking, and positive urgency. The Cronbach's alpha coefficients ranged from 0.66 to 0.81 in a Spanish sample (Cándido et al., 2012). The internal consistency of the scales in the present study was: negative urgency $\alpha=0.72$, lack of premeditation $a=$ 0.77 , lack of perseverance $\alpha=0.78$, sensation seeking $\alpha=0.79$, and positive urgency $\alpha=$ 0.60 .

Risk taking: Spanish version of the Domain-Specific Risk-Taking (DOSPERT-30) scale (Blais and Weber, 2006; Lozano et al., 2017). This is a measure of the tendency to engage in real-life risk-taking behaviours in different domains, and includes the ethical, financial, health, recreation, and social subscales. Sample items include "Revealing a friend's secret to someone else" (Ethical), "Betting a day's income at a high-stake poker game" (Financial), "Riding a motorcycle without a helmet" (Health/Safety), "Moving to a city far away from your extended family" (Social), and "Going whitewater rafting at 
high water in the spring" (Recreational). Higher scores indicate greater RT in the domain of the subscale. The Cronbach's alpha coefficients ranged from.64 to.85 in a Spanish sample (Lozano et al., 2017). The internal consistency of the scales in the present study was: Ethical $\alpha=0.65$, Financial $\alpha=0.81$, Health $\alpha=0.68$, Recreation $\alpha=0.82$, and Social $\alpha=0.67$.

\section{Procedure}

The participants undertook the self-report questionnaires and completed the neuropsychological tasks on a personal computer. The process, which took place in an experimental room and was supervised by a research assistant, lasted approximately 45 minutes.

\section{Data Analysis}

First, a multivariate outlier detection test was performed using all the features' Mahalanobis distance between subjects, and thereafter a Chi-square test was performed on the Mahalanobis distance distribution. The subjects belonging to the far ends of the distribution, which was fixed for a p-value $<0.01$, were defined as outliers; four outliers were found. Pearson correlations between each pair of numerical variables were computed to evaluate linear dependency. A prior power correlation analysis was performed, resulting in, for a population of 94 subjects, a Pearson coefficient of 0.285 achieving a power above $80 \%$. Therefore, we only considered as significant the correlations that had a p-value lower than 0.05 and a Pearson coefficient higher than 0.285 in absolute value. Finally, multilinear regressions were computed to observe which input variables related to locus of control, emotion regulation, executive control, personality, sensation seeking, and impulsivity, explained the RT output variables. To explore the statistical importance of each variable in the multilinear regression model, a feature selection algorithm was implemented. In particular, a backward feature elimination (Guyon et al., 2008) was implemented based on the statistical analysis of the coefficient of each feature. This procedure of iterative feature selection would not miss any hidden relation between input variables; at the same time, it reduces the number of features used and increases the interpretability of the model. All input variables were normalised and an initial multilinear regression, including all inputs, was computed. The feature with the highest $\mathrm{p}$-value was removed from the initial inputs, which resulted in a new set of inputs for the following regression. The computation of the $p$-value of the inputs was based on the null hypothesis that all the linear coefficients of the regression were zero. Due to the fact that a multilinear regression model considered different hypotheses simultaneously a Bonferroni correction was applied to the initial confidence interval chosen. The algorithm continued iteratively until the model included a set of inputs with every p-value under 0.05 . Therefore, the coefficients of the features used in the multilinear regression are statistically different from zero, so all features contribute in the model. Once the backward elimination found a model in which all the variables are significant, it was preselected. In addition, three different checks were performed for the regression: the mean of the residuals had to be equal or close to zero, as well as the 
Why do we take risks? Perception of the situation and risk proneness predict domainspecific risk taking

linear correlation between the input variable, and the residuals and the distribution of the residuals had to follow a normal distribution. If the multilinear regression model overcame these checks, it was considered as the final model; if it did not, the backward elimination continued. We obtained the p-value, the error, and the adjusted coefficient of determination of the regression model. A model was obtained for each RT subscale.

\section{Results}

\section{Descriptive Analysis}

The final dataset included 94 subjects between 20 and 51 years ( 49 males, 45 females; mean age $=35.77, \mathrm{SD}=10.65)$. Table 9 shows the statistical values of the subscales. This table includes a column indicating if the distribution of the subscales is normal or not according to a t-test fixing the p-value sensitivity to 0.05 . Not normal distributions would achieve lower values than this threshold. According to the normality of each subscale, the mean and the standard deviation for normal distributions is shown or, in the case of not normal subscales, the median and the IQR is reported.

Table 9. Descriptive analysis of all variables, organized by subscales.

\begin{tabular}{|c|c|c|c|c|c|c|}
\hline & Scale & Subscale & Mean/Median & Std./IQR & Distribution & Range \\
\hline$\infty$ & Locus of & General luck & 3.00 & 2.00 & Not normal & [0-6] \\
\hline.$\stackrel{\mathscr{H}}{\pi}$ & control & Political control & 3.00 & 2.00 & Not normal & {$[0-5]$} \\
\hline 르 & & Personal initiative & 3.00 & 2.00 & Not normal & {$[0-5]$} \\
\hline$\frac{2}{2}$ & & Interpersonal control & 3.00 & 1.00 & Not normal & {$[0-4]$} \\
\hline$\underbrace{\infty}_{0}$ & & Academic situations & 3.00 & 1.00 & Not normal & {$[0-3]$} \\
\hline 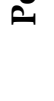 & & $\begin{array}{l}\text { Locus of control } \\
\text { (overall score) }\end{array}$ & 3.00 & 4.00 & Not normal & [2-21] \\
\hline & Emotion & Cognitive reappraisal & 30.00 & 7 & Not normal & [12-40] \\
\hline & regulation & $\begin{array}{l}\text { Emotional } \\
\text { suppression }\end{array}$ & 13.74 & 5.17 & Normal & {$[4-26]$} \\
\hline & $\begin{array}{l}\text { Executive } \\
\text { control }\end{array}$ & $\begin{array}{l}\text { TMT Time Part A } \\
(\mathrm{ms})\end{array}$ & 42147 & 16062.5 & Not normal & $\begin{array}{l}\text { [22113- } \\
113500]\end{array}$ \\
\hline & & $\begin{array}{l}\text { TMT Time Part B } \\
(\mathrm{ms})\end{array}$ & 45668 & 16008.75 & Not normal & $\begin{array}{l}{[23675-} \\
80787]\end{array}$ \\
\hline & & $\begin{array}{l}\text { WCST Perseverative } \\
\text { Errors }\end{array}$ & 35.00 & 33.39 & Not normal & {$[0-91]$} \\
\hline \& & Personality & Neuroticism & 20.63 & 6.99 & Normal & [2-37] \\
\hline 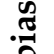 & & Extraversion & 32.95 & 7.31 & Normal & [11-48] \\
\hline$\infty$ & & Openness & 31.97 & 6.55 & Normal & [14-48] \\
\hline 己ี & & Agreeableness & 31.41 & 6.08 & Normal & [14-43] \\
\hline ¿ & & Conscientiousness & 32.69 & 7.25 & Normal & {$[15-48]$} \\
\hline$A$ & $\begin{array}{l}\text { Sensation } \\
\text { seeking }\end{array}$ & $\begin{array}{l}\text { Thrill and adventure } \\
\text { seeking }\end{array}$ & 4.00 & 2.00 & Not normal & {$[0-9]$} \\
\hline & & Experience seeking & 7.00 & 2.00 & Not normal & {$[3-10]$} \\
\hline & & Disinhibition & 5.00 & 3.00 & Not normal & [0-10] \\
\hline
\end{tabular}




\begin{tabular}{|c|c|c|c|c|c|}
\hline & $\begin{array}{l}\text { Boredom } \\
\text { susceptibility }\end{array}$ & 8.00 & 5.00 & Not normal & {$[0-10]$} \\
\hline & $\begin{array}{l}\text { Sensation seeking } \\
\text { (overall score) }\end{array}$ & 23.09 & 5.71 & Normal & [9-36] \\
\hline \multirow[t]{5}{*}{ Impulsivity } & Negative urgency & 9.23 & 2.46 & Normal & {$[4-16]$} \\
\hline & $\begin{array}{l}\text { Lack of } \\
\text { premeditation }\end{array}$ & 7.50 & 3.00 & Not normal & {$[4-12]$} \\
\hline & Lack of perseverance & 7.00 & 3.75 & Not normal & {$[4-14]$} \\
\hline & Sensation seeking & 10.26 & 2.51 & Normal & {$[4-16]$} \\
\hline & Positive urgency & 10.00 & 2.00 & Not normal & {$[5-14]$} \\
\hline \multirow{5}{*}{ 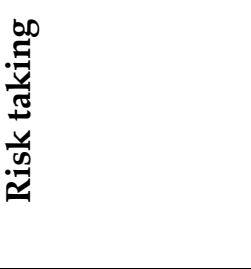 } & Ethical & 14.00 & 8.00 & Not normal & [6-28] \\
\hline & Financial & 17.00 & 9.75 & Not normal & {$[6-42]$} \\
\hline & Health & 18.00 & 8.00 & Not normal & {$[7-38]$} \\
\hline & Recreational & 26.50 & 15.50 & Not normal & {$[7-42]$} \\
\hline & Social & 31.43 & 5.46 & Normal & [18-42] \\
\hline
\end{tabular}

\section{Relation Between RT and the Risk-Related Constructs}

Figure 7 shows the Pearson Correlation coefficient between the RT scale and the variables considered as risk-related constructs.

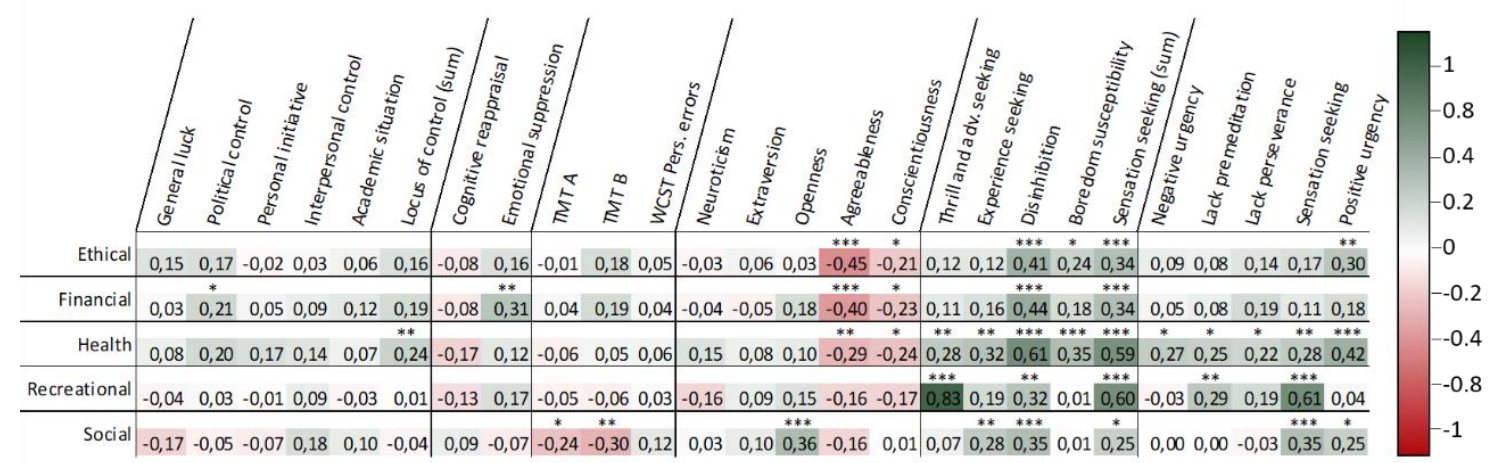

Figure 7. Correlation matrix obtained by Pearson coefficients between every pair of variables and the range of statistical significance by correlation. $* p<0.05, * * p<0.01$, and $* * * p<0.001$. Pearson coefficient of 0.285 achieves a power above $80 \%$.

After the statistical test, multilinear regressions were calculated to identify the most influential variables of the RT subscales. Table 10 lists the coefficient of each variable, including the weight and type of linear dependence (positive or negative).

Table 10. Statistical table showing the multilinear regressions for all output variables.

\begin{tabular}{|c|c|c|c|c|c|c|}
\hline $\begin{array}{l}\text { Predicted } \\
\text { Variable }\end{array}$ & Bias & $\begin{array}{c}\text { Input } \\
\text { variable } \\
\text { Risk taking }\end{array}$ & $\begin{array}{c}\text { Input } \\
\text { variable } \\
\text { Risk } \\
\text { avoidance }\end{array}$ & Coefficient & $\begin{array}{l}\text { Model } \\
\text { error }\end{array}$ & $\begin{array}{l}\text { Adjusted } \\
\text { R square }\end{array}$ \\
\hline \multirow{2}{*}{ 苞 } & Perceptual & - & $\begin{array}{l}\text { Set switching } \\
\text { (-TMT B) }\end{array}$ & $-.0001^{* *}$ & \multirow[t]{2}{*}{4.63} & \multirow[t]{2}{*}{$.32^{* * *}$} \\
\hline & Proneness & - & Agreeableness & $-.3598^{* * *}$ & & \\
\hline
\end{tabular}


Why do we take risks? Perception of the situation and risk proneness predict domainspecific risk taking

\begin{tabular}{|c|c|c|c|c|c|c|}
\hline & & Disinhibition & - & $.7050^{* *}$ & & \\
\hline \multirow{3}{*}{ 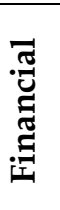 } & Perceptual & & $\begin{array}{l}\text { Set switching } \\
\text { (-TMT B) }\end{array}$ & $-.0001^{* *}$ & \multirow{3}{*}{6.07} & \multirow{3}{*}{$.31^{* * *}$} \\
\hline & Pronenose & - & Agreeableness & $-.3903^{* * *}$ & & \\
\hline & itonentess & Disinhibition & - & $1.0920^{* * *}$ & & \\
\hline \multirow{3}{*}{ 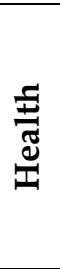 } & \multirow{3}{*}{ Proneness } & Disinhibition & - & $1.5342^{\star * *}$ & \multirow{3}{*}{4.77} & \multirow{3}{*}{$.45^{* * *}$} \\
\hline & & $\begin{array}{c}\text { Lack of } \\
\text { perseverance }\end{array}$ & - & $.6193^{* *}$ & & \\
\hline & & $\begin{array}{l}\text { Positive } \\
\text { urgency }\end{array}$ & - & $.6669^{*}$ & & \\
\hline \multirow{2}{*}{ 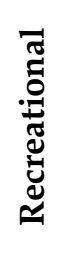 } & \multirow[b]{2}{*}{ Proneness } & $\begin{array}{c}\text { Thrill and } \\
\text { adv. seeking }\end{array}$ & - & $2.2083^{* * *}$ & \multirow[b]{2}{*}{4.75} & \multirow[b]{2}{*}{$.72^{* * *}$} \\
\hline & & $\begin{array}{c}\text { Sensation } \\
\text { seeking } \\
\text { (UPPS-P) }\end{array}$ & - & $.8324^{* * *}$ & & \\
\hline \multirow{2}{*}{ 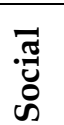 } & \multirow[b]{2}{*}{ Proneness } & Openness & - & $.2608^{\star * *}$ & \multirow[b]{2}{*}{4.92} & \multirow[b]{2}{*}{$.19^{* \star *}$} \\
\hline & & Disinhibition & - & $.6631^{* *}$ & & \\
\hline
\end{tabular}

The first model, composed of set switching, agreeableness, and disinhibition, predicted $32 \%$ of the variance $(\mathrm{p}<0.001$, model error 4.63$)$ of ethical RT. According to these results, ethical RT is predicted by both perceptual and proneness biases. The results showed that disinhibition promotes ethical RT, while set switching and agreeableness lead to ethical risk avoidance.

The second model, also composed of set switching, agreeableness, and disinhibition, predicted $31 \%$ of the variance $(p<0.001$, model error 6.07 ) of financial RT. Financial RT is predicted by both perceptual and proneness biases. The results showed that disinhibition promotes financial RT, while set switching and agreeableness lead to financial risk avoidance.

The third model, composed of disinhibition, lack of perseverance, and positive urgency, predicted $45 \%$ of the variance ( $p<0.001$, model error 4.77 ) of health RT. Health RT is predicted only by proneness biases. The results showed that disinhibition, lack of perseverance, and positive urgency promote health RT.

The fourth model, composed of thrill and adventure seeking and sensation seeking, predicted $72 \%$ of the variance $(p<0.001$, model error 4.75 ) of recreational RT. Recreational RT is predicted only by proneness bias. The results showed that thrill and adventure seeking and sensation seeking (impulsivity subtrait) promote recreational RT.

The fifth model, composed of openness and disinhibition, predicted $19 \%$ of the variance ( $p<0.001$, model error 4.92) of social RT. Social RT is predicted only by proneness biases. The results showed that openness and disinhibition promote social RT. 


\section{Discussion}

Risk taking is a component of the decision-making process in situations involving uncertainty and in which the probability of each outcome - rewards and/or negative consequences (Brand et al., 2007) - is previously known (Bechara et al., 2005; Krain et al., 2006). Risk takers tend to make decisions with both high potential benefits and high potential adverse outcomes, which can depend on perceptual and proneness biases. The results of this study provide a clearer view of the factors that affect RT, considering that some of them have a cross-domain influence, while the influence of others varies depending on the area or type of decision. This study aimed to fill this gap in the literature and expand this line of research in order to better understand decision-making processes in the face of risk. This study hypothesised that locus of control, emotion regulation, and executive control factors act as perceptual biases in RT, and that personality, sensation seeking, and impulsivity traits act as proneness biases in RT. The results are discussed below regarding the relation between RT in the various domains and the variables considered, as well as study limitations.

\section{Relation Between RT in the Different Domains and the Variables Considered}

Perceptual Biases

First, we found moderate positive, significant correlations between emotional suppression and financial RT. Second, we found weak/moderate positive, significant correlations between set switching and social RT.

Regarding regression results, attentional control and set switching appeared as significant predictors of ethical and financial RT. Kim-Spoon et al. (2015) found that attentional control is a regulator of negative affect, which reduces the effects of anger and increases the effects of fear. These results suggest that, when subjects face situations in which they feel negative affect, high attentional control may lead to safe behaviours, for fear of the potential negative outcomes. Situations such as "Not returning a wallet you found that contains $\$ 200$ - an item for ethical RT - or “Betting a day's income on the outcome of a sporting event" - an item for financial RT - might generate the fear of damaging someone, being discovered, or even losing a large amount of money.

Hypothesis 1 posited that individuals with an external locus of control (h1a) and low emotional (h1b) and executive abilities (h1c), would show risky behaviours in those specific domains which require an accurate assessment of risks and benefits. First, we did not find significant relations between locus of control and RT, rejecting hypothesis 1 a.

Second, the results showed that a relation exists between emotional suppression and financial RT, and not with the cognitive reappraisal strategy, which partially supports hypothesis $1 \mathrm{~b}$. The emotional suppression strategy is response-focused, modifying the behavioural aspect of the emotional response, but not the experience of negative emotions (Gross and John, 2003). Individuals tending to emotional suppression put things into perspective less frequently (Pellegrino, 2019) and require a cognitive effort to 
Why do we take risks? Perception of the situation and risk proneness predict domainspecific risk taking

manage negative emotions (Gross and John, 2003). The use of the emotional suppression strategy might affect financial decision making, since it requires effortful processing to make decisions. The results for executive control suggested that attentional control and set switching lead to social RT and risk avoidance in the ethical and financial domains, partially supporting hypothesis 1c. RT can be classified as negative - illegal or dangerous - or positive - socially acceptable and constructive (Duell and Steinberg, 2019). The latter can be considered risky due to the variability and uncertainty of its potential consequences (Figueredo and Jacobs, 2010). Therefore, executive control seems to constitute a perceptual bias that drives positive RT, and to risk avoidance in domains in which taking risks involves potential negative outcomes. In the framework of social RT, Lahat et al. (2012) found that set switching ability in childhood allows knowing and considering both the positive and negative consequences of a situation, moderating the relationship between temperamental aspects and antisocial risk behaviours. In this domain, we could understand that executive control allows a more accurate analysis of the situation, perhaps avoiding social desirability biases that can modify the responses to situations presented as social RT on the DOSPERT scale, such as "Admitting that your tastes are different from those of a friend" or "Speaking your mind about an unpopular issue in a meeting at work." Regarding the ethical and financial domains, executive control appears as a significant predictor of moral judgements and of gambling tasks, such that individuals with greater executive control show greater consistency in their responses (Moore et al., 2008; Blair et al., 2018). These results may suggest that greater consistency in the responses, mediated by executive control, indicates an adaptive RT derived from an accurate assessment of each situation.

\section{Proneness Biases}

First, the results showed moderate positive, significant correlations between openness and social RT. Agreeableness showed moderate/weak negative, significant correlations with RT in the ethical, financial, and health domains. Second, we found strong positive, significant correlations between thrill and adventure seeking and recreational RT. Furthermore, the results showed moderate positive, significant correlations between the experience seeking subtrait and health RT. In addition, disinhibition showed moderate/strong positive, significant correlations in all domains. Boredom susceptibility showed a weak/moderate positive, significant correlated with health RT. Third, the five impulsivity subtraits showed weak/moderate positive, significant correlations with health RT. Lack of premeditation also presented a weak positive, significant correlation with recreational RT, and sensation seeking presented a strong positive, significant correlation with recreational RT, and a weak positive, significant correlation with social RT. Finally, we found moderate positive, significant correlations between positive urgency and ethical RT.

Regarding regression results, the openness personality subtrait appeared as a significant predictor of social RT. The openness subtrait is relevant to an understanding of social attitudes, career changes, and moral reasoning (McCrae and Costa, 1997). The positive 
relation shown between social RT and openness is consistent with other studies (Josef et al., 2016) and this dimension of personality has been identified as a protector against social anxiety (Kaplan et al., 2015). Agreeableness, which is related to needs for compliance and control, was a significant predictor of ethical and financial risk avoidance, which is consistent with the results obtained by other authors (Nicholson et al., 2005; Soane et al., 2010).

The thrill and adventure seeking subtrait, which relates to the desire to engage in risky physical activities (Zuckerman, 1994; Wishart et al., 2017), appeared as a significant predictor of recreational RT. The recreational domain involves risky physical activities and dangerous situations, such as "Bungee jumping off a tall bridge." This relation is consistent with other studies that found positive relations between the thrill and adventure seeking subtrait and risky driving and sport behaviours (Zuckerman, 1994; Wishart et al., 2017). Disinhibition, defined as a rule-breaking tendency (Donohew et al., 2000), appeared as a RT predictor in the ethical, financial, health, and social domains. Disinhibition could act as a RT facilitator in the ethical domain, inciting individuals to ignore previously established ethical norms. This result is consistent with other works that also found that the disinhibition subtrait is a significant predictor of ethical RT, specifically in academically dishonest behaviours (Weber et al., 2002; Etter et al., 2006). The influence of disinhibition on financial RT has been shown in different contexts, including gambling, in which it has a positive influence on frequency of expected future gambling (Wolfgang, 1988) and, recently, problem poker gambling, in which it is associated with the male gender and depression (Bonnaire and Barrault, 2018). The relation between disinhibition and health RT is well established, and has been demonstrated in different circumstances, such as substance abuse (Kopstein et al., 2001), alcohol consumption (Hittner and Swickert, 2006), and risky sex (Bancroft et al., 2003). Lastly, the influence of disinhibition on social RT has been confirmed by numerous studies, including those in which participants with high disinhibition scores showed high levels of violations of societal norms (De Vries et al., 2009) or social RT and expected benefits (Lozano et al., 2017).

Regarding impulsivity subtraits, lack of perseverance, which reflects an absence of focus on a boring or difficult activity, and positive urgency, which arises when an individual displays impulsive behaviours in positive situations (Whiteside and Lynam, 2001; Whiteside et al., 2005), were significant predictors of health RT. These results are also consistent with those obtained in other works, in which health RT was related to high scores in these impulsivity subtraits (e.g., Coskunpinar et al., 2013; Lozano et al., 2017). Situations such as "Engaging in unprotected sex" or "Sunbathing without sunscreen," which are DOSPERT-30 scale items for health RT, involve salient positive rewards, which could explain this result. Lastly, sensation seeking (impulsivity subtrait) appeared as a significant predictor of recreational RT. The sensation seeking subtrait is defined as the attraction to exciting new and potentially dangerous experiences (Whiteside and Lynam, 2001; Whiteside et al., 2005) and has been related to recreational RT by other 
Why do we take risks? Perception of the situation and risk proneness predict domainspecific risk taking

authors in activities such as high-risk sports (Gomà-i-Freixanet et al., 2012; Woodman et al., 2013).

In hypothesis 2, personality traits (h2a), sensation seeking (h2b), and impulsivity (h2c) were expected to have an influence on all RT, constituting a trend toward risk proneness or risk avoidance, regardless of the type of risk. First, the hypothesised relation between RT and openness, agreeableness, and conscientiousness was supported, partially accepting hypothesis 2a. Personality had an influence in all domains, except recreational. The results suggested that personality traits, in isolation, do not have an effect in all RT domains; however, personality, as the conjunction of personality traits, affects RT behaviours in almost all the domains studied. Second, our results suggested that sensation seeking is a bias toward risk proneness in various domains. Specifically, disinhibition was found to be a cross-domain subtrait that influences RT regardless of context, which supports hypothesis $2 \mathrm{~b}$. Third, we found relations between impulsivity subtraits and all RT domains. These results seem to suggest that impulsivity, which is involved in all domains of RT, has a traversal influence on risky behaviours, generating a general trend towards risk (RT or risk avoidance) regardless of the domain, supporting hypothesis 2c.

\section{Limitations}

We acknowledge that the present study has some methodological limitations. First, to increase the statistical power of the analyses, the sample size could be larger. Second, the use of a single measure of RT may lead to biased results. As discussed previously, the scale might not encompass all the situations in which RT can be studied. In future studies, we intend to employ additional RT measures to complement the DOSPERT-30 scale, such as the Balloon Analogue Risk Task (BART; Lejuez et al., 2002), or the Bechara Gambling Task (Bechara et al., 1994), which enable close examination of all the potentially influential variables that affect subjects' responses. Self-reported indexes of engagement in risky behaviours in daily life over specific periods of time (e.g., marijuana consumption during the previous year) have been used in other studies (Lejuez et al., 2003), and could be included. Third, self-reported measures might involve intrinsic biases (de-Juan-Ripoll et al., 2018), since individuals' cognitive and psychological states may be different when answering the questionnaires as opposed to when they face real situations (Kivikangas et al., 2011). In addition, specific self-report items might be open to different interpretations (Lanyon and Goodstein, 1997), and some questions require people to possess overt knowledge of their dispositions (Schmitt, 1994), which is not always possible. In our future research, we will examine different RT metrics to identify ways of improving measurements, and investigate the application of virtual reality technologies in RT assessment. 


\section{Conclusion}

Examining why humans take risks in some situations, and avoid risks in others, is a complex research field. In the present study we proposed an approach in which risk proneness and risk perception affect RT behaviours. On one hand, risk proneness is considered as a general attitude to any type of risk, so that its influence is transversal to all domains. On the other hand, risk perception is understood as a perceptual bias, which may influence RT differently, depending on the domain. The results of this study constitute a foundation upon which to build in this research area and contribute to the increased understanding of human behaviour in risky situations. 
Why do we take risks? Perception of the situation and risk proneness predict domainspecific risk taking 


\title{
Chapter 5. An Immersive Virtual Reality Game for Predicting Risk Taking through the Use of Implicit Measures
}

de-Juan-Ripoll, C.; Llanes-Jurado, J.; Giglioli, I.A.C.; Marín-Morales, J.; Alcañiz, M. An Immersive Virtual Reality Game for Predicting Risk Taking through the Use of Implicit Measures. Appl. Sci. 2021, 11, 825.

\begin{abstract}
Risk taking (RT) measurement constitutes a challenge for researchers and practitioners and has been addressed from different perspectives. Personality traits and temperamental aspects such as sensation seeking and impulsivity influence the individual's approach to RT, prompting risk-seeking or risk-aversion behaviours. Virtual reality has emerged as a suitable tool for RT measurement, since it enables the exposure of a person to realistic risks, allowing embodied interactions, the application of stealth assessment techniques and physiological real-time measurement. In this article, we present the assessment on decision making in risk environments (AEMIN) tool, as an enhanced version of the spheres and shield maze task, a previous tool developed by the authors. The main aim of this article is to study whether it is possible is to discriminate participants with high versus low scores in the measures of personality, sensation seeking and impulsivity, through their behaviours and physiological responses during playing AEMIN. Applying machine learning methods to the dataset we explored: (a) if through these data it is possible to discriminate between the two populations in each variable; and (b) which parameters better discriminate between the two populations in each variable. The results support the use of AEMIN as an ecological assessment tool to measure RT, since it brings to light behaviours that allow to classify the subjects into high/low risk-related psychological constructs. Regarding physiological measures, galvanic skin response seems to be less salient in prediction models.
\end{abstract}

\section{Introduction}

Risk taking (RT) is a component of the decision-making process in uncertain situations, in which the subject rationally knows the probability of each outcome (Bechara et al., 2005; Krain et al., 2006). The decision-making process is influenced by three main elements (Einhorn, 1970; Hunt et al., 1989): decision features, which are the characteristics of the decision itself, such as the ordering of the choice options (Appelt et al., 2011); situational factors, which refer to the context of the decision, for example, time 
An Immersive Virtual Reality Game for Predicting Risk Taking through the Use of Implicit Measures

pressure (Dror et al., 1999); and individual differences, which have been identified as the perception of benefits, the perception of risks and risk attitude in the field of RT (Figner and Weber, 2011). In the first stage of RT process, the subject thinks about the possible positive/negative outcomes of his/her actions before acting (Zuckerman and Kuhlman, 2000). During this process, emotional states have an influence on the weighting of costbenefit assessment (Fesslet, 2001), and its relation with RT has been widely studied. On the first hand, it has been suggested that people experiencing positive emotions tend to maintain this positive state (Isen and Simmonds, 1978) and protect themselves from the potential negative outcomes of a decision (Arkes et al., 1988), which leads to risk avoidance. On the other hand, positive emotions can be associated with greater risk tolerance (Nguyen and Noussair, 2014), promoting RT. These results suggest that the relation between emotional states and RT relies upon the decision-making context. Considering this, in the present paper we are focusing on a cross-domain trait, risk proneness, understood as the propensity to be attracted to potentially risky activities (Raffaelli and Crockett, 2003), which is related to personality traits and temperamental aspects such as sensation seeking and impulsivity, which influence the individual's approach to RT, prompting risk-seeking or risk-aversion behaviours (Zuckerman and Kuhlman, 2000).

\section{Personality, Sensation Seeking, Impulsivity and RT}

Among the numerous personality models developed in psychology research, the Big Five factorial model of personality - composed of neuroticism, extraversion, openness, agreeableness and conscientiousness factors (McCrae and Costa, 1997) - seems to be the most generally recognized in terms of the study of the relation between personality and RT. On the first hand, neuroticism, which is connected to sensitivity to punishment and negative affect (Elliot and Trash, 2010); agreeableness, which is characterized by trust, straightforwardness and compliance; and conscientiousness, understood as a need for compliance under conditions of conformity and control; have been related to risk aversion in most domains (Gullone and Moore, 2000; Hoyle et al., 2000; Nicholson et al., 2005; Schwebel et al., 2006). On the other hand, extraversion, as a generalized need for stimulation; and openness to experience, which relates to cognitive risk seeking, acceptance of experimentation, and tolerance of uncertainty, change and innovation; have been related to risk seeking (Lauriola and Levin, 2001).

Sensation seeking has been defined as "the seeking of varied, novel, complex and intense sensations and experiences, and the willingness to take physical, social, legal, and financial risks for the sake of such experience" (Zuckerman, 1994; p. 27) and has been positively related to RT in several domains, such as recreation, health, career, finance, safety, social life and sex (Nicholson et al., 2005; Donohew et al., 2000). Zuckerman (1994) identified four dimensions of the sensation seeking trait: thrill and adventure seeking, which reflects a desire to engage in physical activities that provide unusual sensations (Zuckerman, 1994); experience seeking, which has been related to lower sensitivity to aversive stimulation (Netter et al., 1996); disinhibition, which appears as significant 
predictor of RT in several domains, as in rule-breaking behaviours and violations of societal norms (Donohew et al., 2000; Roberti, 2004; De Vries et al., 2009) and boredom susceptibility, which is connected to intolerance for routine and repetitive activities (Zuckerman, 2006).

Impulsivity has been defined as the "predisposition toward rapid, unplanned reactions to internal or external stimuli without regard to the negative consequences of these reactions to the impulsive individual or to others" (Moeller et al., 2001; p. 1784) and has been associated with RT in terms of drug use, drink driving and seatbelt use, among others (De Wit, 2008; Stanford et al., 1996). Some authors have also demonstrated its connection with emotional self-control, inhibition and, especially, the management of frustrating situations (Cooper et al., 2000; Boyer, 2006). Whiteside and Lynam (2001) argued that impulsivity is made up of a set of five impulse-related traits: negative urgency, lack of premeditation, lack of perseverance, sensation seeking and positive urgency. According to Whiteside and Lynam (2001) and Whiteside et al. (2005), negative and positive urgency traits relate to the tendency to exhibit impulsive behaviours when facing negative/positive situations. Lack of premeditation relates to thoughtless behaviours and to the tendency to choose alternatives with short-term rewards, rather than options that might lead to more valuable but delayed rewards. Lack of perseverance reflects an absence of focus on a boring or difficult activity. Sensation seeking is an attraction toward exciting, new and potentially dangerous experiences.

\section{Measurement of RT}

RT measurement constitutes a challenge for researchers and practitioners and has been addressed from different perspectives. To date, most of the theoretical constructs used in RT assessment are based on explicit measures such as self-reports, although these measures have been applied from different points of view. While some authors employ self-reported measures to assess risky-related psychological constructs, such as personality, impulsivity and sensation seeking (Lejuez et al., 2002; Skeel et al., 2007; Horvath and Zuckerman, 1993); other authors use self-reported daily habits as a measure of RT (Zuckerman and Kuhlman, 2000; Lejuez et al., 2003). Alternatively, Blais and Weber (2006) developed a measure of the tendency to engage in real-life RT behaviours in different domains: ethic, financial, health, recreational and social.

However, self-reported measures present some limitations. On the first hand, with the use of these instruments it is assumed that humans are able to think and verbalize accurately about their attitudes, emotions and behaviours, while it has been demonstrated that most of the brain processes that regulate attitudes, emotions and behaviours are not conscious, and consequently, cannot be verbalized (Barsade et al., 2009; Becker et al., 2011; George, 2009). On the other hand, questionnaires have an important intrinsic bias since individuals need to remind past situations or imagine 
An Immersive Virtual Reality Game for Predicting Risk Taking through the Use of Implicit Measures

future experiences to answer, rather than actually undergoing the experiences that the researchers wish to analyze (Kivikangas et al., 2011).

To overcome these limitations, the approach of "stealth assessment" (Shute, 2011) emerged focusing on the study of how psycho-cognitive states can be assessed in an ecological, non-intrusive, non-biased way. Studies under this paradigm record subjects' performance during a serious game, and then conclusions are drawn about individual competencies based on the data (Shute et al., 2016; Mayer et al., 2014). In the field of RT, the Bechara gambling task (BGT; Bechara et al., 1994) and the balloon analogue risk task (BART; Lejuez et al., 2002) could be considered the most used measures that aim to assess RT under this methodology. In BGT, participants are given four decks of cards and are asked to choose a card from any one of the four decks. Once a card is chosen, it is turned over, and the amount of money won or lost for choosing that card is revealed. This is repeated for 100 times, and the player is never told the distribution of wins and losses associated with each deck, and instead the distributions are learned from experience. In BART, a balloon is presented in the middle of a screen, and subjects are asked to pump it as much as possible, knowing that it could exploit at any time. At the beginning of the task participants are told that they will obtain a financial reward the more they could inflate each balloon without breaking it. Although the reliability of these tools has been retested (Buelow and Suhr, 2009; White et al., 2008), it has been proved that the correspondence between performance in neuropsychological tests and real-life behaviours is very weak (Manchester et al., 2004; Sbordone, 2008; Bottari et al., 2009).

\section{Virtual Reality for RT Assessment}

Conversely, virtual reality (VR) provides the capacity of simulate real experiences in which subjects can interact as if they were in the real world (Alcañiz et al., 2003), and there is empirical evidence demonstrating similarities between the neural mechanisms that subjects experience when immersed in a virtual environment and in those real life (Tarr and Warren, 2002; Alcañiz et al., 2009). VR allows to record the behavioural responses of the users while they are interacting with a virtual environment (Parsons, 2015), making VR an innovative, effective, active, engaging and adaptive tool that has been applied in numerous fields of human behaviour research (e.g. Alcañiz et al., 2003), providing better results than 2D solutions (Giglioli et al., 2019).

VR has emerged as a suitable tool for RT measurement, since it enables the exposure of a person to realistic risks, allowing embodied interactions, the application of stealth assessment techniques and physiological real-time measurement (de-Juan-Ripoll et al., 2018). On the basis of this, we developed the spheres and shield maze task (SSMT; deJuan-Ripoll et al., 2020), a virtual environment for RT measurement. It consisted in an out-of-context maze, through which participants had to pass from start to finish before three minutes, accumulating as much "karma" as possible by collecting spheres down the road. Participants could lose "karma" if they were attacked by a risk. Furthermore, participants had the option of activating a shield, which protected them from the risks. This virtual environment supposed a first approach for the measurement of the risk- 
related constructs sensation seeking and impulsivity, although it presented two main limitations. First, the practice session was too short and insufficient. Second, it measured only three variables: "karma", distance covered and shield use, ignoring real-time behavioural and psychophysiological measures. In this article, we propose an enhanced version of the SSMT, by which the authors intend to overcome these issues.

\section{Implicit Measures in VR}

The interactions of the users with the virtual environment can be also studied by the analysis of their gaze movements, which have shown to be related to information processing in risky decisions (Glöckner and Herbold, 2010) and problem solving (Knoblich et al., 2001). The eye tracking (ET) measure can be integrated into a VR set-up, in order to record fixations and eye movements during an experience in a virtual environment. This technology has been applied in combination with VR for the study of the influence of contextual elements in human behaviour, such as in street robbery (Kim and Yung, 2020), identifying if the presence of particular components of a physical space can influence in decision-making. Furthermore, ET has been employed to study whether if exists a relationship among gaze patterns and human behaviour (Pettersson et al., 2018; Porras-García et al., 2019), or even if these gaze patterns could contribute to predict humans' decisions (Rojas et al., 2020).

In the field of RT, ET has been employed as a reliable indicator of information processing patterns in risky decisions. On the first hand, greater number of fixations, longer fixations and larger quantity of available information fixed have been related to deeper pre-decision processes, which lead to risk aversion (Kwak et al., 2015; Su et al., 2013; Payne and Braunstein, 1978; Velichkovsky et al., 2002). On the other hand, in a study with construction workers, lower dwell time was connected with a higher risk perception (Habibnezhad et al., 2016). The authors interpreted this result as follows: participants with higher risk perception identified the hazards rapidly, so they could spend their time searching other possible hazards present in the situation.

In addition to behavioural measures, physiological measures have been proposed as implicit measures of human behaviour (Kivikangas et al., 2011). Galvanic skin response (GSR) has been successfully used as a measure of implicit processes such emotional arousal (Nourbakhsh et al., 2013), which plays a decisive role in the decision-making process. GSR has been employed in combination with VR to evaluate the stress generated by changes in contextual aspects, such as architectural stimuli (Ergan et al., 2019), as predictor of anxiety level (Šalkevicius et al., 2019) and as a measure to discriminate between Autism Spectrum Disorder and typical development populations (Alcañiz et al., 2020), among others.

In the field of RT, high physiological arousal acts as a "warning signal" in risky situations and tends to lead to safe decisions (Bechara et al., 2005). This relationship has been demonstrated to be mediated by emotional intelligence, such a way that, low emotional intelligence may lead to maladaptive decision-making, due to an impaired interpretation 
An Immersive Virtual Reality Game for Predicting Risk Taking through the Use of Implicit Measures

of physiological arousal (Yip et al., 2020). Additionally, situational factors, such as time pressure, have an influence on the relationship between GSR and RT. In an experiment with two kind of decisions (time pressure and time delay), the relationship between GSR and RT was positive in situations under time pressure, and negative in situations under time delay (Persson et al., 2018).

Despite these measures having been widely adopted in VR-based experiments, to our knowledge, ET and GSR have not been employed in combination with VR to evaluate RT.

\section{The Current Study}

Starting from these premises, we present the assessment on decision making in risk environments (AEMIN) tool, as a new interactive virtual environment for RT measurement. Compared to the SSMT, AEMIN has longer duration, which allows a wider and enriched recording of information from the subjects, and contains more elements along the maze, such as spheres of different colors and a pause button. Furthermore, features in AEMIN were rated depending on whether the subject was in a risk zone or in a no risk zone, to provide further information about the subjects' behaviour depending on the situation. Additionally, the appearance and characteristics of the risks have been improved, in order to provide a more natural experience and consequently, more natural behaviours. A detailed description of AEMIN is provided in the Materials and Methods section.

The main aim of this study is to discriminate participants with high versus low scores in the measures of neuroticism, extraversion, openness to experience, agreeableness, conscientiousness, sensation seeking and impulsivity, through their behaviours and physiological responses during playing AEMIN. Applying machine learning (ML) methods to the dataset we explored: (a) if through these data it is possible to discriminate RT domains, sensation seeking and impulsivity, allowing to qualitatively determinate a general level of RT for each subject; and (b) which parameters better discriminate between the two populations in each variable.

\section{Materials and Methods}

\section{Participants}

A group of 98 subjects was recruited to participate in the experiment. They were balanced in terms of gender ( 56 men and 55 women) and age ( $35 \%$ under 30, 35\% among $30-45,30 \%$ above 45 ; mean age $=37.08, \mathrm{SD}=10.91$ ). Prior to their participation, they received documentary information on the study and gave their written consent for their involvement. The responses were anonymized and randomized to ensure the privacy of the information. The study obtained the ethical approval of the Ethical Committee of the Polytechnic University of Valencia (P4_18_06_19). 


\section{Self-Reported Measures}

The risk-related constructs were measured by means of a battery of self-reported measures:

Personality: Spanish version of the NEO five-factor inventory (NEO-FFI). This comprises 60 items and is composed by the factors neuroticism, extraversion, openness, conscientiousness and agreeableness (Cordero et al., 1999; Costa and McCrae, 1989). The reliability coefficients' Cronbach's alphas ranged from 0.75 to 0.83 . The internal consistency of the scales in the present study was: neuroticism $\alpha=0.77$; extraversion $\alpha=$ 0.85 ; openness $\alpha=0.79$; agreeableness $\alpha=0.75$; conscientiousness $\alpha=0.84$.

Sensation seeking: Spanish version of the 40-item Sensation Seeking Scale-V (SSS-V; Pérez and Torrubia, 1986; Zuckerman et al., 2006). This includes subscales for thrill and adventure seeking, experience seeking, disinhibition and boredom susceptibility, and a total sensation seeking score. The reliability coefficients' Cronbach's alphas ranged between 0.67 and 0.81, which suggests the subscales have acceptable internal consistency. The internal consistency of the scale in the present study was 0.77 .

Impulsivity: Short Spanish version of the UPPS-P impulsive behaviour scale (Whiteside and Lynam, 2001; Cándido et al., 2012). Composed of 20 items, this measures five impulsivity traits: negative urgency, lack of premeditation, lack of perseverance, sensation seeking and positive urgency. The Cronbach's alphas coefficients ranged from 0.66 to 0.81 . The internal consistency of the scales in the present study was: negative urgency $\alpha=0.72$; lack of premeditation $\alpha=0.77$; lack of perseverance $\alpha=0.78$; sensation seeking $\alpha=0.79$; positive urgency $\alpha=0.60$.

As a measure of the sense of presence in the virtual environment, participants responded the Sense of Presence Inventory, which is composed by the dimensions of spatial presence, engagement, ecological validity and negative effects (ITC-SOPI; Lessiter et al., 2001). Cronbach's alphas coefficients in ITC-SOPI ranged from 0.76 to 0.94 . The internal consistency of the scales in the present study was: spatial presence $\alpha=0.91$; engagement $\alpha=0.84$; ecological validity $\alpha=0.77$; negative effects $\alpha=0.86$.

\section{The Virtual Environment}

We present the assessment on decision making in risk environments (AEMIN) tool, as a new interactive virtual environment for RT measurement. As an extension of the SSMT (De-Juan-Ripoll et al., 2020), AEMIN is an interactive virtual environment that is composed by two mazes that participants must pass through from start to finish before the allocated time expires without (virtually) hurting themselves (see Figure 8a). One of the mazes must be solved individually, while in the other one the subject is accompanied by four avatars. The avatars are represented by robots (see Figure $8 b$ ), which can express basic emotions through a screen located on their faces. 
An Immersive Virtual Reality Game for Predicting Risk Taking through the Use of Implicit Measures
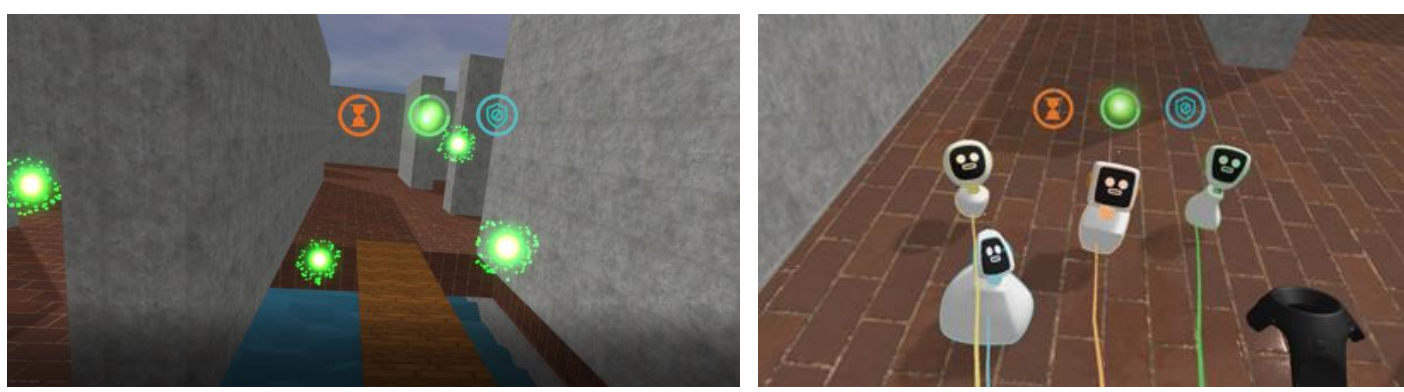

Figure 8. AEMIN maze (a; left) and avatars (b;right)

Participants have $10 \mathrm{~min}$ to negotiate each maze and they are instructed to accumulate as much energy as possible, since it is the source of life of their avatar. If a robot is poor of energy, it shows dying breathing and its movements are slower, which implies a waste of time to find the exit of the maze. There are green spheres distributed throughout the maze, which earn participants' energy if they collect them. Furthermore, participants can lose energy if they are attacked by a risk. These risks are also distributed throughout the maze and are of four types: bridges, swarms of insects, storms and haunted rooms. Some spheres are close to hazards and others are located in no-risk zones. Participants have the option of activating a shield, which protects them from the risks. When the shield is active, the user's speed is reduced and (s)he cannot collect any spheres. The shield is a finite resource that subjects need to optimize. While passing through the maze, the participants have information about the remaining time (orange circle in Figure 8), their level of energy (green circle in Figure 8), and the battery life of the shield (blue circle in Figure 8). Table 11 shows a brief description of each risk and the consequences of each one for the robots. In addition, there are some purple spheres hidden in some endless roads. Catching one of these purple elements can take uncertain effects, such as simplifying the route or subtracting $10 \mathrm{~s}$ to the participant. The game can be paused by the participant at any time, so that (s)he is moved to a virtual relaxing room, until (s)he is ready to return to the game. The reason why we included this virtual room is that the use of it by the participant can be considered as an inhibition strategy, and as an indicator of emotional self-control. The navigation metaphor is indirect walking, in which pushing down on the controller's integrated touchpad moves the user's avatar in the direction (s)he is facing at $2 \mathrm{~m} / \mathrm{s}$ (speeds above $3 \mathrm{~m} / \mathrm{s}$. can increase cybersickness symptoms (So et al., 2001)). Before undertaking the AEMIN game, the participants underwent a guided practice session in which they learned how to travel through the virtual environment, how to collect spheres and how to activate the shield.

Table 11. Description of the risks

Risk

Bridge
Description

Walkway that allows the robots to cross from one side to another to continue the path. Participants can cross it as many

\section{Consequences}

If a robot falls into the pit, it will lose part of the battery of its shield. Additionally, the robot reappears at the beginning of the bridge, 


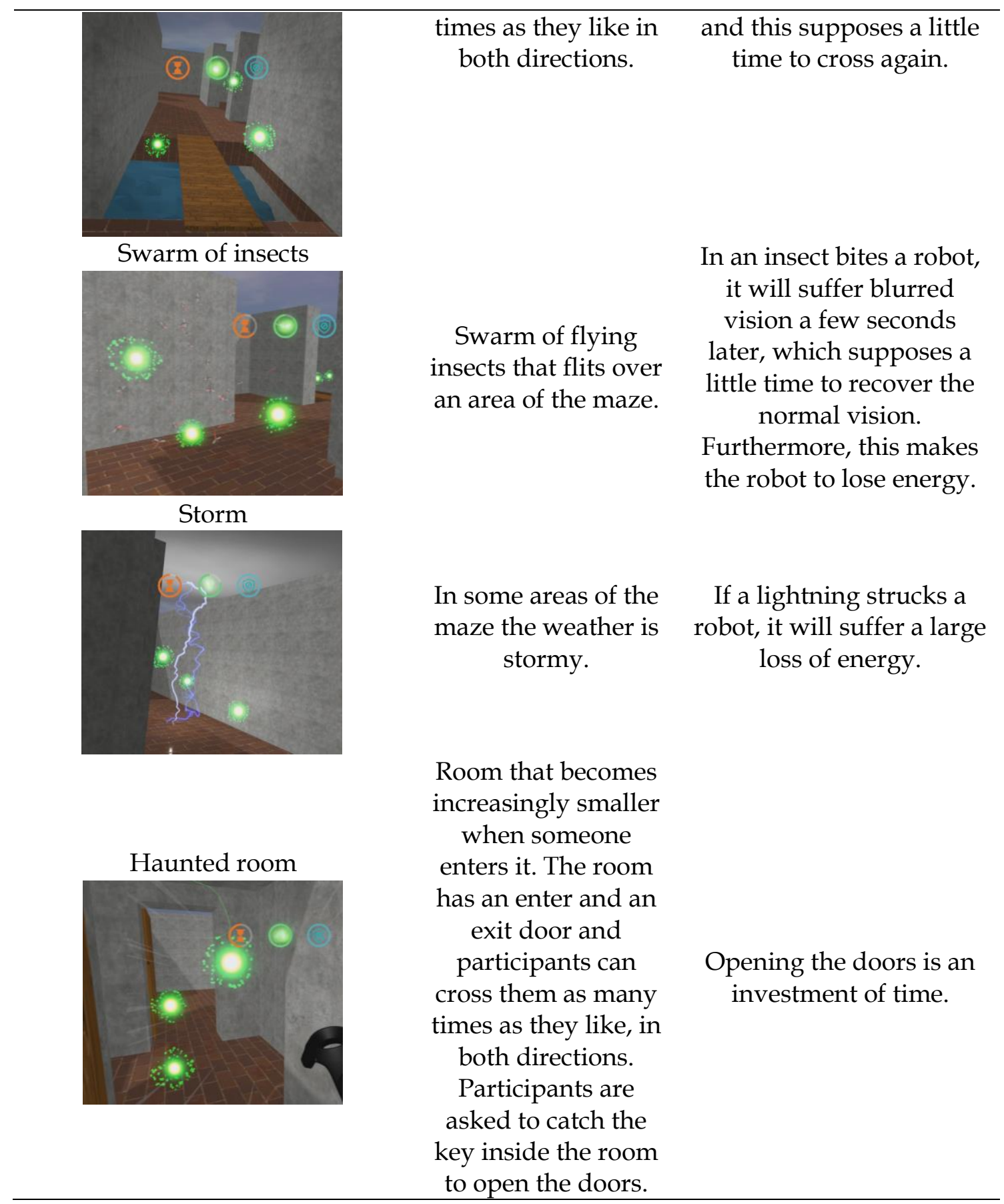

The virtual environment was developed in Unity (version 2018.4.1f1) using c\# as programming language. Participants performed the AEMIN game using the HTC Vive Pro-eye head mounted display1, with $2880 \times 1600$ pixels $(1440 \times 1600$ per eye), a field of view of $110^{\circ}$ degrees, working at $90 \mathrm{~Hz}$ refresh rate. The ET data were obtained from the Unity VR through the ET SDK (SRanipal), with a maximum frequency of $120 \mathrm{~Hz}$ and an accuracy of $0.5^{\circ}-1.1^{\circ}$.

Galvanic Skin Response (GSR) is also recorded in the experimentation. Data was collected with the Shimmer3 GSR sensor2, sampled at $128 \mathrm{~Hz}$. We measured skin conductance between two reusable electrodes attached to human fingers. 
An Immersive Virtual Reality Game for Predicting Risk Taking through the Use of Implicit Measures

The computer used was an Intel Core i7-770 CPU 3.60 GHz with an NVIDIA GeForce GTX 1070.

\section{Experimental Procedure}

Each participant responded to the self-report questionnaires on a personal computer. The process took approximately $30 \mathrm{~min}$, and was completed in an experimental room, supervised by a research assistant. The subject was thereafter conducted to a second experimental room where (s)he received a brief contextualization of the VR game. Consecutively, the research assistant equipped the participant with the GSR device and the HMD system in the correct position. After a calibration process of the eye tracking apparatus, the subject was asked to sit and relax during $90 \mathrm{~s}$ in order to record a GSR baseline. During this period, the subject listened to a relaxing audio to create a common state of calm. After that, the subject stood up and completed the practice session, which included a brief presentation of the avatars. Hereafter, the participant solved the two mazes ( $50 \%$ of the participants began by the individual scene, and the other $50 \%$ started by the group of avatars). Finally, the subjects responded to the presence questionnaires in a personal computer.

\section{Data Processing}

The virtual environment (VE) is divided in two areas: risk zone and no risk zone. The defined risk zone areas correspond to the situation where the subject is inside a risk such as bridge, swarm of insects, storm and haunted room. The no risk zone is defined for the situations where the subject is not inside of a risk zone. According with this division, we analyzed two groups of variables: (a) measures in risk zones; and (b) measures in no risk zones. The features were divided depending on the source of data where have been computed. Three different sources of data were established: VR, ET and GSR. Table 12 summarizes the complete set of features that was used from each source.

Table 12. Description of the set of features obtained by data source

\begin{tabular}{|c|c|c|c|c|}
\hline \multirow{2}{*}{ Data source } & \multicolumn{2}{|l|}{ Risk zone } & \multicolumn{2}{|l|}{ No risk zone } \\
\hline & Features & ${ }^{1} \mathbf{N}$ & Features & ${ }^{1} \mathbf{N}$ \\
\hline \multirow{5}{*}{ Navigation } & Time spent & & Time spent & \\
\hline & Visits to each risk & & - & \\
\hline & Distance covered & & Distance covered & \\
\hline & Time walking & & Time walking & \\
\hline & Velocity & & Velocity & \\
\hline VR & Acceleration & 28 & Acceleration & 20 \\
\hline \multirow{5}{*}{ Interactions } & Green spheres caught & & Green spheres caught & \\
\hline & - & & Purple spheres caught & \\
\hline & Pause button use & & Pause button use & \\
\hline & Shield use & & Shield use & \\
\hline & Total interactions & & Total interactions & \\
\hline \multirow{3}{*}{ ET } & Time to first fixation & & Time to first fixation & \\
\hline & Number of fixations & 37 & Number of fixations & 34 \\
\hline & Fixation duration & & Fixation duration & \\
\hline
\end{tabular}




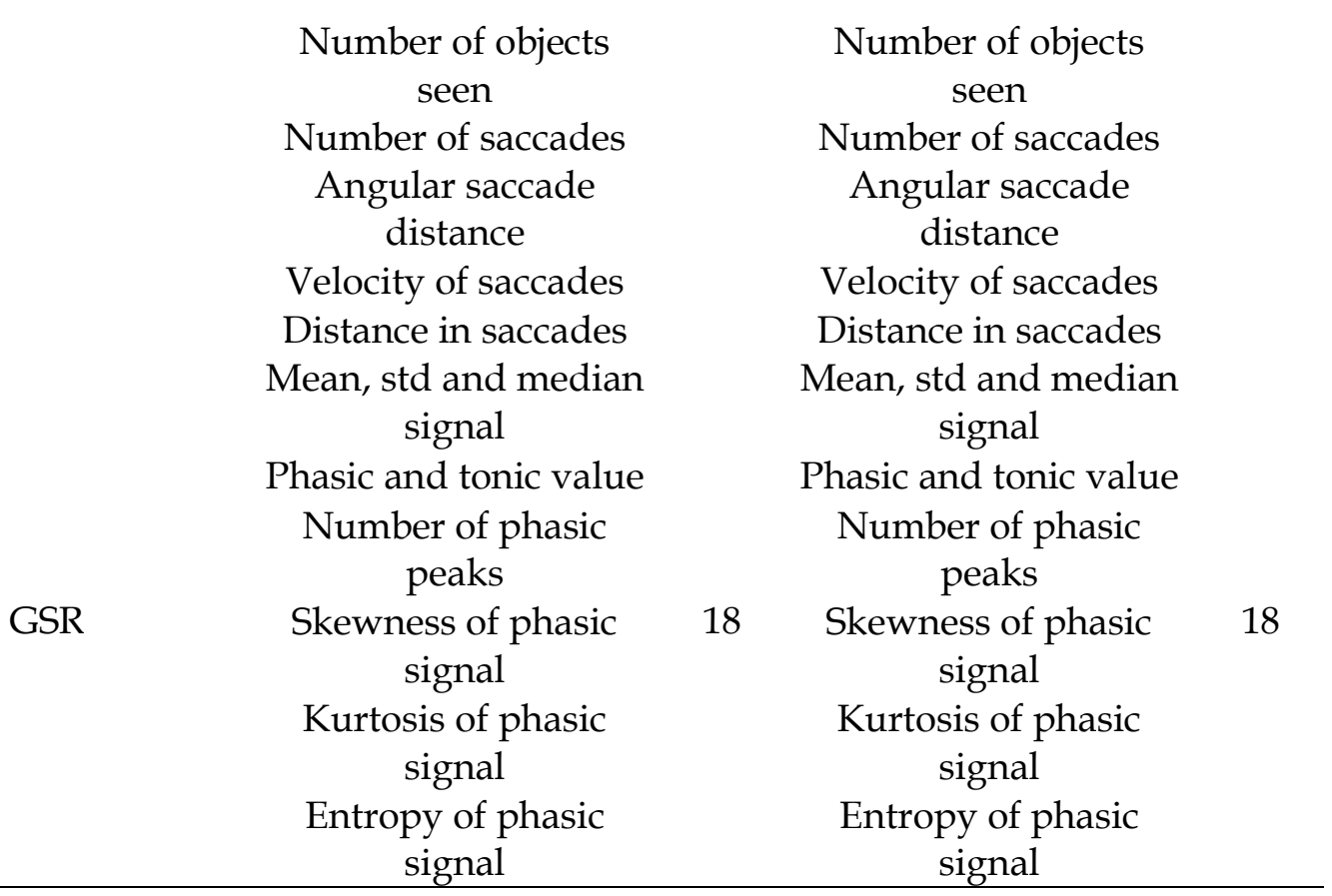

Features study from VR data are divided between navigation and interaction features. The navigation part obtains a set of features related with the trajectory of the subject in the maze whereas the interaction features counts the number of times that the subject uses or touch some element in the maze.

ET data was processed in order to obtain a classification between fixations and saccades, using the dispersion threshold (DT) algorithm with $1^{\circ}$ as a dispersion threshold and 0.25 $s$ as a time window threshold (Llanes-Jurado et al., 2020). A complete set of features was obtained from the classification between fixation and saccade.

Before the obtainment of features from GSR, two previous steps were done. The first of them was the manual cleaning of the signal. Commonly, GSR signal could suffer from different types of noises that hide correlations between the signal of the subject and its level of stress (Shukla et al., 2018). The manual correction was done using Ledalab3 software in MATLAB. The second step was the division of the signal into phasic and tonic components using continuous decomposition analysis (CDA; Benedek and Kaernbach, 2010). After this pre-processing, a set of features was obtained from the raw signal and the phasic and tonic components including time and non-linear domain analysis (Taylor et al., 2015).

In order to approach a classification problem, the target variables were divided in two groups: high score and low score. The division was done according with the normality of the distribution of each target variable. If the distribution was normal, the target was segmented by the mean target value, whereas if the target distribution was not normal, the target was segmented by the median. The significance level between groups in each target variable was checked through a statistical t-test in features with normal distribution and Mann-Whitney for features without a normal distribution. 
An Immersive Virtual Reality Game for Predicting Risk Taking through the Use of Implicit Measures

\section{Statistical Analysis}

Firstly, a multivariate outlier detection was performed by group of variables (VR, ET and GSR). Mahalanobis distance between every subject and the probability that it belongs to a Chi-square distribution was calculated. Subjects that belonged to the most extreme $1 \%$ of the data distribution were defined as outliers.

Some pre-processing steps were done before the modelling study. The variables with a Pearson-correlation higher than 0.95 in absolute value were removed. After that, nonormal feature distributions were transformed using logarithms. The variables which after this transformation were normal distributed keep the transformation, the ones that were not normal were not transformed.

A ML method was applied to find the best possible selection of features that classify whether the subject have a high or low score in the studied target variables. The used model was a support vector machine (SVM; Schoelkopf et al., 2000). The pipeline for the modeling of the data is equal for every target.

The pipeline is designed to find the best possible features to explore the importance of each one in combination with the rest of features. To address this goal, the ML pipeline removes iteratively the feature which achieves the lowest accuracy for each model in the iteration. Iteration $k$, computes the mean accuracy in a cross-validation (CV) of 10 folds and 2 repetitions. After that, a backward feature selection (BFS; Doa, 1992) method removes one feature selecting the set of $k-1$ features with highest accuracy. This method also uses a CV with 10 folds and 2 repetitions. The process ended-up when only one feature remains. The set of features with highest accuracy are selected. After that, an hyperparameter tunning is performed to the SVM. Finally, the model is validated in a $\mathrm{CV}$ of 10 folds with 4 repetitions. The average and standard deviation of the metrics accuracy, kappa, true positive ratio (TPR) and true negative ratio (TNR) were reported. Moreover, the experiment explored the importance of each group of features using four different sets based on the source. Three datasets including VR, GSR and ET features respectively were created. Moreover, an additional dataset which is called ALL that joins all the features was included.

To check the overfitting of the ML pipeline, the obtained results are compared against the ones obtained from a generated random target. The unique condition imposed to the generation of this random target is that it must have a coincidence in its labels lower than a $67.5 \%$, compared with the rest of the real targets, in order to avoid a random target very similar to a real one. The objective is to compare, according with a one-way ANOVA test, the statistical distribution of the set of accuracies obtained from the last $\mathrm{CV}$ of the ML pipeline of the random target and each real target. Six random targets are generated to extend the number of accuracy samples from the random targets. Figure 9 shows a scheme of the ML pipeline used and the overfitting check method exposed. If the comparison between both distributions shows a statistical difference ( $p$-value $<0.05$ ), 
it supports that the ML pipeline is over the chance level. Finally, the dataset with highest accuracy is reported as the best classification model.

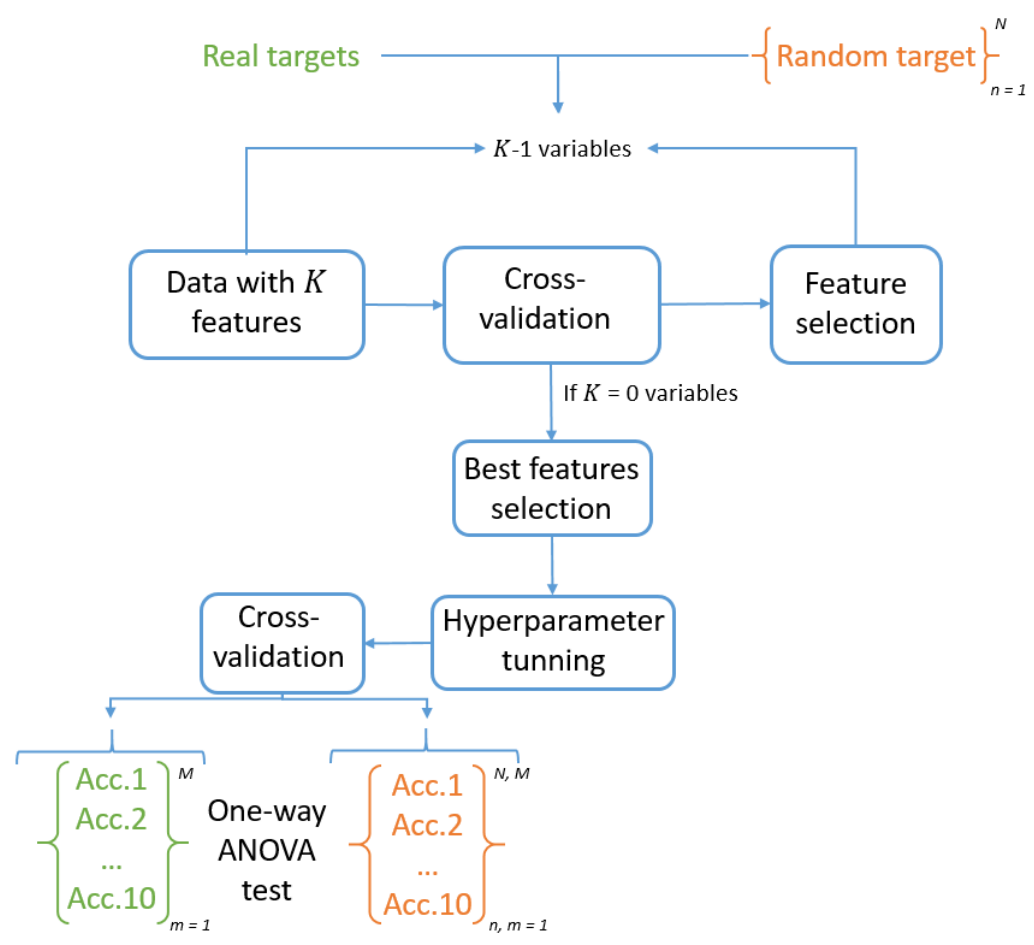

Figure 9. Scheme of ML pipeline and its overfitting check using a set of generated random targets. $M$ indicates the number of the $C V$ repetitions set to 4 , and $N$ the number of random targets generated, equal to 6

Regarding the presence questionnaires, mean and standard deviation for each dimension were calculated.

\section{Results}

From the initial 98 set of subjects, 10 of them were removed due to the not properly collection of data. A total of 88 subjects were processed properly (43 women, 45 men, mean age $=35.33$ and $S D=10.50$ ) (for further details, please see Supplementary Materials). Outlier studies were performed by data source, dividing between VR, ET and GSR. Finally, 3 outliers were found for the data-source of ET, whereas any outlier was found for VR and GSR. The final dataset, without outliers, had in total 85 subjects (42 women, 43 men, mean age $=35.49$ and $\mathrm{SD}=10.64$ ).

The $93.33 \%$ of the target variables were normal distributed whereas, only one target variable, Thrill and adventure seeking, which represents the $6.67 \%$, was not. All the target variables present statistical differences between the high and low groups. Table 13 shows the statistical description of every subscale.

Table 13. Statistical description of each target variable

\begin{tabular}{|c|c|c|c|c|c|c|}
\hline Dimension & Target variable & Mean & ${ }^{1}$ Std & Median & $\begin{array}{c}\text { Number } \\
\text { of } \\
\text { Highs }\end{array}$ & $\begin{array}{l}\text { Number } \\
\text { of Lows }\end{array}$ \\
\hline
\end{tabular}


An Immersive Virtual Reality Game for Predicting Risk Taking through the Use of Implicit Measures

\begin{tabular}{|c|c|c|c|c|c|c|c|}
\hline \multirow{5}{*}{ Personality } & Neuroticism & 20.92 & 7.20 & 21 & 45 & 43 & $* * *$ \\
\hline & Extraversion & 32.64 & 7.32 & 32.5 & 44 & 44 & $* * *$ \\
\hline & Openness & 32.28 & 6.65 & 33 & 45 & 43 & $* * *$ \\
\hline & Agreeableness & 31.35 & 6.12 & 31.5 & 44 & 44 & $* * *$ \\
\hline & Conscientiousness & 32.60 & 7.57 & 33.5 & 49 & 39 & $* * *$ \\
\hline \multirow{5}{*}{$\begin{array}{l}\text { Sensation } \\
\text { seeking }\end{array}$} & $\begin{array}{c}\text { Thrill and } \\
\text { adventure seeking }\end{array}$ & 6.75 & 2.84 & 8 & 34 & 54 & $* * *$ \\
\hline & $\begin{array}{l}\text { Experience } \\
\text { seeking }\end{array}$ & 3.68 & 1.08 & 4 & 48 & 40 & $* * *$ \\
\hline & Disinhibition & 4.31 & 2.18 & 4 & 41 & 47 & $* * *$ \\
\hline & $\begin{array}{c}\text { Boredom } \\
\text { susceptibility }\end{array}$ & 3.89 & 1.87 & 4 & 51 & 37 & $* * *$ \\
\hline & $\begin{array}{l}\text { Sensation seeking } \\
\text { (overall score) }\end{array}$ & 18.63 & 5.59 & 19 & 47 & 41 & $* * *$ \\
\hline \multirow{5}{*}{ Impulsivity } & Negative urgency & 9.35 & 2.51 & 9 & 43 & 45 & $* * *$ \\
\hline & $\begin{array}{c}\text { Lack of } \\
\text { premeditation }\end{array}$ & 5.58 & 1.59 & 5.5 & 44 & 44 & $* * *$ \\
\hline & $\begin{array}{c}\text { Lack of } \\
\text { perseverance }\end{array}$ & 6.82 & 230 & 7 & 48 & 40 & $* * *$ \\
\hline & Sensation seeking & 10.32 & 2.69 & 11 & 45 & 43 & $* * *$ \\
\hline & Positive urgency & 9.98 & 2.08 & 10 & 52 & 36 & $* * *$ \\
\hline
\end{tabular}

1 Standard deviation. 2 Statistical significance of the feature between high and low groups: ${ }^{* * *}$ p-value $<0.001$

A total of 4 features were removed due to its no variation between subjects. 31 features $(20.53 \%)$ were correlated above 0.95 in Pearson coefficient. These variables were removed from the dataset. Moreover, 16 variables were transformed using logarithms. The final dataset ended-up with a total of 120 features were 42 belong to the VR, 60 to ET and 18 to GSR.

Table 14 presents the best models obtained by the ML pipeline, according with the dataset used, the balance of the sample, the significant level between the target variable and the generated random distribution of target variables and four different metrics such as accuracy, kappa, TPR and TNR.

Table 14. Results of the models obtained with highest accuracy for every target variable

\begin{tabular}{|c|c|c|c|c|c|c|c|}
\hline Dimension & Subscale & $\begin{array}{c}\text { Data } \\
\text { s. }\end{array}$ & $\begin{array}{l}{ }^{1} \text { St. } \\
\text { sig. }\end{array}$ & Accuracy & Kappa & ${ }^{2} \mathrm{TPR}$ & ${ }^{3}$ TNR \\
\hline \multirow{5}{*}{ Personality } & Neuroticism & ALL & * & $0.73(0.14)$ & $\begin{array}{c}0.45 \\
(0.29)\end{array}$ & $\begin{array}{c}0.74 \\
(0.14)\end{array}$ & $\begin{array}{c}0.72 \\
(0.24)\end{array}$ \\
\hline & Extraversion & ALL & ** & $0.75(0.15)$ & $\begin{array}{c}0.51 \\
(0.31)\end{array}$ & $\begin{array}{c}0.81 \\
(0.18)\end{array}$ & $\begin{array}{c}0.71 \\
(0.19)\end{array}$ \\
\hline & Openness & ET & $* * *$ & $0.71(0.16)$ & $\begin{array}{c}0.40 \\
(0.34)\end{array}$ & $\begin{array}{c}0.78 \\
(0.17)\end{array}$ & $\begin{array}{c}0.63 \\
(0.30)\end{array}$ \\
\hline & Agreeableness & ALL & - & $0.72(0.16)$ & $\begin{array}{c}0.43 \\
(0.32)\end{array}$ & $\begin{array}{c}0.82 \\
(0.17)\end{array}$ & $\begin{array}{c}0.6 \\
(0.21)\end{array}$ \\
\hline & Conscientiousness & ALL & - & $0.71(0.10)$ & $\begin{array}{c}0.38 \\
(0.21)\end{array}$ & $\begin{array}{c}0.83 \\
(0.12)\end{array}$ & $\begin{array}{c}0.54 \\
(0.27)\end{array}$ \\
\hline
\end{tabular}




\begin{tabular}{|c|c|c|c|c|c|c|c|}
\hline \multirow{5}{*}{$\begin{array}{l}\text { Sensation } \\
\text { seeking }\end{array}$} & $\begin{array}{c}\text { Thrill and } \\
\text { adventure seeking }\end{array}$ & ALL & * & $0.73(0.13)$ & $\begin{array}{c}0.40 \\
(0.27)\end{array}$ & $\begin{array}{c}0.94 \\
(0.13)\end{array}$ & $\begin{array}{c}0.43 \\
(0.19)\end{array}$ \\
\hline & $\begin{array}{l}\text { Experience } \\
\text { seeking }\end{array}$ & ALL & * & $0.73(0.19)$ & $\begin{array}{c}0.46 \\
(0.39)\end{array}$ & $\begin{array}{c}0.78 \\
(0.17)\end{array}$ & $\begin{array}{c}0.68 \\
(0.28)\end{array}$ \\
\hline & Disinhibition & ALL & * & $0.72(0.15)$ & $\begin{array}{c}0.43 \\
(0.31)\end{array}$ & $\begin{array}{c}0.58 \\
(0.32)\end{array}$ & $\begin{array}{c}0.86 \\
(0.13)\end{array}$ \\
\hline & $\begin{array}{c}\text { Boredom } \\
\text { susceptibility }\end{array}$ & VR & $* * *$ & $0.73(0.08)$ & $\begin{array}{c}0.31 \\
(0.24)\end{array}$ & $\begin{array}{c}0.30 \\
(0.25)\end{array}$ & $\begin{array}{c}0.98 \\
(0.05)\end{array}$ \\
\hline & $\begin{array}{l}\text { Sensation seeking } \\
\text { (overall score) }\end{array}$ & ALL & - & $0.67(0.14)$ & $\begin{array}{c}0.35 \\
(0.28)\end{array}$ & $\begin{array}{c}0.69 \\
(0.17)\end{array}$ & $\begin{array}{c}0.67 \\
(0.26)\end{array}$ \\
\hline \multirow{5}{*}{ Impulsivity } & Negative urgency & VR & $* * *$ & $0.78(0.14)$ & $\begin{array}{c}0.55 \\
(0.28)\end{array}$ & $\begin{array}{c}0.70 \\
(0.19)\end{array}$ & $\begin{array}{c}0.86 \\
(0.16)\end{array}$ \\
\hline & $\begin{array}{c}\text { Lack of } \\
\text { premeditation }\end{array}$ & ALL & $* *$ & $0.75(0.10)$ & $\begin{array}{c}0.50 \\
(0.20)\end{array}$ & $\begin{array}{c}0.72 \\
(0.25)\end{array}$ & $\begin{array}{c}0.79 \\
(0.21)\end{array}$ \\
\hline & $\begin{array}{c}\text { Lack of } \\
\text { perseverance }\end{array}$ & VR & - & $0.67(0.17)$ & $\begin{array}{c}0.33 \\
(0.32)\end{array}$ & $\begin{array}{c}0.68 \\
(0.29)\end{array}$ & $\begin{array}{c}0.65 \\
(0.23)\end{array}$ \\
\hline & Sensation seeking & ALL & - & $0.68(0.21)$ & $\begin{array}{c}0.36 \\
(0.42)\end{array}$ & $\begin{array}{c}0.68 \\
(0.26)\end{array}$ & $\begin{array}{c}0.67 \\
(0.25)\end{array}$ \\
\hline & Positive urgency & VR & $* *$ & $0.71(0.16)$ & $\begin{array}{c}0.34 \\
(0.37)\end{array}$ & $\begin{array}{c}0.92 \\
(0.10)\end{array}$ & $\begin{array}{c}0.41 \\
(0.31)\end{array}$ \\
\hline
\end{tabular}

$1{ }^{*} \mathrm{p}<0.05$, ${ }^{* *} \mathrm{p}<0.01$ and ${ }^{* * *} \mathrm{p}<0.001 ; 2$ true positive rate; 3 true negative rate

According with Table 14, neuroticism, extraversion, openness, thrill and adventure seeking, experience seeking, disinhibition, boredom susceptibility, negative urgency, lack of premeditation and positive urgency, have been well recognized since their accuracy shows statistical differences with random models. On the other hand, agreeableness, conscientiousness, sensation seeking (overall), lack of perseverance and sensation seeking have not been recognized over the chance level. The data source ALL appears $10(66.67 \%)$ times as the data source with highest accuracy, VR data source 4 $(26.67 \%)$ times and ET once $(6.67 \%)$. Table 15 summarizes the selected features for each model.

Table 15. Selected features for each classification model

\begin{tabular}{|c|c|c|c|c|c|c|c|}
\hline \multirow{2}{*}{ Dim. } & \multirow{2}{*}{$\begin{array}{l}\text { Subscale (n } \\
\text { features) }\end{array}$} & \multicolumn{3}{|c|}{ Risk zone } & \multicolumn{3}{|c|}{ No risk zone } \\
\hline & & VR & ET & GSR & VR & ET & GSR \\
\hline \multirow{3}{*}{ Pers. } & $\begin{array}{c}\text { Neuroticism } \\
(6)\end{array}$ & Time spent & $\begin{array}{l}\text { Visits to } \\
\text { keys } \\
\text { Visits to } \\
\text { green } \\
\text { spheres }\end{array}$ & - & $\begin{array}{c}\text { Total } \\
\text { interactions }\end{array}$ & $\begin{array}{l}\text { Fixation } \\
\text { duration } \\
\text { Visits to } \\
\text { purple } \\
\text { spheres }\end{array}$ & - \\
\hline & $\begin{array}{c}\text { Extraversion } \\
\text { (4) }\end{array}$ & $\begin{array}{l}\text { Green } \\
\text { spheres } \\
\text { caught }\end{array}$ & $\begin{array}{c}\text { Distance } \\
\text { in } \\
\text { saccades }\end{array}$ & - & - & $\begin{array}{l}\text { Fixation } \\
\text { duration } \\
\text { Velocity } \\
\text { of } \\
\text { saccades }\end{array}$ & - \\
\hline & Openness (5) & - & $\begin{array}{l}\text { Number } \\
\text { of } \\
\text { objects } \\
\text { seen } \\
\text { Angular } \\
\text { saccade } \\
\text { distance }\end{array}$ & - & - & $\begin{array}{l}\text { Distance } \\
\text { in } \\
\text { saccades }\end{array}$ & - \\
\hline
\end{tabular}


An Immersive Virtual Reality Game for Predicting Risk Taking through the Use of Implicit Measures

\begin{tabular}{|c|c|c|c|c|c|c|c|}
\hline & $\begin{array}{l}\text { Thrill and } \\
\text { adventure } \\
\text { seeking (5) }\end{array}$ & $\begin{array}{c}\text { Time spent } \\
\text { Green } \\
\text { spheres } \\
\text { caught } \\
\text { Visits to each } \\
\text { risk } \\
\text { Distance } \\
\text { covered }\end{array}$ & - & - & $\begin{array}{c}\text { Pause } \\
\text { button use }\end{array}$ & - & - \\
\hline \multirow{3}{*}{$\begin{array}{l}\text { Sens. } \\
\text { Seek. }\end{array}$} & $\begin{array}{l}\text { Experience } \\
\text { seeking (9) }\end{array}$ & Acceleration & $\begin{array}{c}\text { Fixation } \\
\text { duration } \\
\text { Visits to } \\
\text { keys }\end{array}$ & - & $\begin{array}{c}\text { Time spent } \\
\text { Purple } \\
\text { spheres } \\
\text { caught } \\
\text { Total } \\
\text { interactions }\end{array}$ & $\begin{array}{l}\text { Fixation } \\
\text { duration }\end{array}$ & $\begin{array}{c}\text { Number } \\
\text { of phasic } \\
\text { peaks } \\
\text { Phasic } \\
\text { value }\end{array}$ \\
\hline & $\begin{array}{c}\text { Disinhibition } \\
(11)\end{array}$ & $\begin{array}{l}\text { Velocity } \\
\text { Distance } \\
\text { covered }\end{array}$ & $\begin{array}{l}\text { Distance } \\
\text { in } \\
\text { saccades }\end{array}$ & $\begin{array}{c}\text { Skewness } \\
\text { of phasic } \\
\text { signal }\end{array}$ & $\begin{array}{l}\text { Purple } \\
\text { spheres } \\
\text { caught } \\
\text { Velocity }\end{array}$ & $\begin{array}{l}\text { Number } \\
\text { of } \\
\text { fixations } \\
\text { Velocity } \\
\text { in } \\
\text { saccades }\end{array}$ & $\begin{array}{c}\text { Number } \\
\text { of phasic } \\
\text { peaks } \\
\text { Phasic } \\
\text { value } \\
\text { Skewness } \\
\text { of phasic } \\
\text { signal }\end{array}$ \\
\hline & $\begin{array}{c}\text { Boredom } \\
\text { susceptibility } \\
\text { (11) }\end{array}$ & $\begin{array}{l}\text { Shield use } \\
\text { Total } \\
\text { interactions }\end{array}$ & $\begin{array}{l}\text { Fixation } \\
\text { duration } \\
\text { Distance } \\
\text { in } \\
\text { saccades }\end{array}$ & - & - & $\begin{array}{l}\text { Angular } \\
\text { saccade } \\
\text { distance } \\
\text { Velocity } \\
\text { and } \\
\text { distance } \\
\text { in } \\
\text { saccades }\end{array}$ & $\begin{array}{c}\text { Kurtosis } \\
\text { of phasic } \\
\text { signal } \\
\text { Phasic } \\
\text { value }\end{array}$ \\
\hline \multirow{3}{*}{ Imp. } & $\begin{array}{l}\text { Negative } \\
\text { urgency (4) }\end{array}$ & $\begin{array}{c}\text { Time spent } \\
\text { Pause button } \\
\text { use }\end{array}$ & - & - & $\begin{array}{c}\text { Total } \\
\text { interactions }\end{array}$ & - & - \\
\hline & $\begin{array}{c}\text { Lack of prem. } \\
\text { (5) }\end{array}$ & Velocity & $\begin{array}{l}\text { Velocity } \\
\text { of } \\
\text { saccades }\end{array}$ & - & $\begin{array}{l}\text { Purple } \\
\text { spheres } \\
\text { caught }\end{array}$ & $\begin{array}{l}\text { Visits to } \\
\text { green } \\
\text { spheres }\end{array}$ & $\begin{array}{l}\text { Phasic } \\
\text { value }\end{array}$ \\
\hline & $\begin{array}{c}\text { Positive } \\
\text { urgency (10) }\end{array}$ & $\begin{array}{c}\text { Time spent } \\
\text { Visits to each } \\
\text { risk } \\
\text { Shield use }\end{array}$ & - & - & $\begin{array}{l}\text { Time spent } \\
\text { Distance } \\
\text { covered } \\
\text { Pause } \\
\text { button use } \\
\text { Shield use }\end{array}$ & - & - \\
\hline
\end{tabular}

Regarding the presence questionnaire, the results for the ITC-SOPI were (mean, SD): spatial presence $3.79,0.53$; engagement 3.99, 0.5; ecological validity 3.26, 0.75; and negative effects $2.36,0.87$.

\section{Discussion}

In this article, we present the assessment on decision making in risk environments (AEMIN) tool, as a new interactive virtual environment for RT measurement. The main aim of this study is to discriminate participants with high versus low scores in the measures of personality, sensation seeking and impulsivity, through their behaviours and physiological responses during playing AEMIN. Applying ML methods to the dataset we explored: (a) if through these data it is possible to discriminate between RT 
domains, allowing to qualitatively determinate a general level of RT for each subject; and (b) which parameters better discriminate between the two populations in each variable.

The results are discussed by sections: (1) accuracy of the models to discriminate RT domains; (2) the influence of the features used in each model selected; (3) limitations and further studies; (4) conclusion.

\section{Accuracy of the Models to Discriminate RT Domains}

Personality Recognition

Regarding the final models on personality recognition, the dimensions of neuroticism, extraversion and openness to experience have been properly recognized. The validation set using 88 subjects achieved 72.6\% accuracy (kappa: 0.447 ), 75.4\% accuracy (kappa: 0.506 ) and $70.8 \%$ accuracy (kappa 0.402 ) respectively. The selected models for predicting agreeableness and conscientiousness have not overcome the chance level.

Interestingly, these results show that neuroticism, extraversion and openness to experience are the better predicted personality dimensions. On the first hand, neuroticism has been related to negative affect and sensitivity to punishment (Elliot and Trash, 2010), but its relationship with RT seems to be more complex and context-related. Therefore, although high levels of neuroticism may lead to risk aversion in most domains, as a way of avoiding guilt or anxiety about negative outcomes, the relation between neuroticism and RT seems to be inverse in the health domain (Nicholson et al., 2005), in which some studies identified a tendency to take risks to alleviate anxiety and other emotions in subjects with high neuroticism (Vollrath and Torgersen, 2002). On the other hand, high extraversion and openness to experience have been related to risk approach across domains, due to a generalized need for stimulation and cognitive risk seeking, acceptance of experimentation, tolerance of uncertainty, change and innovation (McCrae and Costa, 1997; Lauriola and Levin, 2001). In the light of these findings, we could conclude that suitably our tool brings out the personality dimensions most context-dependent and related to the approach to risk, and not so much those related to general risk avoidance.

Sensation Seeking Recognition

Regarding the final models on sensation seeking recognition, the dimensions of experience seeking, thrill and adventure seeking, boredom susceptibility and disinhibition were predicted with robust models. The validation set achieved $73.3 \%$ accuracy (kappa: 0.456), 72.6\% accuracy (kappa: 0.311), 72.1\% accuracy (kappa: 0.425) and $73.1 \%$ accuracy (kappa: 0.402), respectively. The selected model for predicting overall sensation seeking score seemed to be overfitted.

These results demonstrate that AEMIN is a suitable tool to measure sensation seeking. As mentioned in previous sections, there is a great consensus in the literature regarding the influence of each of the sensation seeking subdimensions on RT (Zuckerman, 1994; 
An Immersive Virtual Reality Game for Predicting Risk Taking through the Use of Implicit Measures

Donohew et al., 2000; Netter et al., 1996; Roberti, 2004; De Vries et al.,2009; Zuckerman, 2006), so we consider that AEMIN meets the expectations in this regard.

Impulsivity Recognition

Regarding the final models on impulsivity recognition, the dimensions of negative urgency, lack of premeditation and positive urgency were predicted with robust models. The validation set achieved 77.5\% accuracy (kappa: 0.553), 75.1\% accuracy (kappa: 0.5) and $70.8 \%$ accuracy (kappa: 0.341), respectively. The selected models for predicting lack of perseverance and sensation seeking seemed to be overfitted.

In this case, three of the five subdimensions of impulsivity were well predicted. Interestingly, negative and positive urgency, which are related to context-related behaviours - when facing negative/positive situations (Whiteside and Lynam, 2001) are included. This result suggests that with AEMIN we could identify RT behaviours in widely varying situations, encompassing negative and positive contexts.

\section{Influence of the Features Used in Each Model Selected}

Influence of VR Features

Regarding VR variables, the results show that navigation variables, which are related to the movements of the subject in the virtual environment, seem to be more meaningful in risky zones; while interaction variables, which are related to the interactions of the subjects with the different elements of the virtual environment (buttons and virtual elements), seem to be more relevant in no risk zones. Results of the presence questionnaires are similar, or even better, to those obtained in other works (De Leo et al., 2014; Piccione et al., 2019).

Starting with the navigation variables in risk zone, the results show that the time spent in risk zone has a strong influence on the prediction of variables of personality, impulsivity and sensation seeking. Longer time spent in a risk zone could mean either that the subject has passed through these areas slower, or that (s)he has passed through them a greater number of times. In any case, this may be related to the higher/lower susceptibility to punishment or to negative consequences. The neuroticism and negative urgency variables, in which time spent in risk zone appears as important predictor, are related to the sensitivity to punishment or to negative stimuli (Elliot and Trash, 2010; Whiteside and Lynam, 2001), so this would explain the relationship with the time spent in risk zone in our virtual environment. On the other hand, it also appears as important for the classification of the subjects in thrill and adventure seeking and positive urgency variables, together with the number of visits to each risk. In these cases, it is possible that subjects with greater interest in risky physical activities or with impulsive behaviours when facing situations perceived as positive decide to experiment and spend more time in these risk areas, to see what the consequences are.

The variable of distance covered in risk zone refers to the length of the subject's trajectory in the risk zones of the maze. This variable appears as important in the classification of 
the subjects in the variables of thrill and adventure seeking and disinhibition, both belonging to the dimension of sensation seeking. This variable was also measured in the previous version of AEMIN (De-Juan-Ripoll et al., 2020), and significant correlations were obtained with almost all sensation seeking subdimensions, so our results in both articles seem to be consistent. Covering a greater distance in AEMIN could be interpreted as a greater interest in exploring different areas of the maze, which could be related to the variables thrill and adventure seeking and disinhibition, since both of them are reflected in high engagement in activities that generate new sensations and in rulebreaking behaviours (Zuckerman, 1994).

Velocity and acceleration in risk zones appear as important variables in predicting lack of premeditation, experience seeking, and disinhibition. The action of quickly passing through the risk areas, without stopping to pick up spheres could have a double interpretation. On the one hand, it can be understood as an unpremeditated or risky action. Instead, it could also be interpreted as an intention to pass something bad as quickly as possible, avoiding the possible damage that could be caused by passing through a risk area.

As for the interaction variables in risk zones, the number of green spheres collected in risk zones helps to classify subjects into extraversion and thrill and adventure seeking subdimensions. Picking up spheres that are in risk areas can pose a risk, since the subject must pass through these areas without the protection of the shield to pick them up. Therefore, the decision to take a sphere that is in a risk zone may be related to excitement seeking - which is characterized by an interest for shinny colors and noisy environments (Costa and McCrae, 1992) - a common feature of the extraversion and thrill and adventure seeking dimensions (Aluja et al., 2003).

The use of the shield only influences in risk zones, to classify subjects in terms of boredom susceptibility. This result seems surprising, since it was expected that the use of the shield would be a somewhat more revealing variable in terms of the behaviours of the subjects, which would add richness to the predictive models of a greater number of variables. In the SSMT (De-Juan-Ripoll et al., 2020), the use of the shield was related to subdimensions of impulsivity and sensation seeking, for which similar results were expected in the predictive models of the present article. One possible reason could be that participants did not fully understand the mechanics of the shield and did not use it enough to reflect certain behavioural patterns. This will be considered as one of the limitations of this research, and we will work to improve the understanding of the shield element in enhanced versions of AEMIN.

The use of the pause button in risk situations appears as an important variable in the prediction of negative urgency. The use of the pause button in risky situations may reflect a strategy of psychological distancing from negative stimuli, while the non-use of this resource may be due to thoughtless reactions to risky situations. This could have a 
An Immersive Virtual Reality Game for Predicting Risk Taking through the Use of Implicit Measures

strong relationship with the negative urgency variable, defined as the tendency to show impulsive behaviours in negative situations (Whiteside et al., 2005).

Regarding the interaction variables in no risk zone, the number of purple spheres collected appears as significant to classify the subjects in high/low lack of premeditation, experience seeking and disinhibition. These purple spheres were included in the virtual environment as elements that generate uncertainty, so collecting these spheres is clearly a risky behaviour, which can be taken due to a lack of premeditation, or due to the voluntary search for new experiences or sensations.

The use of the pause button in no risk zone is meaningful for the prediction of thrill and adventure seeking. The use of this button in non-risk areas may be related to wanting to rest from the experience in general or to being curious to try it, and not so much to applying a specific coping technique in a specific moment of stress as occurs in the risk areas.

Total interactions with elements in no risk zones appears as an important variable for predicting neuroticism, negative urgency and experience seeking. A greater or lesser number of interactions with the elements of the virtual environment can be related to very different behaviours or decisions, since in the virtual environment there are very different elements, from the shield, to the spheres or the pause button. What the total interactions variable can be an indicator of, is perhaps a greater or lesser involvement of the subject within the virtual environment, as well as a better understanding of the mechanics of the game. On the other hand, it can also be related to anxious or impulsive behaviours, as well as the search for different experiences and the desire to explore the virtual environment.

\section{Influence of ET Features}

Our results show that ET variables have a strong influence in most of the classification models, so we could say that it is an important measure in combination with those variables of the VR dataset, both in risk zones and in no risk zones. The variables that provide the most relevant information to classify the subjects in terms of risk-related dimensions are: fixation duration, number of fixations in no risk zones, visits to keys, green spheres and purple spheres, angular saccade distance, velocity in saccades and distance in saccades.

As mentioned in previous sections, fixations duration could be an indicator of depth of processing (Al-Moteri et al., 2017), and a good predictor of perception (Krupinski et al., 1998) and risk aversion (Kwak et al., 2015). The fixations duration in risk zones appeared as a meaningful variable to classify subjects in boredom susceptibility. This result suggests that participants with high boredom susceptibility show different information processing patterns in risk zones than those with low boredom susceptibility, since these areas arouse a different interest in them, taking them out of the routine of the game. Conversely, fixations duration in no risk zones was an important variable in the 
classification models of neuroticism, extraversion and experience seeking. In these cases, a deeper processing of information in no risk areas can be interpreted as a state of alert, waiting for something bad to happen, or as a search for new or different elements in areas that apparently are simpler and show a smaller number of stimuli than risk zones.

Regarding the number of fixations and visits to concrete objects, these variables are an indicator of interest in concrete elements (Al-Moteri et al., 2017) and have been related to risk aversion, as a strategy to collect information in the analytical pre-decision process (Kwak et al., 2015; Su et al., 2013; Payne and Braunstein, 1978). Spheres and keys that open the doors are the most important elements when studying the number of fixations in AEMIN. The number of fixations in green spheres located in risk zones appears as an important variable in the classification of subjects regarding neuroticism, while the number of fixations in green spheres in no risk zones is related to lack of premeditation. On the other hand, the number of fixations on keys is a fundamental variable in the classification of the subjects in neuroticism and experience seeking. Finally, the number of fixations in purple spheres is important to classify as high or low neuroticism. In light of these results, we could understand that the elements that can be captured or collected during the game (green spheres, purple spheres and keys) are the most relevant when analyzing the number of fixations. On the other hand, other elements of the game that seem more visually striking and of greater interest within the game, such as risks, do not appear as meaningful variables from the point of view of the number of fixations. Interestingly, these results could help game designers to guide the user's attention to specific elements of the virtual environment, incorporating the interaction of "collecting", as a guarantee that visual patterns related to personality, impulsivity and sensation seeking will come to light.

Angular saccade distance and distance in saccades could discriminate global and focal visual search strategies (Al-Moteri et al., 2017; Kundel et al., 2007). These variables appear as relevant for classification in risk zones, for predicting extraversion, openness, boredom susceptibility and disinhibition. These variables are also meaningful for the classification in boredom susceptibility when the subject is in a no risk zone. These results could indicate that subjects' visual search patterns in risk zones can help to classify them in high or low extraversion, openness and disinhibition. On the other hand, to differentiate subjects with high or low boredom susceptibility, it is necessary to study their visual search strategy throughout the experience, both in risk areas and in no risk areas.

Finally, the velocity in saccades is an indicator, together with the number and duration of fixations, of an adaptive attention process, depending on the uncertainty or the perceived difficulty of each situation, so that slower saccades have been related to information acquisition processes in situations perceived as uncertain or difficult (Velichkovsky et al., 2002; Brunyé and Gardony, 2017; Heekeren et al., 2008). In our study, the velocity in saccades appears as an important variable in risk areas for classifying subjects in lack of premeditation, while it is meaningful in no risk areas for 
An Immersive Virtual Reality Game for Predicting Risk Taking through the Use of Implicit Measures

classifying subjects in extraversion, openness, boredom susceptibility and disinhibition. This result could be interpreted as follows: the velocity in saccades in no risk areas, as a behaviour dependent on the perception of difficulty or uncertainty of a situation, is an indicator of the subjects' interpretation of the no risk zones, based on their level of extraversion, openness, boredom susceptibility, and disinhibition. Thus, it is possible that some participants were in a high alert state while passing through these areas, since they identified them as of low certainty, while other subjects crossed these areas with the feeling of being in a safe place.

Influence of GSR Features

The variables obtained from GSR while the subject was in the no risk areas were relevant in the final models, while they were not relevant when the subject was in risk areas. All the GSR variables selected in the final models correspond to metrics of the phasic component of the signal, which is characterized by rapid and event-related changes, so it takes less time to show changes (Sharma et al., 2016). The GSR signal usually peaks between 2 and $10 \mathrm{~s}$ after stimulation and recovers at approximately the same rate (Sharma et al., 2016 ). Ayata et al. (2016) found that a 3-s time window in the phasic signal is the most optimal for the prediction of valence and arousal. Since the periods of time in which subjects usually remain in risk areas are short (between 1 and $8 \mathrm{~s}$ ) except in rooms, where they can spend more time, it is possible that changes in the phasic signal, which can be interpreted as a "warn" in risky situations (Bechara et al., 2005), are reflected few seconds after the subject has left the risk areas.

Another possible interpretation of these results is that changes in the phasic component are meaningful to differentiate subjects with high/low extraversion, boredom susceptibility and disinhibition based on their level of activation in the no risk zones. In this regard, decisions in no risk zones present less time pressure, and they are of the type: selection of paths or decision of whether to take spheres or not. Since time pressure has been raised as one of the influential factors in the relationship between GSR and RT (Persson et al., 2018), it is possible that, in these decisions in which there are no situational biases, decision-making is more guided by individuals' personality and temperamental factors than in risk zones.

\section{Limitations and Further Studies}

We acknowledge that this study presents some methodological limitations. First, the sample size was not large. Second, we built the high/low target variables basing on the mean or median results of the responses from this study, so it may not be extrapolated to the rest of the population. Third, it could be possible that participants did not fully understand the mechanics of the shield and did not use it enough to reflect certain behavioural patterns. For future investigations, we will recruit a larger sample of participants, we will look for validated reference scales to label the subjects and we will work to improve the understanding of the shield element in enhanced versions of AEMIN. 


\section{Conclusions}

Concerning the features that better predict each dimension, we could conclude that behavioural measures - interaction with the virtual environment and ET-provide the core information in the classification models. Therefore, the results support the use of AEMIN as an ecological assessment tool to measure RT, since it brings to light behaviours that allow to classify the subjects into high/low risk-related psychological constructs. Regarding physiological measures, GSR seems to be less salient in prediction models. 
An Immersive Virtual Reality Game for Predicting Risk Taking through the Use of Implicit Measures 


\section{Chapter 6. General discussion}

This research focuses on the study of the use of VR for the evaluation of decision-making processes in the face of risk. This chapter discusses the main results obtained, in terms of the specific objectives presented in Chapter 1. The discussion is divided into three sections: (SO1 and $\mathrm{SO} 2$ ) state of the art regarding the definition of $\mathrm{RT}$, existing measures and VR as an alternative tool; (SO3) design premises of virtual environments for the evaluation of the psychological constructs identified as determinants to define RT, and (SO4) VR in combination with physiological measures such an adequate tool for the evaluation of RT in an implicit way.

\section{RT definition and current measures}

People make decisions that carry a certain risk every day. Studying decision-making processes in situations that present risk can be of great interest, both for practitioners and researchers. Although the concept of RT has been studied from different points of view, there is no clear consensus in the literature when it comes to clearly defining its meaning, as well as those psychological dimensions that intervene in this decisionmaking process in the face of risk.

Consequently, the evaluation of RT continues to be a challenge for companies and researchers, who try to approach it from different perspectives, using mainly questionnaire measures and neuropsychological tasks. Instead, these measurement techniques present various limitations widely supported by the literature, both from a methodological point of view and their ability to evaluate implicit processes.

The results of this research aim to shed light on these questions, filling this gap with the identification of a series of psychological dimensions that influence RT, as well as presenting VR as an adequate tool for the development of alternative measures to the traditional ones in the scope of RT.

\section{Identification of the psychological components of RT}

In Chapter 4 we identify the main psychological dimensions that intervene in decisionmaking processes in risk situations. The results of this study provide a greater understanding of the concept of RT, identifying the factors compose that it. In addition, those factors that affect RT in a transversal way are identified, as well as those that influence RT differently depending on the type of decision. This study aimed to fill a gap in the literature and expand this line of research in order to better understand the RT process.

First, this study hypothesised that personality (1), sensation seeking (2), and impulsivity traits (3) act as proneness biases in RT, constituting a trend toward risk proneness or risk avoidance, regardless of the type of risk. 
(1) Regarding personality, we found that personality dimensions influence all domains of RT, except the recreational, partially supporting this hypothesis. Specifically, the openness and agreeableness subtraits appeared as the main ones when relating personality traits with RT in the domains studied. These results are consistent with those found in other studies (Josef et al., 2016; Nicholson et al., 2005; Soane et al., 2010).

(2) Regarding sensation seeking, we found significant influences of sensation seeking subtraits and all the RT domains studied, supporting the hypothesis of the study. Although all the sensation seeking dimensions appear to be relevant in their relation with RT, the disinhibition subtrait stands out, since it presents a highly significant relation with all the RT areas studied, acting as a cross-domain trait.

(3) Regarding impulsivity, we found that implsivity subtraits influence all the RT domains studied, supporting the hypothesis of the study. Specifically, lack of perseverance, positive urgency and sensation seeking appeared as significant predictors of RT in different domains, which is consistent with other works (Coskunpinar et al., 2013; Lozano et al., 2017; Gomà-i-Freixanet et al., 2012; Woodman et al., 2013).

Second, this study hypothesised that locus of control (4), emotion regulation (5), and executive control factors (6) act as perceptual biases in RT, influencing depending on the area or type of decision.

(4) Regarding locus of control, we did not find significant relations with RT, rejecting this hypothesis.

(5) Regarding emotion regulation, we found positive significant correlations between emotional suppression and financial RT, supporting the hypothesis of the study. The use of the emotional suppression strategy involves an additional effort, which can skew the perception of certain complex situations such as economic situations.

(6) Regarding executive control, we found that attentional control and set switching present a strong influence in ethical, financial and social RT, supporting the hypothesis of the study. Kim-Spoon et al. (2015) found that attentional control regulates negative affect, reducing the effects of anger and increasing the effects of fear. Therefore, executive control seems to constitute a perceptual bias that drives positive RT, and to risk avoidance in domains in which taking risks involves potential negative outcomes.

\section{Current measures of RT and VR as an alternative tool}

The measurement of RT is currently a challenge for researchers, and has been approached from different perspectives over the years. Questionnaires are the most traditionally used technique for RT measurement, in some cases used as a single measure, such as compliance with safety practices in the workplace (Mohamed et al., 2009), safety behaviours (Seo et al., 2015) or engagement in RT behaviours in daily life 
(Lejuez et al., 2003); and in others used in combination with other questionnaires that measure psychological constructs, such as personality (Lejuez et al., 2002; Parker et al., 2001; Skeel et al., 2007), impulsivity (Lejuez et al., 2002; Lejuez et al., 2003; Lozano et al., 2017) or sensation seeking (Horvath and Zuckerman, 1993, Lejuez et al., 2002, Lejuez et al., 2003; Lozano et al., 2017) . In contrast, questionnaires present some limitations at a methodological level, as well as in terms of their ability to evaluate implicit processes.

To overcome these limitations, the "stealth assessment" paradigm (Shute, 2011) emerged as a methodology focused on measuring a series of parameters while the subject performs a task or a game. Subsequently, conclusions are raised based on the results obtained. It is interesting that the subject does not know that (s)he is being evaluated, and therefore the results obtained are free from biases. Under this paradigm, we can find those measurement tools that use behavioural tasks for the evaluation of RT. In these tasks, the user is in a controlled laboratory environment and solves a task, generally in 2D format on a computer, although there are also original versions on paper-and-pencil format of some of them. The Bechara Gambling Task (Bechara et al., 1994), the Balloon Anallogue Risk Task (Lejuez et al., 2002), the Angling Risk Task (Pleskak, 2008), the Bomb Risk Elicitation Task (Crosetto and Filippin, 2013) and the CakeGambling Task (Van Leijenhorst et al., 2008) are the main behavioural tasks employed for RT measurement found in the literature. The fact that these behavioural tasks focus the measurement of RT on decisions of a financial nature, calls into question its validity in terms of the possibility of extrapolating these results to other areas of RT. Additionally, this approach is probably not capable of activating the implicit processes that are intended to measure, causing the correspondence between results in neuropsychological tests and real-life behaviours to be very weak (Manchester et al., 2004; Sbordone, 2008; Bottari et al., 2009).

In this sense, VR-based instruments have been proposed as an alternative to traditional instruments, which allows taking a further step in the evaluation of human behaviour, allowing to evaluate implicit processes in an ecological and unbiased way, thanks to the immersive capabilities of VR technology. In Chapter 2, we propose a VR-based alternative RT measurement method, which aims to advance in four specific aspects:

- Real-world risks. Thanks to VR, we are able to generate the sense of presence in the user (Slater, 2009), which evokes the perception of virtual experiences as if they were occurring in real life, activating similar neural mechanisms (Alcañiz et al., 2009). Risk situations can be dangerous and difficult to recreate in real life, so VR provides great advantages when simulating these types of situations allowing users to interact without real risk (Amokrane et al., 2008).

- Embodied cognition. This concept is defined as the study of how the use of our own body influences our capacity for perception, communication and learning. VR allows us to involve our body in certain actions carried out in the first person (Kilteni et al., 2012), which has been shown to lead us to make more emotional decisions (Greene et al., 2001; Amit et al., 2014). 
- Stealth assessment. This method allows to assess behaviours and reactions related to specific capabilities, providing evaluations in real time (Mislevy et al., 2003) and reducing anxiety in the users, while maintaining validity and reliability (Shute et al., 2008). Embedding assessments in immersive virtual environments is an innovative approach (Shute and Spector, 2008) that, in our view, is an improvement from the standpoint of ecological validity.

- Physiological real-time measurement. Several physiological measures have been proposed as implicit measures of human behaviour (Kivikangas et al., 2011). VR provides the possibility of combining the exposure to interactive virtual experiences and the physiological measurement during the experience.

The improvement regarding these four aspects leads us to conclude that VR constitutes a tool with great potential for measuring RT, thanks to its ability to generate risk situations perceived as realistic, which allow embodied interactions. In addition, these virtual experiences can be raised under the stealth assessment paradigm, allowing the physiological measurement of the user during the experience.

\section{Design premises of virtual environments for $R T$ assessment}

Once the psychological dimensions that constitute RT have been identified, and the approach to the use of VR as a tool for its evaluation has been raised, this section contains the conclusions obtained in terms of basic guidelines for the design of a virtual environment for the evaluation of RT. These premises are raised from the perspective of the design of two virtual environments (one initial -SSMT - and the other as an extension - AEMIN -) with a maze format, and with the characteristics defined in Chapters 3 and 5 respectively.

As a summary, both the SSMT and AEMIN represent an out-of-context maze, from which the participants must exit before time expires. Along the route, participants may encounter a series of risks that can cause them to lose energy. To maintain a good energy level, there are a series of green spheres distributed throughout the maze, which participants can take if they wish. In addition, in both mazes users can activate a shield, as a protective element against risks. The main improvements that AEMIN incorporates compared to the SSMT are: aesthetic improvement of the experience (specifically the representation of risks for greater realism), longer duration, inclusion of avatars in part of the route, presence of purple spheres with unexpected effect for participants, option to pause the game as an additional metric as well as an improvement of the tutorial at the beginning of the game.

Those interactions or characteristics of the virtual environments that brought to light behaviours that helped to predict some of the psychological constructs related to RT are proposed as guidelines. These guidelines can help improving the predictive capabilities of the system developed in this research, developing new versions of the virtual environment presented, but maintaining those characteristics that gave good results in 
this work. It should be noted that in the present investigation, efforts have been focused on the use of VR environments to measure the variables identified as proneness biases of RT. This is because, due to the large number of variables to predict, it has been chosen to obtain a smaller number of predictive models, but more optimized. Therefore, the psychological dimensions identified as influencing RT in a transversal manner, regardless of the type of risk, - personality, sensation seeking and impulsivity - have been selected. In future research, studies on the predictive capabilities of the system developed in the field of perceptual biases of RT will be proposed.

In the following lines, the main conclusions obtained regarding the characteristics of the virtual environment developed that have been shown to be essential for the prediction of the dimensions of personality, sensation seeking and impulsivity, identified as proneness biases of RT, are raised. To facilitate the interpretation of the results, the VR predictive variables have been classified into navigation variables and interaction variables. Navigation variables are related to the movements of the subject in the virtual environment, while interaction variables are related to the interactions of the subjects with the different elements of the virtual environment (buttons and virtual elements).

- Navigation variables. The variables that constitute this block refer to those related to the user's movements within the virtual environment, and are mainly: the time spent, the visits to risks, the distance covered, the speed and the acceleration of the displacements. These variables are of special interest when the user is in risk areas within the maze, since decisions in these areas can lead to more prominent negative consequences than in no risk areas. Therefore, it is convenient to measure the variables related to user navigation in risk and no risk areas independently. Regarding the type of risk, four risk typologies were proposed, with different visual characteristics and consequences in the game. No significant differences were observed in terms of the predictive capacity of the navigation variables between the different risks. This may be because all risks were interpreted in a similar way by the users, or because the four risk typologies form a complete set, which must be interpreted holistically. Navigation variables in risk areas can have a double interpretation. On the one hand, showing a navigation pattern marked by numerous visits to risks, a long distance covered and high speed and acceleration, can be understood as a risky behaviour, due to a generalized propensity towards risk. Instead, these behaviours can also be due to a high degree of disorientation and/or frustration of the user because of the time pressure to fulfil the goal of the game. For this reason, it is of great importance to accompany these behavioural measures by physiological measures that help to correctly interpret these navigation patterns of users.

- Interaction variables. The most influential variables in the predictive models within this block refer to the number of user interactions with the green spheres, the purple spheres, the shield and the pause button mainly. The decision to use or not use each of these elements within the game raised potential positive and 
negative outcomes. At this point, it is worth highlighting the importance of these consequences being compensated, so as not to favour the use or non-use of any of the elements. In the case of the virtual environments developed in this study, it was observed that the use of the shield was less decisive in the predictive models than expected. This result seems surprising, since it was expected that the use of the shield would be a somewhat more revealing variable in terms of the behaviours of the subjects, which would add richness to the predictive models of a greater number of variables. One possible reason could be that participants did not fully understand the mechanics of the shield and did not use it enough to reflect certain behavioural patterns. On the other hand, the type of interaction with each of the virtual elements is of great importance. In the virtual environments developed, two main types of interaction were used: by collision of the control with the virtual element in the case of the spheres, and by pressing the buttons of the control in the cases of pause and use of the shield. In this sense, users seemed comfortable when carrying out these interactions, which suggests that the result of these kind of interactions is favourable.

At a general level, it is worth highlighting the importance of the practice session prior to the experience. In the case of the SSMT, during this practice session the user tested the metaphor navigation, the use of the shield and the interaction with the spheres. The moment in which (s)he was ready to start the game was left to his/her own decision. The results showed that this tutorial format was insufficient, since some users overestimated their learning capacity and this was reflected in errant and inaccurate behaviours within the virtual environment. In the case of AEMIN, a more complete and guided practice session was developed, lasting about 15 minutes, to consolidate the learning results and ensure that the user began the experience with the necessary knowledge.

\section{VR stimulation and behavioural and physiological measures for RT assessment}

The SSMT and AEMIN virtual environments were designed to evaluate RT in combination with implicit measures, which allow evaluating psychological attributes of users during the experience without the need for them to self-evaluate (Gawronski and De Houwer, 2014). In the study presented in Chapter 5, eye tracking and GSR measurements were included. These measures have been widely studied in the literature, and have appeared as reliable predictors of implicitly evaluated psychological traits and states such as attentional processes and information processing in the case of eye tracking (Carter and Luke, 2020; Glöckner and Herbold, 2010); and emotional activation in the case of GSR (Nourbakhsh et al., 2013).

To the best of our knowledge, this is the first study that validates a tool to assess RT using a decontextualized approach, transversal to different domains and types of risk 
decision, using VR tools and eye tracking and GSR measures. Some studies have used VR for the evaluation of RT simulating specific contexts (Isleyen and Duzgun, 2019; Asghar et al., 2019), but no studies have been found that use VR for the evaluation of the psychological processes involved in risk decision making. Regarding the use of eye tracking and GSR measures for the evaluation of RT, although these have been used independently to analyze information processing patterns in risky decisions (Kwak et al., 2015; Su et al., 2013; Payne and Braunstein, 1978; Velichkovsky et al., 2002; Habibnezhad et al., 2016) and physiological activation in risky situations (Bechara et al., 2005), no studies have been found that use these measures in combination with VR for RT assessment.

In particular, eye tracking and GSR, together with the behavioural measures of navigation and interaction with the virtual environment described in the previous section, have proven to be good predictors of the psychological dimensions identified as explanatory of risk proneness: personality, sensation seeking and impulsivity. The models achieved $70.8 \%$ to $75.4 \%$ accuracy along the personality dimensions (except for the agreeableness and conscientiousness subdimensions, which did not overcome the chance level), $72.1 \%$ to $73.3 \%$ accuracy along the sensation seeking dimensions and $70.8 \%$ to $77.5 \%$ accuracy along the impulsivity dimensions (except for the sensation seeking subdimension, which did not overcome the chance level). These results suggest that the approach used in this research constitutes a good starting point regarding the use of VR together with eye tracking and GSR measures for the evaluation of RT from a holistic and decontextualized perspective, which aims to open the way towards the understanding of human behaviour in risk situations of different natures. 
General discussion 


\section{Chapter 7. Conclusions and future research}

RT is fundamental to the decision-making process and of interest to both psychologists and security agencies. Investigating why people take risks in certain situations and avoid risks in others is a complex field of research. In the present study we proposed an approach in which risk proneness and risk perception affect RT behaviours. First, risk proneness is seen as a general attitude towards any type of risk, so its influence is transversal. Second, risk perception is understood as a distortion of perception that can influence RT differently depending on the domain. The results of this study form a foundation on which this research area can be built and contribute to a better understanding of human behaviour in risk situations.

The evaluation of RT is currently at a turning point, since, although it is still a challenge for both researchers and companies, technological advances as well as research in the field of organizational neuroscience are opening the way to a new generation of tools thanks to which it is possible to generate virtual worlds in which to evaluate user responses in an ecological, non-intrusive way and with reliable results. In this research, we propose VR as an alternative with great potential for evaluating the dimensions that make up RT, thanks to its innumerable advantages in terms of immersion and its compatibility with the use of implicit measurements. Specifically, we present the SSMT as a first virtual environment developed in order to evaluate, through the behaviours and physiological reactions of the subjects, the propensity towards risk. The results of this study suggest that VR, and specifically the design and characteristics of the SSMT, constitute a good starting point for evaluating RT in a decontextualized way that can be extrapolated to different real-life situations. Next, we present AEMIN as an improved version of the SSMT for assessing risk proneness. The results of this study support that AEMIN is an adequate tool for the evaluation of RT, since it evokes behaviours and reactions that allow users to be classified into high / low profiles in terms of the variables that make up risk proneness.

This research has some limitations from the methodological point of view. First, the sample of participants may be insufficient. Furthermore, in the case of the SSMT validation study, the sample is made up of university students. For future research, we will consider increasing the sample to enhance the statistical power of the analyzes, also using participants who face risks in their real life, in order to validate the instruments with the target population. Second, a single reference measure (the DOSPERT-30 scale) has been used to study which are the dimensions that make up the RT and their relation with the different domains. As discussed in Chapter 4, this measure is likely not to cover all risk situations present in real life. Future studies will consider the use of additional measures such as the Balloon Analogue Risk Task (BART; Lejuez et al., 2002), or the Bechara Gambling Task (Bechara et al., 1994), as well as self-reported measures of risk habits as has been done in other studies (Lejuez et al., 2003), in order to further analyze the relation of each of the proposed variables with RT. Third, user responses to AEMIN 
suggest that some of the interactions or rules of the game were not fully understood by all users, probably because the practice session and the instructions provided were not entirely adequate. In future research we will improve this practice session in order to guarantee a full understanding of the game mechanics and thus obtain more reliable results free from external biases.

In accordance with the limitations, further research is needed to achieve a better definition of the concept of RT, using different gold standard measures that allow us to disaggregate more precisely the decision-making process in the face of risk from a psychological perspective. Additionally, more in-depth studies are required about the predictive capabilities of AEMIN in the field of risk proneness, applying the necessary improvements based on the conclusions obtained in the present investigation, as well as optimizing the ML models used. Finally, studies will be carried out to evaluate the predictive capabilities of AEMIN in the perceptual biases of RT, so that it is possible to achieve a system capable of evaluating RT in an ecological way, both from a crosssituational point of view and from a perspective focused on specific areas of real life. 


\section{Research activities}

\section{Associated projects}

ATHENEA: Advanced THErapeutical tools for meNtal hEAlth (DPI2016-77396-R). Ministerio de Economía, Industria y Competitividad (Madrid, Spain).

Contrato predoctoral FPI (BES-2017-079857). Ministerio de Economía, Industria y Competitividad (Madrid, Spain).

\section{Journal papers}

de-Juan-Ripoll, C., Soler-Domínguez, J. L., Guixeres, J., Contero, M., Álvarez Gutiérrez, N., \& Alcañiz, M. (2018). Virtual reality as a new approach for risk taking assessment. Frontiers in psychology, 9, 2532.

de-Juan-Ripoll, C., Soler-Domínguez, J. L., Chicchi Giglioli, I. A., Contero, M., \& Alcañiz, M. (2020). The spheres \& shield maze task: a virtual reality serious game for the assessment of risk taking in decision making. Cyberpsychology, Behaviour, and Social Networking, 23(11), 773-781.

de-Juan-Ripoll, C., Chicchi Giglioli, I. A., Llanes Jurado, J., Marín-Morales, J., \& Alcañiz, M. (2021). Why do we take risks? Perception of the situation and risk proneness predict domain-specific risk taking. Frontiers in Psychology, 12, 655.

de-Juan-Ripoll, C.; Llanes-Jurado, J.; Giglioli, I.A.C.; Marín-Morales, J.; Alcañiz, M. An Immersive Virtual Reality Game for Predicting Risk Taking through the Use of Implicit Measures. Appl. Sci. 2021, 11, 825.

\section{Conference papers}

Giglioli, I. C., de Juan Ripoll, C., Llorens, R., \& Raya, M. A. (2018). Feasibility of serious games for assessing attentional abilities in people with different educational level. Age, 39(8.75), 25-55.

Parra, E., de Juan Ripoll, C., Raya, M. A., \& Giglioli, I. A. C. (2018, November). Individuals' Variables in Cognitive Abilities Using a Narrative Serious Game. In Joint International Conference on Serious Games (pp. 109-119). Springer, Cham. 
Research activities 


\section{References}

Abrams, R. A., Meyer, D. E., \& Kornblum, S. (1989). Speed and accuracy of saccadic eye movements: characteristics of impulse variability in the oculomotor system. Journal of Experimental Psychology: Human Perception and Performance, 15(3), 529. Doi: 10.1037/0096-1523.15.3.529

Ahmed, S. U. (1985). nAch, risk-taking propensity, locus of control and entrepreneurship. Personality and Individual differences, 6(6), 781-782. Doi: 10.1016/0191-8869(85)90092-3

Alcañiz M, Baños R, Botella C, Rey B. The EMMA project: emotions as a determinant of presence. PsychNology Journal 2003; 1(2), 141-150.

Alcañiz Raya, M., Chicchi Giglioli, I. A., Marín-Morales, J., Higuera-Trujillo, J. L., Olmos, E., Minissi, M. E., ... \& Abad, L. (2020). Application of Supervised Machine Learning for Behavioural Biomarkers of Autism Spectrum Disorder Based on Electrodermal Activity and Virtual Reality. Frontiers in Human Neuroscience, 14, 90. Doi: 10.3389/fnhum.2020.00090

Alcañiz, M., Lozano, J. A., and Rey, B. (2003). Technological background of VR. Stud. Health Technol. Inform. 99, 199-214.

Alcañiz, M., Rey, B., Tembl, J., and Parkhutik, V. (2009). A neuroscience approach to virtual reality experience using transcranial doppler monitoring. Presence Tel. Virtual Environ. 18, 97-111. Doi: 10.1162/pres.18.2.97

Al-Moteri, M. O., Symmons, M., Plummer, V., \& Cooper, S. (2017). Eye tracking to investigate cue processing in medical decision-making: A scoping review. Computers in Human Behaviour, 66, 52-66. Doi: 10.1016/j.chb.2016.09.022

Aluja, A., Garcia, O., \& Garcia, L. F. (2003). Relationships among extraversion, openness to experience, and sensation seeking. Personality and Individual Differences, 35(3), 671-680. Doi: 10.1016/S0191-8869(02)00244-1

Ames, S. L., Zogg, J. B., \& Stacy, A. W. (2002). Implicit cognition, sensation seeking, marijuana use and driving behaviour among drug offenders. Personality and Individual Differences, 33(7), 1055-1072. Doi: 10.1016/S0191-8869(01)00212-4

Amit, E., Gottlieb, S., and Greene, J. D. (2014). "Visual versus verbal thinking and dualprocess moral cognition," in Dual-Process Theories of the Social Mind, eds J. W. Sherman, B. Gawronski and Y. Trope (New York, FL: Guilford Press), 340-354.

Amokrane, K., Lourdeaux, D., and Burkhardt, J. M. (2008). HERA: learner tracking in a virtual environment. IJVR 7, 23-30.

Appelt, K. C., Milch, K. F., Handgraaf, M. J., \& Weber, E. U. (2011). The decision making individual differences inventory and guidelines for the study of individual 
differences in judgment and decision-making research. Judgment and Decision making.

Arkes, H. R., Herren, L. T., \& Isen, A. M. (1988). The role of potential loss in the influence of affect on risk-taking behaviour. Organizational behaviour and human decision processes, 42(2), 181-193. Doi: 10.1016/0749-5978(88)90011-8

Asghar, I., Egaji, O. A., Dando, L., Griffiths, M., \& Jenkins, P. (2019, August). A virtual reality based gas assessment application for training gas engineers. In Proceedings of the 9th International Conference on Information Communication and Management (pp. 57-61). Doi: 10.1145/3357419.3357443

Ayata, D., Yaslan, Y., \& Kamaşak, M. (2016, October). Emotion recognition via random forest and galvanic skin response: Comparison of time based feature sets, window sizes and wavelet approaches. In 2016 Medical Technologies National Congress (TIPTEKNO) (pp. 1-4). IEEE. Doi: 10.1109/TIPTEKNO.2016.7863130

Baird, I. S., and Thomas, H. (1985). Toward a contingency model of strategic risk taking. Acad. Manag. Rev. 10, 230-243. Doi: 10.5465/amr.1985.4278108

Bancroft, J., Janssen, E., Strong, D., Carnes, L., Vukadinovic, Z., \& Long, J. S. (2003). Sexual risk-taking in gay men: The relevance of sexual arousability, mood, and sensation seeking. Archives of sexual behaviour, 32(6), 555-572. Doi: 10.1023/A:1026041628364

Barratt ES. Impulsiveness subtraits: Arousal and information processing. J.T. Spence \& C.E. Izard (Eds.): Motivation, Emotion and Personality 1985; 137-145.

Barry D, Petry NM. Predictors of decision-making on the Iowa Gambling Task: Independent effects of lifetime history of substance use disorders and performance on the Trail Making Test. Brain and cognition 2008; 66(3), 243-252. Doi: 10.1016/j.bandc.2007.09.001

Barsade, S. G., Ramarajan, L., and Westen, D. (2009). Implicit affect in organizations. Res. Organ. Behav. 29, 135-162. Doi: 10.1016/j.riob.2009.06.008

Bechara A, Damasio AR, Damasio H, Anderson SW. Insensitivity to future consequences following damage to human prefrontal cortex. Cognition 1994; 50(1-3), 7-15.

Bechara A, Damasio H, Tranel D, Damasio AR. The Iowa Gambling Task and the somatic marker hypothesis: some questions and answers. Trends in Cognitive Sciences 2005; 9(4), 159-162. Doi: 10.1016/j.tics.2005.02.002

Becker, W. J., Cropanzano, R., and Sanfey, A. G. (2011). Organizational neuroscience: taking organizational theory inside the neural black box. J. Manag. 37, 933-961. Doi: $10.1177 / 0149206311398955$ 
Benedek, M.; Kaernbach, C. A continuous measure of phasic electrodermal activity. J. Neurosci. Methods 2010, 190, 80-91. Doi: 10.1016/j.jneumeth.2010.04.028

Blair, M. A., Moyett, A., Bato, A. A., DeRosse, P., \& Karlsgodt, K. H. (2018). The role of executive function in adolescent adaptive risk-taking on the balloon analogue risk task. Developmental neuropsychology, 43(7), 566-580. Doi: 10.1080/87565641.2018.1510500

Blais, A. R., \& Weber, E. U. (2006). A domain-specific risk-taking (DOSPERT) scale for adult populations. Judgment and Decision making, 1(1).

Blanco, C., Potenza, M. N., Kim, S. W., Ibáñez, A., Zaninelli, R., Saiz-Ruiz, J., \& Grant, J. E. (2009). A pilot study of impulsivity and compulsivity in pathological gambling. Psychiatry Research, 167(1-2), 161-168. Doi: 10.1016/j.psychres.2008.04.023

Bohil, C. J., Alicea, B., and Biocca, F. A. (2011). Virtual reality in neuroscience research and therapy. Nat. Rev. Neurosci. 12, 752-762. Doi: 10.1038/nrn3122

Bornovalova, M. A., Cashman-Rolls, A., O’ donnell, J. M., Ettinger, K., Richards, J. B., and Lejuez, C. W. (2009). Risk taking differences on a behavioural task as a function of potential reward/loss magnitude and individual differences in impulsivity and sensation seeking. Pharmacol. Biochem. Behav. 93, 258-262. Doi: 10.1016/j.pbb.2008.10.023

Bottari, C., Dassa, C., Rainville, C., and Dutil, E. (2009). The factorial validity and internal consistency of the instrumental activities of daily living profile in individuals with a traumatic brain injury. Neuropsychol. Rehabil. 19, 177-207. Doi: 10.1080/09602010802188435

Boyer, T. W. (2006). The development of risk-taking: a multi-perspective review. Dev. Rev. 26, 291-345. Doi: 10.1016/j.dr.2006.05.002

Brand, M., Recknor, E. C., Grabenhorst, F., \& Bechara, A. (2007). Decisions under ambiguity and decisions under risk: Correlations with executive functions and comparisons of two different gambling tasks with implicit and explicit rules. Journal of Clinical and Experimental Neuropsychology, 29(1), 86-99. Doi: $10.1080 / 13803390500507196$

Brief, A. P. (1998). Attitudes in and Around Organizations. Thousand Oaks, CA: Sage.

Brittain, J., \& Sitkin, S. B. (1990). Facts, figures, and organizational decisions: Carter racing and quantitative analysis in the organizational behaviour classroom. Organizational Behaviour Teaching Review, 14(1), 62-81. Doi: 10.1177/105256298901400108?journalCode=jmec

Brockhaus, Sr. (1980). Risk taking propensity of entrepreneurs. Acad. Manag. J. 23, 509520. 
Brunyé, T. T., \& Gardony, A. L. (2017). Eye tracking measures of uncertainty during perceptual decision making. International Journal of Psychophysiology, 120, 6068. Doi: $10.1016 /$ j.ijpsycho.2017.07.008

Buelow, M. T., \& Suhr, J. A. (2009). Construct validity of the Iowa gambling task. Neuropsychology review, 19(1), 102-114. Doi: 10.1007/s11065-009-9083-4

Burr, D. C., Morrone, M. C., \& Ross, J. (1994). Selective suppression of the magnocellular visual pathway during saccadic eye movements. Nature, 371(6497), 511-513.

Businelle MS, Apperson MR, Kendzor DE, Terlecki MA, Copeland AL. The relative impact of nicotine dependence, other substance dependence, and gender on Bechara Gambling Task performance. Experimental and clinical psychopharmacology 2008; 16(6), 513. Doi: 10.1037/a0013510

Byrnes, J. P., Miller, D. C., and Schafer, W. D. (1999). Gender differences in risk taking: a meta-analysis. Psychol. Bull. 125:367. Doi: 10.1037/0033-2909.125.3.367

Cabello, R., Salguero, J. M., Fernández-Berrocal, P., \& Gross, J. J. (2013). A Spanish adaptation of the emotion regulation questionnaire. European Journal of Psychological Assessment. Doi: 10.1027/1015-5759/a000150

Cándido, A., Orduña, E., Perales, J. C., Verdejo-García, A., \& Billieux, J. (2012). Validation of a short Spanish version of the UPPS-P impulsive behaviour scale. Trastornos adictivos, 14(3), 73-78. Doi: 10.1016/S1575-0973(12)70048-X

Carter, B. T., \& Luke, S. G. (2020). Best practices in eye tracking research. International Journal of Psychophysiology, 155, 49-62. Doi: 10.1016/j.ijpsycho.2020.05.010

Cavalcanti, J., and Soares, M. (2012). Ergonomic analysis of safety signs: a focus of informational and cultural ergonomics. Work 41(Suppl. 1), 3427-3432. Doi: 10.3233/WOR-2012-0619-3427

Chicchi Giglioli IA, de Juan Ripoll C, Parra E, Alcañiz Raya M. Are 3D virtual environments better than 2D interfaces in serious games performance? An explorative study for the assessment of executive functions. Applied Neuropsychology: Adult 2019; 1-10. Doi: 10.1080/23279095.2019.1607735

Chittaro L, Ranon R. Serious games for training occupants of a building in personal fire safety skills. In Games and Virtual Worlds for Serious Applications 2009; VSGAMES'09. Conference in (pp. 76-83). IEEE. Doi: 10.1109/VS-GAMES.2009.8

Colquitt, J. A., Scott, B. A., and LePine, J. A. (2007). Trust, trustworthiness, and trust propensity: a meta-analytic test of their unique relationships with risk taking and job performance. J. Appl. Psychol. 92, 909-927. Doi: 10.1037/0021-9010.92.4.909 
Cooper, M. L., Agocha, V. B., and Sheldon, M. S. (2000). A motivational perspective on risky behaviours: the role of personality and affect regulatory processes. J. Pers. 68, 1059-1088. Doi: 10.1111/1467-6494.00126

Cordero, A., Pamos, A., \& Seisdedos, N. (1999). Inventario de Personalidad Neo Revisado (NEO PI-R). Inventario Neo Reducido de Cinco Factores (NEO-FFI). Adaptación española. Madrid, España: TEA.

Coskunpinar, A., Dir, A. L., \& Cyders, M. A. (2013). Multidimensionality in impulsivity and alcohol use: A meta-analysis using the UPPS model of impulsivity. Alcoholism: Clinical and Experimental Research, 37(9), 1441-1450. Doi: 10.1111/acer.12131

Costa, P. T., \& McCrae, R. R. (1989). NEO PI/FFI manual supplement for use with the NEO Personality Inventory and the NEO Five-Factor Inventory. Psychological Assessment Resources.

Costa, P.T.; McCrae, R.R. NEO-PI-R. Professional manual. In Psychological Assessment Resourses; PAR Inc.: Odessa, FL, USA, 1992.

Crisp, B. R., \& Barber, J. G. (1995). The effect of locus of control on the association between risk perception and sexual risk-taking. Personality and individual differences, 19(6), 841-845. Doi: 10.1016/S0191-8869(95)00117-4

Crosetto, P., \& Filippin, A. (2013). The "bomb" risk elicitation task. Journal of Risk and Uncertainty, 47(1), 31-65. Doi: 10.1007/s11166-013-9170-z

Dahlen ER, Martin RC, Ragan K, Kuhlman MM. Driving anger, sensation seeking, impulsiveness, and boredom proneness in the prediction of unsafe driving. Accident Analysis and Prevention 2005; 37(2), 341-348. Doi: 10.1016/j.aap.2004.10.006

Dalgarno B, Lee MJ. What are the learning affordances of 3-D virtual environments?. British Journal of Educational Technology 2010; 41(1), 10-32. Doi: 10.1111/j.14678535.2009.01038.x

de-Juan-Ripoll C, Soler-Domínguez J, Guixeres J, Contero M, Álvarez Gutiérrez N, Alcañiz M. Virtual reality as a new approach for risk taking assessment. Frontiers in Psychology 2018; 9(2532), 1-8. Doi: 10.3389/fpsyg.2018.02532

De Leo, G., Diggs, L. A., Radici, E., \& Mastaglio, T. W. (2014). Measuring sense of presence and user characteristics to predict effective training in an online simulated virtual environment. Simulation in Healthcare, 9(1), 1-6. Doi: 10.1097/SIH.0b013e3182a99dd9

Del Missier, F., Mäntylä, T., \& Bruine de Bruin, W. (2010). Executive functions in decision making: An individual differences approach. Thinking \& Reasoning, 16(2), 69-97. Doi: $10.1080 / 13546781003630117$ 
De Vries, R. E., de Vries, A., \& Feij, J. A. (2009). Sensation seeking, risk-taking, and the HEXACO model of personality. Personality and Individual Differences, 47(6), 536-540. Doi: 10.1016/j.paid.2009.05.029

de Wit, H. (2009). Impulsivity as a determinant and consequence of drug use: a review of underlying processes. Addict. Biol. 14, 22-31. Doi: 10.1111/j.13691600.2008.00129

Diamond, A. (2013). Executive functions. Annual review of psychology, 64, 135-168. Doi: 10.1146/annurev-psych-113011-143750

Doak, J. (1992). An evaluation of feature selection methods and their application to computer security. Techninal Report CSE-92-18

Dohmen, T., Falk, A., Huffman, D., Sunde, U., Schupp, J., and Wagner, G. G. (2011). Individual risk attitudes: measurement, determinants, and behavioural consequences. J. Eur. Econ. Assoc. 9, 522-550. Doi: 10.1111/j.15424774.2011.01015

Donohew, R. L., Hoyle, R. H., Clayton, R. R., Skinner, W. F., Colon, S. E., and Rice, R. E. (1999). Sensation seeking and drug use by adolescents and their friends: models for marijuana and alcohol. J. Stud. Alcohol. 60, 622-631. Doi: $10.15288 /$ jsa.1999.60.622

Donohew L, Zimmerman R, Cupp PS, Novak S, Colon S, Abell R. Sensation seeking, impulsive decision-making, and risky sex: Implications for risk-taking and design of interventions. Personality and Individual Differences 2000; 28(6), 10791091. Doi: 10.1016/S0191-8869(99)00158-0

Dror, I. E., Basola, B., \& Busemeyer, J. R. (1999). Decision making under time pressure: An independent test of sequential sampling models. Memory \& cognition, 27(4), 713-725. Doi: 10.3758/BF03211564

Duell, N., \& Steinberg, L. (2019). Positive risk taking in adolescence. Child development perspectives, 13(1), 48-52. Doi: 10.1111/cdep.12310

Durantin, G., Gagnon, J. F., Tremblay, S., and Dehais, F. (2014). Using near infrared spectroscopy and heart rate variability to detect mental overload. Behav. Brain Res. 259, 16-23. Doi: 10.1016/j.bbr.2013.10.042

Dvorak, R. D., \& Day, A. M. (2014). Marijuana and self-regulation: Examining likelihood and intensity of use and problems. Addictive behaviours, 39(3), 709-712. Doi: 10.1016/j.addbeh.2013.11.001

Einhorn HJ. The use of nonlinear, noncompensatory models in decision making. Psychological bulletin 1970; 73(3), 221. 
Elliot, A. J., \& Thrash, T. M. (2010). Approach and avoidance temperament as basic dimensions of personality. Journal of personality, 78(3), 865-906. Doi: 10.1111/j.1467-6494.2010.00636.x

Elsler, D., Takala, J., and Remes, J. (2017). An International Comparison of the Cost of Work-related Accidents and Illnesses. Available at: https://osha.europa.eu/sites/default/files/publications/documents/internati onal_comparison-of_costs_work_related_accidents.pdf

Endsley MR. (2000) Theoretical underpinnings of situation awareness: a critical review. MR Endsley \& DJ Garland (Eds.) (pp. 1-24). Mahwah, NJ: Lawrence Erlbaum Associates, Inc.

Endsley MR. Situation awareness global assessment technique (SAGAT). Proceedings of the IEEE National 1988; (pp. 789-795). Dayton, OH, USA, USA: IEEE. Doi: 10.1109/NAECON.1988.195097

Ergan, S., Radwan, A., Zou, Z., Tseng, H. A., \& Han, X. (2019). Quantifying human experience in architectural spaces with integrated virtual reality and body sensor networks. Journal of Computing in Civil Engineering, 33(2), 04018062. Doi: 10.1061/\%28ASCE\%29CP.1943-5487.0000812

Ernst, L. H., Plichta, M. M., Lutz, E., Zesewitz, A. K., Tupak, S. V., Dresler, T., et al. (2013). Prefrontal activation patterns of automatic and regulated approach-avoidance reactions - a functional near-infrared spec- troscopy (fNIRS) study. Cortex 49, 131-142. Doi: 10.1016/j.cortex.2011.09.013

Eslinger, P. J., \& Damasio, A. R. (1985). Severe disturbance of higher cognition after bilateral frontal lobe ablation: patient EVR. Neurology, 35(12), 1731-1731. Doi: 10.1212/WNL.35.12.1731

Etter, S., Cramer, J. J., \& Finn, S. (2006). Origins of academic dishonesty: Ethical orientations and personality factors associated with attitudes about cheating with information technology. Journal of Research on Technology in Education, 39(2), 133-155. Doi: 10.1080/15391523.2006.10782477

Evers, C., Marijn Stok, F., \& de Ridder, D. T. (2010). Feeding your feelings: Emotion regulation strategies and emotional eating. Personality and Social Psychology Bulletin, 36(6), 792-804. Doi: 10.1177/0146167210371383

Eysenck, H. J. (1973). Eysenck on extraversion. Halsted Press.

Eysenck, S. B., Pearson, P. R., Easting, G., \& Allsopp, J. F. (1985). Age norms for impulsiveness, venturesomeness and empathy in adults. Personality and individual differences, 6(5), 613-619. Doi: 10.1016/0191-8869(85)90011-X

Falk, L., \& Rickardsson, A. (2010). Executive functions and adolescent risk taking: A dual system approach. 
Fenton-O'Creevy, M., Soane, E., Nicholson, N., \& Willman, P. (2011). Thinking, feeling and deciding: The influence of emotions on the decision making and performance of traders. Journal of Organizational Behaviour, 32(8), 1044-1061. Doi: $10.1002 /$ job.720

Ferrando, P. J., Demestre, J., Anguiano-Carrasco, C., \& Chico, E. (2011). Evaluación TRI de la escala IE de Rotter: un nuevo enfoque y algunas consideraciones. Psicothema, 23(2), 282-288.

Fessler, D. M. T. (2001). Emotions and cost-benefit assessment: The role of shame and self-esteem in risk taking. In G. Gigerenzer \& R. Selten (Eds.), Bounded rationality: The adaptive toolbox (p. 191-214). The MIT Press.

Figueredo, A. J., \& Jacobs, W. J. (2010). Aggression, risk-taking, and alternative life history strategies: The behavioural ecology of social deviance. Bio-psychosocial perspectives on interpersonal violence, 3-28.

Figner B, Weber EU. Who takes risks when and why? Determinants of risk taking. Current Directions in Psychological Science 2011; 20(4), 211-216. Doi: $10.1177 / 0963721411415790$

Ford, M., Wentzel, K., Wood, D., Stevens, E., and Siesfeld, G. A. (1990). Processes associated with integrative social competence: emotional and contextual influences on adolescent social responsibility. J. Adolesc. Res. 4, 405-425. Doi: $10.1177 / 074355488944002$

Forgas, J. P. (1982). Reactions to life dilemmas: risk taking, success and responsibility attribution. Aust. J. Psychol. 34, 25-35. Doi: 10.1080/00049538208254714

Forgas, J. P. (1995). Mood and judgment: the affect infusion model (AIM). Psychol. Bull. 117, 39-66. Doi: 10.1037/0033-2909.117.1.39

Forgas, J. P., and Bower, G. H. (1987). Mood effects on person-perception judgments. J. Pers. Soc. Psychol. 53, 53-60. Doi: 10.1037//0022-3514.53.1.53

Foster, J. D., Shenesey, J. W., \& Goff, J. S. (2009). Why do narcissists take more risks? Testing the roles of perceived risks and benefits of risky behaviours. Personality and Individual Differences, 47(8), 885-889. Doi: 10.1016/j.paid.2009.07.008

Fowler C. Virtual reality and learning: Where is the pedagogy?. British journal of educational technology 2015; 46(2), 412-422. Doi: 10.1111/bjet.12135

Fucito, L. M., Juliano, L. M., \& Toll, B. A. (2010). Cognitive reappraisal and expressive suppression emotion regulation strategies in cigarette smokers. Nicotine \& Tobacco Research, 12(11), 1156-1161. Doi: 10.1093/ntr/ntq146

Gallagher, S. (2005). How the Body Shapes the Mind. Oxford: Oxford University Press. Doi: 10.1093/0199271941.001.0001 
Gardner, M., and Steinberg, L. (2005). Peer influence on risk taking, risk preference, and risky decision making in adolescence and adulthood: an experimental study. Dev. Psychol. 41, 625-635. Doi: 10.1037/0012-1649.41.4.625

Gawronski, B., \& De Houwer, J. (2014). Implicit measures in social and personality psychology.

George, J. M. (2009). The illusion of will in organizational behaviour research: nonconscious processes and job design. J. Manag. 35, 1318-1339. Doi: 10.1177/0149206309346337

Glöckner, A., and Herbold, A. K. (2011). An eye-tracking study on information processing in risky decisions: evidence for compensatory strategies based on automatic processes. J. Behav. Decis. Mak. 24, 71-98. Doi: 10.1002/bdm.684

Gomà i Freixanet, M., Martha, C., \& Muro, A. (2012). Does the Sensation Seeking trait differ among participants engaged in sports with different levels of physical risk?. Anales de psicología, vol. 28, nº 1, 2012.

Gonzalez, D. O., Martin-Gorriz, B., Berrocal, I. I., Morales, A. M., Salcedo, G. A., \& Hernandez, B. M. (2017). Development and assessment of a tractor driving simulator with immersive virtual reality for training to avoid occupational hazards. Computers and Electronics in Agriculture, 143, 111-118. Doi: 10.1016/j.compag.2017.10.008

Grant, D. A., \& Berg, E. A. (1993). Wisconsin Card Sorting Test (WCST).

Gore, P. M., \& Rotter, J. B. (1963). A personality correlate of social action 1. Journal of personality, 31(1), 58-64. Doi: 10.1111/j.1467-6494.1963.tb01840.x

Greene, J. D. (2009). Dual-process morality and the personal/impersonal distinction: a reply to mcguire, langdon, coltheart, and mackenzie. J. Exp. Soc. Psychol. 45, 581584. Doi: 10.1016/j.jesp.2009.01.003

Greene, J. D., Morelli, S. A., Lowenberg, K., Nystrom, L. E., and Cohen, J. D. (2008). Cognitive load selectively interferes with utilitarian moral judgment. Cognition 107, 1144-1154. Doi: 10.1016/j.cognition.2007.11.004

Greene, J. D., Sommerville, R. B., Nystrom, L. E., Darley, J. M., and Cohen, J. D. (2001). An fMRI investigation of emotional engagement in moral judgment. Science 293, 2105-2108. Doi: 10.1126/science.1062872

Gross, J. J. (2002). Emotion regulation: Affective, cognitive, and social consequences. Psychophysiology, 39(3), 281-291. Doi: 10.1017/S0048577201393198

Gross, J. J., \& John, O. P. (2003). Individual differences in two emotion regulation processes: implications for affect, relationships, and well-being. Journal of personality and social psychology, 85(2), 348. Doi: 10.1037/0022-3514.85.2.348 
Gross, J. J., \& Thompson, R. A. (2007). Emotion regulation: Conceptual foundations.

Gullone, E., Moore, S., Moss, S., and Boyd, C. (2000). The adolescent risk-taking questionnaire: development and psychometric evaluation. J. Adolesc. Res. 15, 231-250. Doi: 10.1177/0743558400152003

Guszkowska, M., \& Bołdak, A. (2010). Sensation seeking in males involved in recreational high risk sports. Biology of Sport, 27(3).

Guyon, I., Gunn, S., Nikravesh, M., \& Zadeh, L. A. (Eds.). (2008). Feature extraction: foundations and applications (Vol. 207). Springer.

Habibnezhad, M., Fardhosseini, S., Vahed, A. M., Esmaeili, B., \& Dodd, M. D. (2016, January). The relationship between construction workers' risk perception and eye movement in hazard identification. In Construction Research Congress 2016 (pp. 2984-2994). Doi: 10.1061/9780784479827.297

Hasanzadeh, S., Polys, N. F., \& Jesus, M. (2020). Presence, mixed reality, and risk-taking behaviour: A study in safety interventions. IEEE transactions on visualization and computer graphics, 26(5), 2115-2125.Doi: 10.1109/TVCG.2020.2973055

Hedberg, J., and Alexander, S. (1994). Virtual reality in education: defining researchable issues. Educ. Media Int. 31, 214-220. Doi: 10.1080/0952398940310402

Heekeren, H. R., Marrett, S., \& Ungerleider, L. G. (2008). The neural systems that mediate human perceptual decision making. Nature reviews neuroscience, 9(6), 467-479.

Heilman, R. M., Crişan, L. G., Houser, D., Miclea, M., \& Miu, A. C. (2010). Emotion regulation and decision making under risk and uncertainty. Emotion, 10(2), 257. Doi: $10.1037 / \mathrm{a} 0018489$

Higbee, K. L. (1972). Perceived control and military riskiness. Perceptual and motor skills, 34(1), 95-100. Doi: 10.2466/pms.1972.34.1.95

Highhouse S, Nye CD, Zhang DC, Rada TB. Structure of the Dospert: Is There Evidence for a General Risk Factor? Journal of Behavioural Decision Making 2017; 30(2), 400-406. Doi: 10.1002/bdm.1953

Hittner, J. B., \& Swickert, R. (2006). Sensation seeking and alcohol use: A meta-analytic review. Addictive behaviours, 31(8), 1383-1401. Doi: 10.1016/j.addbeh.2005.11.004

Horvath, P., and Zuckerman, M. (1993). Sensation seeking, risk appraisal, and risky behaviour. Personal. Individ. Differ. 14, 41-52. Doi: 10.1016/0191-8869(93)90173Z

Houston, D. A., Sherman, S. J., \& Baker, S. M. (1991). Feature matching, unique features, and the dynamics of the choice process: Predecision conflict and postdecision 
satisfaction. Journal of Experimental Social Psychology, 27(5), 411-430. Doi: 10.1177/0272989X0002000107

Hoyle, R. H., Fejfar, M. C., \& Miller, J. D. (2000). Personality and sexual risk taking: A quantitative review. Journal of personality, 68(6), 1203-1231. Doi: 10.1111/14676494.00132

Hoyle RH, Stephenson MT, Palmgreen P, Lorch EP, Donohew RL. Reliability and validity of a brief measure of sensation seeking. Personality and individual differences 2002; 32(3), 401-414. Doi: 10.1016/S0191-8869(01)00032-0

Huang HM, Rauch U, Liaw SS. Investigating learners' attitudes toward virtual reality learning environments: Based on a constructivist approach. Computers \& Education 2010; 55(3), 1171-1182. Doi: 10.1016/j.compedu.2010.05.014

Hunt RG, Krzystofiak FJ, Meindl JR, Yousry AM. Cognitive style and decision making. Organizational behaviour and human decision processes 1989; 44(3), 436-453. Doi: 10.1016/0749-5978(89)90018-6

Isen, A. M., \& Simmonds, S. F. (1978). The effect of feeling good on a helping task that is incompatible with good mood. Social Psychology, 346-349. Doi: 10.2307/3033588

Isleyen, E., \& Duzgun, H. S. (2019). Use of virtual reality in underground roof fall hazard assessment and risk mitigation. International Journal of Mining Science and Technology, 29(4), 603-607. Doi: 10.1016/j.ijmst.2019.06.003

Jackson DN, Hourany L, Vidmar NJ. A four-dimensional interpretation of risk taking. Journal of Personality 1972; 40(3), 483-501. Doi: 10.1111/j.14676494.1972.tb00075.x

Jorgensen, P. F. (1996). "Affect, persuasion, and communication processes," in Handbook of Communication and Emotion, eds P. A. Andersen and L. K. Guerrero (Amsterdam: Elsevier), 403-422. Doi: 10.1016/B978-012057770$5 / 50017-5$

Josef, A. K., Richter, D., Samanez-Larkin, G. R., Wagner, G. G., Hertwig, R., \& Mata, R. (2016). Stability and change in risk-taking propensity across the adult life span. Journal of personality and social psychology, 111(3), 430. Doi: $10.1037 /$ pspp0000090

Just, M. A., \& Carpenter, P. A. (1980). A theory of reading: From eye fixations to comprehension. Psychological review, 87(4), 329. Doi: 10.1037/0033295X.87.4.329

Kahneman, D., and Tversky, A. (1986). “Choices, values, and frames”, in Judgement and Decision Making: An Interdisciplinary Reader, eds H. R. Arkes and K. R. Hammond (New York, NY: Cambridge University Press), 194-210. 
Kalivas, P. W., \& Volkow, N. D. (2005). The neural basis of addiction: a pathology of motivation and choice. American Journal of Psychiatry, 162(8), 1403-1413. Doi: 10.1176/appi.ajp.162.8.1403

Kaplan, S. C., Levinson, C. A., Rodebaugh, T. L., Menatti, A., \& Weeks, J. W. (2015). Social anxiety and the big five personality traits: The interactive relationship of trust and openness. Cognitive behaviour therapy, 44(3), 212-222. Doi: 10.1080/16506073.2015.1008032

Kilteni, K., Groten, R., and Slater, M. (2012). The sense of embodiment in virtual reality. Presence Teleoperators Virtual Environ. 21,373-387. Doi: 10.1162/PRES_a_00124

Kim-Spoon, J., Holmes, C., \& Deater-Deckard, K. (2015). Attention regulates anger and fear to predict changes in adolescent risk-taking behaviours. Journal of Child Psychology and Psychiatry, 56(7), 756-765. Doi: 10.1111/jcpp.12338

Kim, D., \& Jung, S. (2020). Using Eye-Tracking Technology to Measure Environmental Factors Affecting Street Robbery Decision-Making in Virtual Environments. Sustainability, 12(18), 7419. Doi: 10.3390/su12187419

Kivikangas, J. M., Chanel, G., Cowley, B., Ekman, I., Salminen, M., Järvelä, S., et al. (2011). A review of the use of psychophysiological methods in game research. J. Gaming Virtual Worlds 3, 181-199. Doi: 10.1386/jgvw.3.3.181_1

Kivimäki, M., and Kalimo, R. (1993). Risk perception among nuclear power plant personnel: a survey. Risk Anal. 13, 421-424. Doi: 10.1111/j.15396924.1993.tb00742

Knoblich, G., Ohlsson, S., and Raney, G. E. (2001). An eye movement study of insight problem solving. Mem. Cogn. 29, 1000-1009. Doi: 10.1016/j.actpsy.2008.08.008

Kontra, C., Goldin-Meadow, S., and Beilock, S. L. (2012). Embodied learning across the life span. Topics Cogn. Sci. 4, 731-739. Doi: 10.1111/j.1756-8765.2012.01221

Kopstein, A. N., Crum, R. M., Celentano, D. D., \& Martin, S. S. (2001). Sensation seeking needs among 8th and 11th graders: characteristics associated with cigarette and marijuana use. Drug and alcohol dependence, 62(3), 195-203. Doi: 10.1016/S03768716(00)00170-8

Krain AL, Wilson AM, Arbuckle R, Castellanos FX, Milhama, MP. Distinct neural mechanisms of risk and ambiguity: A meta-analysis of decision-making. NeuroImage 2006; 32(1), 477-484. Doi: 10.1016/j.neuroimage.2006.02.047

Krupinski, E. A., Nodine, C. F., \& Kundel, H. L. (1998). Enhancing recognition of lesions in radiographic images using perceptual feedback. Optical Engineering, 37(3), 813-819. Doi: $10.1117 \% 2 F 1.601914 \& S S O=1$ 
Kundel, H. L., Nodine, C. F., Conant, E. F., \& Weinstein, S. P. (2007). Holistic component of image perception in mammogram interpretation: gaze-tracking study. Radiology, 242(2), 396-402. Doi: 10.1148/radiol.2422051997

Kwak, Y., Payne, J. W., Cohen, A. L., \& Huettel, S. A. (2015). The rational adolescent: Strategic information processing during decision making revealed by eye tracking. Cognitive development, 36, 20-30. Doi: 10.1016/j.cogdev.2015.08.001

Lahat, A., Degnan, K. A., White, L. K., McDermott, J. M., Henderson, H. A., Lejuez, C. W., \& Fox, N. A. (2012). Temperamental exuberance and executive function predict propensity for risk-taking in childhood. Development and psychopathology, 24(3), 847. Doi: 10.1017/S0954579412000405

Lanyon, I., and Goodstein, L. D. (1997). Personality Assessment, 3rd Edn. New York, NY: Wiley.

Lauriola M, Levin IP. Personality traits and risky decision-making in a controlled experimental task: An exploratory study. Personality and individual differences 2001; 31(2), 215-226. Doi: 10.1016/S0191-8869(00)00130-6

Lee, J., \& Jeong, J. (2013). Correlation of risk-taking propensity with cross-frequency phase-amplitude coupling in the resting EEG. Clinical neurophysiology, 124(11), 2172-2180. Doi: 10.1016/j.clinph.2013.05.007

Leeman RF, Hoff RA, Krishnan-Sarin S, Patock-Peckham JA, Potenza MN. Impulsivity, sensation-seeking, and part-time job status in relation to substance use and gambling in adolescents. Journal of Adolescent Health 2014; 54(4), 460-466. Doi: 10.1016/j.jadohealth.2013.09.014

Lejuez CW, Aklin WM, Zvolensky MJ, Pedulla CM. Evaluation of the Balloon Analogue Risk Task (BART) as a predictor of adolescent real-world risk-taking behaviours. Journal of adolescence 2003; 26(4), 475-479. Doi: 10.1016/S0140-1971(03)00036-8

Lejuez, C. W., Read, J. P., Kahler, C. W., Richards, J. B., Ramsey, S. E., Stuart, G. L., et al. (2002). Evaluation of a behavioural measure of risk taking: the Balloon Analogue Risk Task (BART). J. Exp. Psychol. Appl. 8, 75-84. Doi: 10.1037/1076-898X.8.2.75

Lessiter, J., Freeman, J., Keogh, E., \& Davidoff, J. (2001). A cross-media presence questionnaire: The ITC-Sense of Presence Inventory. Presence: Teleoperators \& Virtual Environments, 10(3), 282-297. Doi: 10.1162/105474601300343612

Levin, I. P., Gaeth, G. J., Schreiber, J., \& Lauriola, M. (2002). A new look at framing effects: Distribution of effect sizes, individual differences, and independence of types of effects. Organizational behaviour and human decision processes, 88(1), 411-429. Doi: 10.1006/obhd.2001.2983 
Lindgren, R., and Johnson-Glenberg, M. (2013). Emboldened by embodiment: six precepts for research on embodied learning and mixed reality. Educ. Res. 42, 445452. Doi: 10.3102/0013189X13511661

Llanes-Jurado, J.; Marín-Morales, J.; Guixeres, J.; Alcañiz, M. Development and Calibration of an Eye-Tracking Fixation Identification Algorithm for Immersive Virtual Reality. Sensors. 2020, 20, 4956. Doi: 10.3390/s20174956

Lo, A. W., \& Repin, D. V. (2002). The psychophysiology of real-time financial risk processing. Journal of cognitive neuroscience, 14(3), 323-339. Doi: $10.1162 / 089892902317361877$

Lovreglio R, Gonzalez V, Amor R, Spearpoint M, Thomas J, Trotter M, Sacks R. The need for enhancing earthquake evacuee safety by using virtual reality serious games. In Proceedings of the Lean \& Computing in Construction Congress, Crete, Greece 2017; (pp. 4-12). Doi: 10.24928/JC3-2017/0058

Lozano, L. M., Megías, A., Catena, A., Perales, J. C., Baltruschat, S., \& Cándido, A. (2017). Spanish validation of the domain-specific risk-taking (DOSPERT-30) scale. Psicothema, 29(1), 111-118. Doi: 10.7334/psicothema2016.132

MacCrimmon, K. R., and Wehrung, D. A. (1990). Characteristics of risk taking executives. Manag. Sci. 36, 422-435. Doi: 10.1287/mnsc.36.4.422

Magar, E. C., Phillips, L. H., \& Hosie, J. A. (2008). Self-regulation and risk-taking. Personality and individual differences, 45(2), 153-159. Doi: 10.1016/j.paid.2008.03.014

Manchester, D., Priestley, N., and Jackson, H. (2004). The assessment of executive functions: coming out of the office. Brain Injury 18, 1067-1081. Doi: 10.1080/02699050410001672387

Manes, F., Sahakian, B., Clark, L., Rogers, R., Antoun, N., Aitken, M., \& Robbins, T. (2002). Decision-making processes following damage to the prefrontal cortex. Brain, 125(3), 624-639. Doi: 10.1093/brain/awf049

Marín-Morales, J., Higuera-Trujillo, J. L., Greco, A., Guixeres, J., Llinares, C., Scilingo, E. P., et al. (2018). Affective computing in virtual reality: emotion recognition from brain and heartbeat dynamics using wearable sensors. Sci. Rep. 8:13657. Doi: 10.1038/s41598-018-32063-4

Mayer, I., Bekebrede, G., Warmelink, H., \& Zhou, Q. (2014). A brief methodology for researching and evaluating serious games and game-based learning. In Psychology, pedagogy, and assessment in serious games (pp. 357-393). IGI Global. Doi: 10.4018/978-1-4666-4773-2.ch017 
McCrae, R. R., \& Costa Jr, P. T. (1997). Conceptions and correlates of openness to experience. In Handbook of personality psychology (pp. 825-847). Academic Press. Doi: 10.1016/B978-012134645-4/50032-9

Mellers, B. A., Schwartz, A., Ho, K., \& Ritov, I. (1997). Decision affect theory: Emotional reactions to the outcomes of risky options. Psychological Science, 8(6), 423-429. Doi: 10.1111/j.1467-9280.1997.tb00455.x

Miller, R. L., \& Mulligan, R. D. (2002). Terror management: The effects of mortality salience and locus of control on risk-taking behaviours. Personality and Individual differences, 33(7), 1203-1214. Doi: 10.1016/S0191-8869(02)00009-0

Mischel, W., \& Ayduk, O. (2004). Willpower in a cognitive-affective processing system. Handbook of self-regulation: Research, theory, and applications, 99-129.

Mislevy, R. J., Almond, R. G., and Lukas, J. F. (2003). A Brief Introduction to EvidenceCentered Design. ETS Research Report Series. Princeton: Educational Testing Service. Doi: 10.1002/j.2333-8504.2003.tb01908

Miu, A. C., \& Crişan, L. G. (2011). Cognitive reappraisal reduces the susceptibility to the framing effect in economic decision making. Personality and Individual Differences, 51(4), 478-482. Doi: 10.1016/j.paid.2011.04.020

Moeller, F. G., Barratt, E. S., Dougherty, D. M., Schmitz, J. M., \& Swann, A. C. (2001). Psychiatric aspects of impulsivity. American journal of psychiatry, 158(11), 17831793. Doi: 10.1176/appi.ajp.158.11.1783

Mohamed, S., Ali, T. H., and Tam, W. Y. V. (2009). National culture and safe work behaviour of construction workers in Pakistan. Safety Sci. 47, 29-35. Doi: 10.1016/j.ssci.2008.01.003

Moore, A. B., Clark, B. A., \& Kane, M. J. (2008). Who shalt not kill? Individual differences in working memory capacity, executive control, and moral judgment. Psychological science, 19(6), 549-557. Doi: 10.1111/j.1467-9280.2008.02122.x

Mora F. (2013). Neuroeducación. Alianza Editorial.

Moreno M, Estevez AF, Zaldivar F, et al. Impulsivity differences in recreational cannabis users and binge drinkers in a university population. Drug and Alcohol Dependence 2012; 124(3), 355-362. Doi: 10.1016/j.drugalcdep.2012.02.011

Motowildo, S. J., Borman, W. C., and Schmit, M. J. (1997). A theory of individual differences in task and contextual performance. Hum. Perform. 10, 71-83. Doi: 10.1207/s15327043hup1002_1

Netter, P., Hennig, J., \& Roed, I. S. (1996). Serotonin and dopamine as mediators of sensation seeking behaviour. Neuropsychobiology, 34(3), 155-165. Doi: $10.1159 / 000119318$ 
Nguyen, Y., \& Noussair, C. N. (2014). Risk aversion and emotions. Pacific economic review, 19(3), 296-312. Doi: 10.1111/1468-0106.12067

Nicholson, N., Fenton-O'Creevy, M., Soane, E., \& Willman, P. (2002). Risk propensity and personality. London Business School, Open University Business School and Said Business School Oxford, London.

Nicholson, N., Soane, E., Fenton-O'Creevy, M., and Willman, P. (2005). Personality and domain-specific risk taking. J. Risk Res. 8, 157-176. Doi: 10.1080/1366987032000123856

Nourbakhsh, N.; Wang, Y.; Chen, F. GSR and blink features for cognitive load classification. In Lecture Notes in Computer Science (LNCS); Springer: Berlin/Heidelberg, Germany, 2013; Volume 8117, pp. 159-166. Doi: 10.1007/9783-642-40483-2_11

Oquendo MA, Baca-García E, Graver R, Morales M, Montalvan V, Mann J. Spanish adaptation of the Barratt Impulsiveness Scale (BIS-11). European Journal of Psychiatry 2001; 15(3), 147-155.

Orlebeke JF, Van der Molen MW, Dolan C, Stoffels EJ. The additive factor logic applied to the personality trait disinhibition. Personality and individual differences 1990; 11(6), 553-558. Doi: 10.1016/0191-8869(90)90037-R

Palmgreen P, Donohew L, Lorch EP, Hoyle RH, Stephenson MT. Television campaigns and adolescent marijuana use: tests of sensation seeking targeting. American Journal of Public Health 2001; 91(2), 292.

Panno, A., Lauriola, M., \& Figner, B. (2013). Emotion regulation and risk taking: Predicting risky choice in deliberative decision making. Cognition \& emotion, 27(2), 326-334. Doi: 10.1080/02699931.2012.707642

Parker, S. K., Axtell, C. M., and Turner, N. (2001). Designing a safer workplace: importance of job autonomy, communication quality, and supportive supervisors. J. Occup. Health Psychol. 6, 211-228. Doi: 10.1037/1076-8998.6.3.211

Parsey, C. M., and Schmitter-Edgecombe, M. (2013). Applications of technology in neuropsychological assessment. Clin. Neuropsychol. 27, 1328-1361. Doi: 10.1080/13854046.2013.834971

Parsons, T. D. (2015). Virtual reality for enhanced ecological validity and experimental control in the clinical, affective and social neurosciences. Front. Hum. Neurosci. 9:660. Doi: 10.3389/fnhum.2015.00660

Patton JH, Stanford MS, Barratt ES. Factor structure of the Barratt Impulsiveness Scale. Journal of Clinical Psychology 1995; 51(6), 768-774. Doi: 10.1002/10974679(199511)51:6<768::AID-JCLP2270510607>3.0.CO;2-1 
Paulhus, D. L. (1991). "Measurement and control of response bias," in Measures of Personality and Social Psychological Attitudes, eds J. P. Robinson, P. R. Shaver, and L. S. Wrightsman (Cambridge, MA: Academic Press), 1759. Doi: 10.1016/B978-0-12-590241-0.50006-X

Paulus, M. P., Rogalsky, C., Simmons, A., Feinstein, J. S., and Stein, M. B. (2003). Increased activation in the right insula during risk-taking decision making is related to harm avoidance and neuroticism. Neuroimage 19, 1439-1448. Doi: 10.1016/S1053-8119(03)00251-9

Payne, J. W., \& Braunstein, M. L. (1978). Risky choice: An examination of information acquisition behaviour. Memory \& Cognition, 6, 554-561. Doi:10.3758/BF03198244

Pedersen, W., Clausen, S. E., \& Lavik, N. J. (1989). Patterns of drug use and sensationseeking among adolescents in Norway. Acta Psychiatrica Scandinavica, 79(4), 386-390. Doi: 10.1111/j.1600-0447.1989.tb10274.x

Pellegrino, A. J. (2019). Associations Between Emotional Regulation, Risk Taking, and College Adaptation.

Pérez J, Torrubia R. Fiabilidad y validez de la versión española de la Escala de Búsqueda de Sensaciones (Forma V). Revista Latinoamericana de Psicología 1986; 18(001), 7-22. Doi: 10.1016/j.wasman.2014.03.014

Perpiñá, C., Segura, M., \& Sánchez-Reales, S. (2017). Cognitive flexibility and decisionmaking in eating disorders and obesity. Eating and Weight Disorders-Studies on Anorexia, Bulimia and Obesity, 22(3), 435-444. Doi: 10.1007/s40519-016-0331-3

Persson, E., Asutay, E., Hagman, W., Västfjäll, D., \& Tinghög, G. (2018). Affective response predicts risky choice for fast, but not slow, decisions. Journal of Neuroscience, Psychology, and Economics, 11(4), 213. Doi: 10.1037/npe0000096

Perugini, M., Richetin, J., \& Zogmaister, C. (2010). Prediction of behaviour.

Pessoa, L. (2009). How do emotion and motivation direct executive control?. Trends in cognitive sciences, 13(4), 160-166. Doi: 10.1016/j.tics.2009.01.006

Pettersson, J., Albo, A., Eriksson, J., Larsson, P., Falkman, K. W., \& Falkman, P. (2018, June). Cognitive ability evaluation using virtual reality and eye tracking. In 2018 IEEE International Conference on Computational Intelligence and Virtual Environments for Measurement Systems and Applications (CIVEMSA) (pp. 1-6). IEEE. Doi: 10.1109/CIVEMSA.2018.8439999

Pharo, H., Sim, C., Graham, M., Gross, J., \& Hayne, H. (2011). Risky business: executive function, personality, and reckless behaviour during adolescence and emerging adulthood. Behavioural neuroscience, 125(6), 970. Doi: 10.1037/a0025768 
References

Piaget, J., and Cook, M. T. (1952). The Origins of Intelligence in Children, Vol. 8, (New York, NY: International University Press), 18.

Piccione, J., Collett, J., \& De Foe, A. (2019). Virtual skills training: the role of presence and agency. Heliyon, 5(11), e02583. Doi: 10.1016/j.heliyon.2019.e02583

Pleskac, T. J. (2008). Decision making and learning while taking sequential risks. Journal of Experimental Psychology: Learning, Memory, and Cognition, 34(1), 167. Doi: $10.1037 \%$ 2F0278-7393.34.1.167

Pleskac, T. J., Wallsten, T. S., Wang, P., \& Lejuez, C. W. (2008). Development of an automatic response mode to improve the clinical utility of sequential risk-taking tasks. Experimental and clinical psychopharmacology, 16(6), 555. Doi: $10.1037 / \mathrm{a} 0014245$

Plunkett, H. R., \& Buehner, M. J. (2007). The relation of general and specific locus of control to intertemporal monetary choice. Personality and Individual Differences, 42(7), 1233-1242. Doi: 10.1016/j.paid.2006.10.002

Popham LE, Kennison SM, Bradley KI. Ageism, sensation-seeking, and risk-taking behaviour in young adults. Current psychology 2011; 30(2), 184. Doi: $10.1007 /$ s12144-011-9107-0

Porras-Garcia, B., Ferrer-Garcia, M., Ghita, A., Moreno, M., López-Jiménez, L., VallvéRomeu, A., ... \& Gutiérrez-Maldonado, J. (2019). The influence of gender and body dissatisfaction on body-related attentional bias: An eye-tracking and virtual reality study. International Journal of Eating Disorders, 52(10), 1181-1190. Doi: 10.1002/eat.23136

Portell, M., and Solé, M. D. (2001). Riesgo Percibido: Un Procedimiento de Evaluación. Disponible en la Red. Available at: http://www.insht.es/InshtWeb/Contenidos/Documentacion/FichasTecnicas/ NTP/Ficheros/501a600/ntp_578.pdf

Raffaelli, M., \& Crockett, L. J. (2003). Sexual risk taking in adolescence: the role of selfregulation and attraction to risk. Developmental psychology, 39(6), 1036. Doi: 10.1037/0012-1649.39.6.1036

Rayner, K. (2009). The 35th Sir Frederick Bartlett Lecture: Eye movements and attention in reading, scene perception, and visual search. Quarterly journal of experimental psychology, 62(8), 1457-1506. Doi: 10.1080/17470210902816461

Reitan, R. M. (1958). Validity of the Trail Making Test as an indicator of organic brain damage. Perceptual and motor skills, 8(3), 271-276. Doi: 10.2466/pms.1958.8.3.271

Risk Research Committee (1980). Accidents in Norway. How Do We Perceive and Handle Risk? Oslo: Risk Research Committee. 
Rizzo A, Bowerly T, Buckwalter JG, Klimchuk D, Mitura R, Parsons TD. A virtual reality scenario for all seasons: the virtual classroom. CNS Spectrums 2006; 11(1), 3544. Doi: 10.1080/09602010343000183

Roberti JW. A review of behavioural and biological correlates of sensation seeking. Journal of research in personality 2004; 38(3), 256-279. Doi: 10.1016/S00926566(03)00067-9

Robson, L. S., Stephenson, C. M., Schulte, P. A., Amick, B. C. III, Irvin, E. L., Eggerth, D. E., et al. (2012). A systematic review of the effectiveness of occupational health and safety training. Scand. J. Work Environ. Health 38, 193-208. Doi: $10.5271 /$ sjweh.3259

Rodríguez-Garzón, I., Delgado-Padial, A., Martinez-Fiestas, M., and Lucas-Ruiz, V. (2015). The delay of consequences and perceived risk: an analysis from the workers' view point. Rev. Facultad Ingeniería Univ. Antioquia 74, 165-176.

Rohrmann, B. (2008, June). Risk perception, risk attitude, risk communication, risk management: A conceptual appraisal. In 15th Internaional Emergency Management Society (TIEMS) Annual Conference (Vol. 2008).

Rojas, J. C., Marín-Morales, J., Ausín Azofra, J. M., \& Contero, M. (2020). Recognizing Decision-Making Using Eye Movement: A Case Study With Children. Frontiers in Psychology, 11, 2542. Doi: 10.3389/fpsyg.2020.570470

Rolison, J. J., Hanoch, Y., Wood, S., \& Liu, P. J. (2014). Risk-taking differences across the adult life span: a question of age and domain. Journals of Gerontology Series B: Psychological Sciences and Social Sciences, 69(6), 870-880. Doi: 10.1093/geronb/gbt081

Rotter, J.B. (1966). Generalized expectancies for internal versus external control of reinforcement. Psychological Monographs, 80(609). Doi: 10.1037/h0092976

Rundmo, T. (1996). Associations between risk perception and safety. Safety Sci. 24, 197209. Doi: 10.1016/S0925-7535(97)00038-6

Rupp, A. A., Gushta, M., Mislevy, R. J., and Shaffer, D. W. (2010). Evidence-centered design of epistemic games: measurement principles for complex learning environments. J. Technol. Learn. Assess. 8, 1-47.

Sacks, R., Perlman, A., \& Barak, R. (2013). Construction safety training using immersive virtual reality. Construction Management and Economics, 31(9), 1005-1017. Doi: 10.1080/01446193.2013.828844

Šalkevicius, J., Damaševičius, R., Maskeliunas, R., \& Laukienè, I. (2019). Anxiety level recognition for virtual reality therapy system using physiological signals. Electronics, 8(9), 1039. Doi: 10.3390/electronics8091039 
Salminen, S., \& Klen, T. (1994). Accident locus of control and risk taking among forestry and construction workers. Perceptual and motor skills, 78(3), 852-854. Doi: $10.1177 / 003151259407800334$

Sbordone, R. J. (2008). Ecological validity of neuropsychological testing: critical issues. Neuropsychol. Handb. 367:394.

Schmitt, N. (1994). Method bias: The importance of theory and measurement. J. Organ. Behav. 15, 393-398. Doi: 10.1002/job.4030150504

Schoemaker, P. J. (1993). Determinants of risk-taking: behavioural and economic views. J. Risk Uncertain. 6, 49-73. Doi: 10.1007/BF01065350

Schöllkopf, B., Smola, A. J., Williamson, R. C. \& Bartlett, P. L. New support vector algorithms. Neural Comput 12, 1207-1245 (2000). Doi: 10.1162/089976600300015565

Schroeter, R., Oxtoby, J., and Johnson, D. (2014). “AR and gamification concepts to reduce driver boredom and risk taking behaviours," in Proceedings of the 6th International Conference on Automotive User Interfaces and Interactive Vehicular Applications, Seattle, WA, Doi: 10.1145/2667317.2667415

Schwebel, D. C., Severson, J., Ball, K. K., \& Rizzo, M. (2006). Individual difference factors in risky driving: The roles of anger/hostility, conscientiousness, and sensationseeking. Accident Analysis \& Prevention, 38(4), 801-810. Doi: 10.1016/j.aap.2006.02.004

Seo, H. C., Lee, Y. S., Kim, J. J., and Jee, N. Y. (2015). Analyzing safety behaviours of temporary construction workers using structural equation modeling. Safety Sci. 77, 160-168. Doi: 10.1016/j.ssci.2015.03.010

Sequeira, H., Hot, P., Silvert, L., and Delplanque, S. (2009). Electrical autonomic correlates of emotion. Int. J. Psychophysiol. 71, 50-56. Doi: 10.1016/j.ijpsycho.2008.07.009

Sharma, M., Kacker, S., \& Sharma, M. (2016). A brief introduction and review on galvanic skin response. Int J Med Res Prof, 2, 13-17. Doi: 10.21276/ijmrp.2016.2.6.003

Shi, Y., Du, J., Ahn, C. R., \& Ragan, E. (2019). Impact assessment of reinforced learning methods on construction workers' fall risk behaviour using virtual reality. Automation in Construction, 104, 197-214. Doi: 10.1016/j.autcon.2019.04.015

Shukla, J.; Barreda-Ángeles, M.; Oliver, J.; Puig, D. Efficient wavelet-based artifact removal for electrodermal activity in real-world applications. Biomedical Signal Processing and Control. 2018, 42, 45-52. Doi: 10.1016/j.bspc.2018.01.009

Shute, V. J. (2011). Stealth assessment in computer-based games to support learning. Computer Games Instruction 55, 503-524. 
Shute, V. J., Hansen, E. G., and Almond, R. G. (2008). You can't fatten a hog by weighing it-or can you? evaluating an assessment for learning system called ACED. Int. J. Artif. Intell. Educ. 18, 289-316.

Shute, V. J., Wang, L., Greiff, S., Zhao, W., \& Moore, G. (2016). Measuring problem solving skills via stealth assessment in an engaging video game. Computers in Human Behaviour, 63, 106-117. Doi: 10.1016/j.chb.2016.05.047

Simon, H. A. (1976). Administrative Behaviour: A Study of Decision-Making Processes in Administrative Organization. New York, NY: Macmillan.

Sitkin, S. B., and Weingart, L. R. (1995). Determinants of risky decision-making behaviour: a test of the mediating role of risk perceptions and propensity. Acad. Manag. J. 38, 1573-1592. Doi: 10.2307/256844

Skeel, R. L., Neudecker, J., Pilarski, C., and Pytlak, K. (2007). The utility of personality variables and behaviourally-based measures in the prediction of risk-taking behaviour. Personal. Individ. Differ. 43, 203-214. Doi: 10.1016/j.paid.2006.11.025

Slater, M. (2009). Place illusion and plausibility can lead to realistic behaviour in immersive virtual environments. Philos. Trans. R. Soc. B Biol. Sci. 364, 3549-3557. Doi: $10.1098 /$ rstb.2009.0138

Slovic, P. (1987). Perception of risk. Science, 236(4799), 280-285. Doi: $10.1126 /$ science. 3563507

Sneddon, A., Mearns, K., and Flin, R. (2013). Stress, fatigue, situation awareness and safety in offshore drilling crews. Safety Sci. 56, 80-88. Doi: 10.1016/j.ssci.2012.05.027

So RHY, Lo WT, Ho ATK. Effects of Navigation Speed on Motion Sickness Caused by an Immersive Virtual Environment. Human Factors: The Journal of the Human Factors and Ergonomics Society 2001; 43(3), 452-461. Doi: $10.1518 / 001872001775898223$

Soane, E., Dewberry, C., \& Narendran, S. (2010). The role of perceived costs and perceived benefits in the relationship between personality and risk-related choices. Journal of Risk Research, 13(3), 303-318. Doi: $10.1080 / 13669870902987024$

Soler, J. L., Contero, M., and Alcañiz, M. (2017). "VR serious game design based on embodied cognition theory," in Proceedings of the Joint International Conference on Serious Games, (Berlin: Springer), 12-21. Doi: 10.1007/978-3-319-70111-0_2

Stanford, M. S., Greve, K. W., Boudreaux, J. K., Mathias, C. W., and Brumbelow, J. L. (1996). Impulsiveness and risk-taking behaviour: Comparison of high-school and college students using the Barratt Impulsiveness Scale. Personal. Individ. Differ. 21, 1073-1075. Doi: 10.1016/S0191-8869(96)00151-1 
References

Steinberg, L. (2004). Risk taking in adolescence: what changes, and why? Ann. N. Y. Acad. Sci. 1021, 51-58. Doi: 10.1196/annals.1308.005

Su, Y., Rao, L. L., Sun, H. Y., Du, X. L., Li, X., \& Li, S. (2013). Is making a risky choice based on a weighting and adding process? An eye-tracking investigation. Journal of Experimental Psychology: Learning, Memory, and Cognition, 39(6), 1765. Doi: $10.1037 / \mathrm{a} 0032861$

Tarr MJ, Warren WH. Virtual reality in behavioural neuroscience and beyond. Nature neuroscience 2002; 5, 1089. Doi: 10.1038/nn948

Taylor, S.; Jaques, N.; Chen, W.; Fedor, S.; Sano, A.; Picard, R. Automatic Identification of Artifacts in Electrodermal Activity Data. Conference proceedings: Annual International Conference of the IEEE Engineering in Medicine and Biology Society. IEEE Engineering in Medicine and Biology Society. 2015. 1934-1937. Doi: 10.1109/EMBC.2015.7318762

Tellegen, A. (1982). Brief manual for the multidimensional personality questionnaire. Unpublished manuscript, University of Minnesota, Minneapolis, 8, 1031-1010.

Tellegen, A. (1985). “Structures of mood and personality and their relevance to assessing anxiety, with an emphasis on self-report," in Anxiety and the Anxiety Disorders, eds A. H. Tuma and J. D. Maser (Hillsdale, NJ: Lawrence Erlbaum Associates, Inc), 681-706.

Terry, D. J., Galligan, R. F., \& Conway, V. J. (1993). The prediction of safe sex behaviour: The role of intentions, attitudes, norms and control beliefs. Psychology and health, 8(5), 355-368. Doi: 10.1080/08870449308401928

Tous, J. M. (1984). Cuestionarios del «lugar de control». Documento de trabajo. U. de Barcelona.

Tremblay SA (2017) Cognitive Approach to Situation Awareness: Theory and Application. S. Banbury \& S. Tremblay, Eds. London: Routledge. Doi: $10.4324 / 9781315263977$

Trocki, K. F., Drabble, L. A., \& Midanik, L. T. (2009). Tobacco, marijuana, and sensation seeking: comparisons across gay, lesbian, bisexual, and heterosexual groups. Psychology of Addictive Behaviours, 23(4), 620. Doi: 10.1037/a0017334

Tsujii, T., and Watanabe, S. (2010). Neural correlates of belief-bias reasoning under time pressure: a near-infrared spectroscopy study. Neuroimage 50, 1320-1326. Doi: 10.1016/j.neuroimage.2010.01.026

Van Leijenhorst, L., Westenberg, P. M., \& Crone, E. A. (2008). A developmental study of risky decisions on the cake gambling task: age and gender analyses of probability estimation and reward evaluation. Developmental neuropsychology, 33(2), 179196. Doi: $10.1080 / 87565640701884287$ 
Velichkovsky, B. M., Rothert, A., Kopf, M., Dornhöfer, S. M., \& Joos, M. (2002). Towards an express-diagnostics for level of processing and hazard perception. Transportation Research Part F: Traffic Psychology and Behaviour, 5, 145-156. Doi:10.1016/S1369-8478(02)00013-X

Verhulst N, De Keyser A, Gustafsson A, Shams P, Van Vaerenbergh Y. (2019) Neuroscience in service research: An overview and discussion of its possibilities. Journal of Service Management.

Verschoor A, D'Exelle B, Perez-Viana B. Lab and life: Does risky choice behaviour observed in experiments reflect that in the real world?. Journal of Economic Behaviour \& Organization 2016; 128, 134-148. Doi: 10.1016/j.jebo.2016.05.009

Vila-Ballo, A., Cunillera, T., Rostan, C., Hdez-Lafuente, P., Fuentemilla, L., \& RodriguezFornells, A. (2015). Neurophysiological correlates of cognitive flexibility and feedback processing in violent juvenile offenders. Brain research, 1610, 98-109. Doi: 10.1016/j.brainres.2015.03.040

Vollrath, M., \& Torgersen, S. (2002). Who takes health risks? A probe into eight personality types. Personality and Individual Differences, 32(7), 1185-1197. Doi: 10.1016/S0191-8869(01)00080-0

Vygotsky, L. (1978). Interaction between learning and development. Read. Dev. Children 23, 34-41.

Wang, L., Shute, V., and Moore, G. (2015). Lessons learned and best practices of stealth assessments. Int. J. Gaming Computer Mediat. Simul. 74, 66-87. Doi: 10.4018/IJGCMS.2015100104

Wagner, M. K. (2001). Behavioural characteristics related to substance abuse and risktaking, sensation-seeking, anxiety sensitivity, and self reinforcement. Addictive behaviours, 26(1), 115-120. Doi: 10.1016/S0306-4603(00)00071-X

Weber, E. U. (2010). Risk attitude and preference. Wiley Interdisciplinary Reviews: Cognitive Science, 1(1), 79-88. Doi: 10.1002 /wcs.5

Weber, E. U., Blais, A. R., \& Betz, N. E. (2002). A domain-specific risk-attitude scale: Measuring risk perceptions and risk behaviours. Journal of Behavioural Decision Making, 15, 263-290. Doi: 10.1002/bdm.414

Weber, E. U., \& Milliman, R. A. (1997). Perceived risk attitudes: Relating risk perception to risky choice. Management science, 43(2), 123-144. Doi: 10.1287/mnsc.43.2.123

Weller, J. A., \& Tikir, A. (2011). Predicting domain-specific risk taking with the HEXACO personality structure. Journal of Behavioural Decision Making, 24(2), 180-201. Doi: $10.1002 / \mathrm{bdm} .677$ 
References

White, T. L., Lejuez, C. W., and de Wit, H. (2008). Test-retest characteristics of the Balloon Analogue Risk Task (BART). Exp. Clin. Psychopharmacol. 16, 565. Doi: $10.1037 / \mathrm{a} 0014083$

Whiteside, S. P., \& Lynam, D. R. (2001). The five factor model and impulsivity: Using a structural model of personality to understand impulsivity. Personality and individual differences, 30(4), 669-689. Doi: 10.1016/S0191-8869(00)00064-7

Whiteside, S. P., Lynam, D. R., Miller, J. D., \& Reynolds, S. K. (2005). Validation of the UPPS impulsive behaviour scale: a four-factor model of impulsivity. European Journal of Personality: Published for the European Association of Personality Psychology, 19(7), 559-574. Doi: 10.1002/per.556

Wills, T. A., Walker, C., Mendoza, D., and Ainette, M. G. (2006). Behavioural and emotional self-control: relations to substance use in samples of middle and high school students. Psychol. Addict. Behav. 20, 265-278. Doi: 10.1037/0893164X.20.3.265

Wilson, M. (2002). Six views of embodied cognition. Psychon. Bull. Rev. 9, 625-636. Doi: 10.3758/BF03196322

Wishart, D., Somoray, K., \& Rowland, B. (2017). Role of thrill and adventure seeking in risky work-related driving behaviours. Personality and individual differences, 104, 362-367. Doi: 10.1016/j.paid.2016.08.033

Wolfgang, A. K. (1988). Gambling as a function of gender and sensation seeking. Journal of Gambling Behaviour, 4(2), 71-77. Doi: 10.1007/BF01020103

Woodman, T., Barlow, M., Bandura, C., Hill, M., Kupciw, D., \& MacGregor, A. (2013). Not all risks are equal: the risk taking inventory for high-risk sports. Journal of sport and exercise psychology, 35(5), 479-492. Doi: 10.1123/jsep.35.5.479

Yip, J. A., Stein, D. H., Côté, S., \& Carney, D. R. (2020). Follow your gut? Emotional intelligence moderates the association between physiologically measured somatic markers and risk-taking. Emotion, 20(3), 462. Doi: 10.1037/emo0000561

You, X., Ji, M., \& Han, H. (2013). The effects of risk perception and flight experience on airline pilots' locus of control with regard to safety operation behaviours. Accident Analysis \& Prevention, 57, 131-139. Doi: 10.1016/j.aap.2013.03.036

Yuen, K. S., and Lee, T. M. (2003). Could mood state affect risk-taking decisions? J. Affect. Disord. 75, 11-18. Doi: 10.1016/S0165-0327(02)00022-8

Zeelenberg, M., Van Dijk, W. W., SR Manstead, A., \& der Pligt, J. (1998). The experience of regret and disappointment. Cognition \& Emotion, 12(2), 221-230. Doi: $10.1080 / 026999398379727$ 
Zimerman, L., Shalvi, S., \& Bereby-Meyer, Y. (2014). Self-reported ethical risk taking tendencies predict actual dishonesty. Judgment and Decision making, 9(1), 58-64.

Zuckerman, M. (1979). Sensation seeking and risk taking. In Emotions in personality and psychopathology (pp. 161-197). Springer, Boston, MA. Doi: 10.1007/978-1-46132892-6_7

Zuckerman, M. (1984). Sensation seeking: A comparative approach to a human trait. Behavioural and brain sciences, 7(3), 413-434. Doi: 10.1017/S0140525X00018938

Zuckerman, M. (1994). Behavioural expressions and biosocial bases of sensation seeking. Cambridge university press.

Zuckerman, M. (2006). Biosocial bases of sensation seeking. Biology of personality and individual differences, 37-59.

Zuckerman M. Sensation seeking. The International Encyclopedia of Communication 2008. Doi: 10.1002/9781405186407.wbiecs029

Zuckerman, M. (2010). Sensation seeking. The Corsini encyclopedia of psychology, 1-4. Doi: 10.1002/9780470479216.corpsy0843

Zuckerman, M., \& Como, P. (1983). Sensation seeking and arousal systems. Personality and Individual Differences, 4(4), 381-386. Doi: 10.1016/0191-8869(83)90003-X

Zuckerman M, Eysenck SB, Eysenck HJ. Sensation seeking in England and America: cross-cultural, age, and sex comparisons. Journal of consulting and clinical psychology 1978; 46(1), 139. Doi: 10.1037/0022-006X.46.1.139

Zuckerman M, Kolin EA, Price L, Zoob I. Development of a sensation-seeking scale. Journal of Consulting Psychology 1964; 28(6), 477-482. Doi: 10.1037/h0040995

Zuckerman M, Kuhlman DM. Personality and Risk-Taking: Common Bisocial Factors. Journal of Personality 2000; 68(6), 999-1029. Doi: 10.1111/1467-6494.00124 